\title{
Synthesis, Crystal Growth, Structure, Crystalline Perfection, Thermal, Linear and Nonlinear Optical Investigations on 2-Amino-5-Nitropyridine 4- Chlorobenzoic Acid (1:1): A Novel Organic Single Crystal for NLO and Optical Limiting Optical Applications
}

Sivasubramani Vediyappan ( $\sim$ sivasubramaniv1989@gmail.com )

SSN Colege of Engineering https://orcid.org/0000-0002-1881-7831

Arumugam Raja

SSN College of Engineering

Ro Mu Jauhar

SSN College of Engineering

Ramachandran Kasthuri

SSN College of Engineering

Vishwanathan Vijayan

All India Institute of Medical Science

Muthu Senthil Pandian

SSN College of Engineering

Ramasamy Perumalsamy

SSN College of Engineering

Research Article

Keywords: Crystal growth, Optical material, X-ray diffraction, Thermal analysis, Third-harmonic generation (THG), Optical limiting (OL)

Posted Date: March 10th, 2021

DOI: https://doi.org/10.21203/rs.3.rs-256433/v1

License: (c) (1) This work is licensed under a Creative Commons Attribution 4.0 International License. Read Full License 


\title{
Synthesis, crystal growth, structure, crystalline perfection, thermal, linear and nonlinear optical investigations on 2-amino-5-nitropyridine 4-chlorobenzoic acid (1:1): A novel organic single crystal for NLO and optical limiting optical applications
}

\author{
Sivasubramani Vediyappan ${ }^{a^{*},}$, Arumugam Raja ${ }^{\mathrm{a}}$, RO. MU. Jauhara, \\ Ramachandran Kasthuria ${ }^{\mathrm{a}}$, Viswanathan Vijayan ${ }^{\mathrm{b}}$, Muthu Senthil Pandian ${ }^{\mathrm{a}}$, \\ Ramasamy Perumalsamya

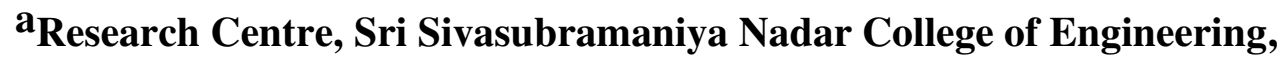 \\ Kalavakkam-603 110, Chennai, Tamil Nadu, India \\ ${ }^{b}$ Department of Biophysics, All India Institute of Medical Sciences (AIIMS), \\ New Delhi-110 029, India
}

\begin{abstract}
2-amino-5-nitropyridine 4-chlorobenzoic acid (1:1) (2A5NP4CBA), a potentially useful organic adduct compound has been synthesized and grown as optically transparent single crystals by conventional slow evaporation solution technique (SEST) for the first time in the literature. The formation of the new crystalline material was confirmed by the single-crystal X-ray diffraction (SXRD) analysis and the crystal structure of the grown crystal was found to be monoclinic. Fourier transform infrared (FTIR) spectrum has been recorded by the KBr pellet technique to determine the various vibrational functional groups in the title material. The powder X-ray diffraction (PXRD) and high-resolution X-ray diffraction (HRXRD) analyses have been carried out and the obtained results reveal that the grown crystal has a single-phase and is free from structural grain boundaries. The obtained less value (32 arc-s) of full width at half maximum (FWHM) for (001) plane indicates the excellent crystalline quality of the title 2A5NP4CBA single crystal. The linear optical properties were evaluated by the UV-vis-NIR absorption and transmittance analyses and the obtained results reveal that the grown crystal
\end{abstract}


possesses more than $70 \%$ of optical transmittance window with the cut-off edge at $419 \mathrm{~nm}$. The thermal analysis discloses that the grown crystal possesses good thermal stability of about $187^{\circ} \mathrm{C}$. To determine the appropriateness of the grown crystal for the high-power laser application, laser damage threshold (LDT) analysis has been carried out by Nd: YAG laser of a wavelength of $1064 \mathrm{~nm}$. The third-order nonlinear optical coefficients such as nonlinear absorption $(\beta)$, nonlinear refraction $\left(\mathrm{n}_{2}\right)$ and nonlinear susceptibility $\left(\chi^{(3)}\right)$ have been evaluated by utilizing the single beam Z-scan technique using a solid-state laser of wavelength $532 \mathrm{~nm}$. The calculated $\chi^{(3)}$ value is found to be reasonably good compared to other organic single crystals which are reported in the literature. The optical limiting (OL) behavior of the title crystal was evaluated using a solid-state laser at $532 \mathrm{~nm}$ and the limiting threshold was found to be $7.8 \mathrm{~mW} / \mathrm{cm}^{2}$.

Keywords: Crystal growth; Optical material; X-ray diffraction; Thermal analysis; Third-harmonic generation (THG); Optical limiting (OL)

*Corresponding author (V. Sivasubramani)

Mobile: +91-9791802135, Telephone-+91-44-27475166

Email: sivasubramaniv1989@gmail.com

\section{Introduction}

In the modern world, the development of functional materials with desirable properties is intensely facilitating the fast-growing multi-disciplinary research areas like nonlinear optics (NLO), dielectric, piezoelectric, pyroelectric and ferroelectric, etc [1]. Over the last few decades, the nonlinear optical (NLO) single crystals play an inevitable role in a wide range of technological applications such as lasers, optoelectronics, information processing, optical data storage, optical switching, THz generation and detection, etc [2-4]. The rapid advancements in 
photonic and optoelectronic devices strongly depend on the ease of design and fabrication of the NLO single crystals. From the technological point of view, a single crystal with an inherent high nonlinearity and desired physico-chemical properties (like optical, mechanical, thermal, electrical, chemical stability and laser damage threshold, etc) are mandatory for numerous applications. Also, the grown crystals should possess a large size with high quality and low economical aspects. In this regard, the large demand for growing NLO single crystals is increasing day by day. Therefore, the crystal growth researchers are still putting enormous efforts into the design and development of novel organic, inorganic and semi-organic single crystals to attain high performances in real-time NLO devices.

In general, most of the organic single crystals possess a large NLO coefficient and fast response time due to the presence of inherent features such as $\pi$-delocalization length, donor- $\pi$-acceptor (D- $\pi$-A) molecular structure, multiple hydrogen-bonding interactions and robust NLO chromophores [5-6]. Due to the distinctive features, the organic NLO single crystals could be employed in a wide range of applications such as high-density optical data storage, electro-optical modulation, frequency conversion, laser devices and $\mathrm{THz}$ generation and detection, etc [7-8]. Due to the possessing of synthetic flexibility and high nonlinearity, extensive research work is being done by the crystal growers towards the design and development of organic single crystals to satisfy all the technological necessities mentioned earlier.

Among the organic/inorganic compounds, pyridine-based single crystals have attracted crystal growth researchers due to their ability to form ionic co-crystals with many numbers of organic or inorganic counterparts [9]. Most of the pyridine-based compounds have been synthesized through the protonation reaction by forming short/multiple hydrogen bonds between 
anion and cation. Pyridine is a basic heterocyclic compound that consists of five carbon atoms and one nitrogen atom. The pyridinium nitrogen plays a vital role in various types of reactions such as protonation, alkylation and acylation. In general, the pyridine-based single crystals possess inter and intramolecular charge transfer molecular structure that occurs between the donor and acceptor chromophores resulting in a large molecular polarization which significantly leads to the strong nonlinearity. In the last few decades, extensive research has been made in the synthesis of pyridine-based compounds due to their multifunctional properties including inter and intramolecular charge transfer, electrostatic behavior, hydrogen bond and $\pi-\pi$ interactions [10]. Moreover, the pyridine-based compounds are used in a wide variety of medical drugs and biologically active compounds such as antitumor, antibiotic, anticonvulsant, antimicrobial, antibacterial, antiviral agents, etc [11]. In the literature, it is found that the pyridine-based materials serve a wide range of applications including semiconductors, photovoltaic cells, optical data carriers, optical switching, organic light-emitting diodes (OLEDs), etc [12].

Among the pyridine-based materials, the 2-amino-5-nitropyridine (2A5NP) is one of the attractive materials for NLO applications due to its D- $\pi$-A charge transfer molecular structure. It consists of electron donor (amino) and electron acceptor (nitro) groups to induce a high NLO response. The pyridine nitrogen and amino group play a role as cationic bonding and proton acceptor. Owing to the interesting molecular structure, the 2A5NP based single crystals are well recognized as NLO building blocks for the organic and semi-organic molecular complexes. Thus, the 2A5NP derivative single crystals are projected as forefront candidates for the fundamental and applied investigations. Interestingly, the 2A5NP derivative single crystals display promising properties including large nonlinear coefficient $(10-40 \mathrm{pm} / \mathrm{V})$, a wide range of transparency $(0.4-1.8 \mu \mathrm{m})$, high laser damage threshold, phase matching property as well as improved structural stability [13-14]. Structural and NLO properties of typical 2A5NP derivative 
single crystals have been already explored in the literature [15-20]. Among the 2A5NP derivative crystals, 2A5NPDP single-crystal displays multifunctional properties like electrooptic, piezoelectric, thermo-optic and dielectric [21-22]. Due to the charge asymmetry, the large second harmonic generation (SHG) efficiency is observed in 2A5NPP and 2A5NPT single crystals $[23,17]$. Therefore, substantial research work has been undertaken for designing 2A5NP derivative crystals for their possible usage in photonic and optoelectronic applications. From the above discussion, it is clear that there is plenty of scope for the investigation of the 2A5NP derivative single crystals. Based on the above discussions, 2A5NP4CBA material has been designed and the optically transparent single crystals have been grown for the first time in the literature. In this manuscript, we report the synthesis, solubility, crystal growth, structural, optical (linear and nonlinear) and thermal properties of the 2A5NP4CBA single crystal.

\section{Experimental procedures}

\subsection{Material synthesis, solubility measurement and crystal growth}

The starting raw materials, 2A5NP (Merck 98\%) and 4-chlorobenzoic acid (Merck 98\%) were taken in the molar ratio of 1:1 for the synthesis of 2A5NP4CBA material. HPLC grade methanol was used as a solvent for the reaction. Then, the calculated amount of raw materials were completely dissolved using a magnetic stirrer. Then, the filtered saturated solution was allowed to dry by heating at room temperature and finally, the yellow color crystalline material was obtained. The $\mathrm{pH}$ of the prepared solution was measured to be 2 . The reaction scheme of 2A5NP and 4-chlorobenzoic acid is presented in Figure 1. The success of growing optically transparent single crystals with minimized crystal defects mainly depends on the purity of the synthesized materials. Hence, the synthesized crystalline material was recrystallized more than twice by methanol to obtain high purity. 


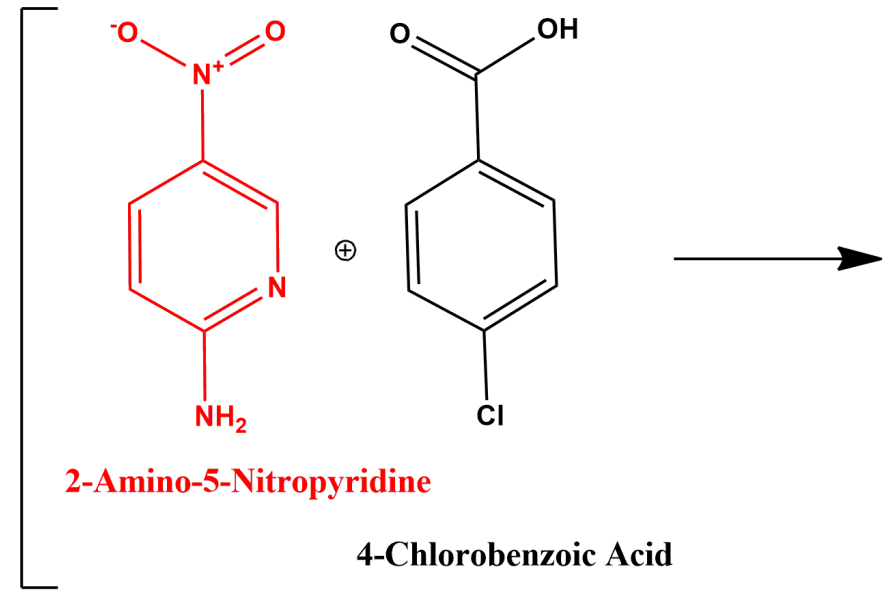

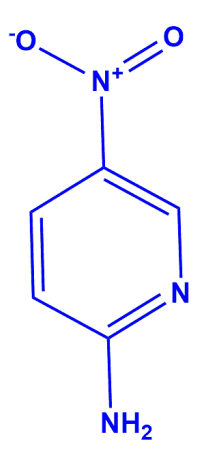

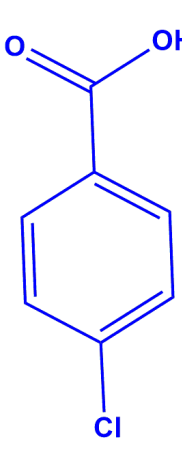

2-Amino-5-Nitropyridine 4-Chlorobenzoic Acid (1:1)

\section{Figure 1. Reaction scheme of 2A5NP with 4-chlorobenzoic acid}

The solubility measurement of 2A5NP4CBA material has been carried out by the gravimetric method using three different solvents (methanol, ethanol and water) from room temperature to $55^{\circ} \mathrm{C}$. In the beginning, a volume of $100 \mathrm{~mL}$ of methanol was transferred into the closed glass beaker and it was kept in a constant temperature bath $(\mathrm{CTB})$. At $35^{\circ} \mathrm{C}$, the powder material was slowly added to the glass beaker until it reaches the equilibrium concentration. For every $5^{\circ} \mathrm{C}$, the solution was continuously stirred for 2 hours to ensure the equilibrium concentration. The same procedures were followed for ethanol and water solvents at different temperatures. The corresponding solubility diagram of 2A5NP4CBA is shown in Figure 2. 


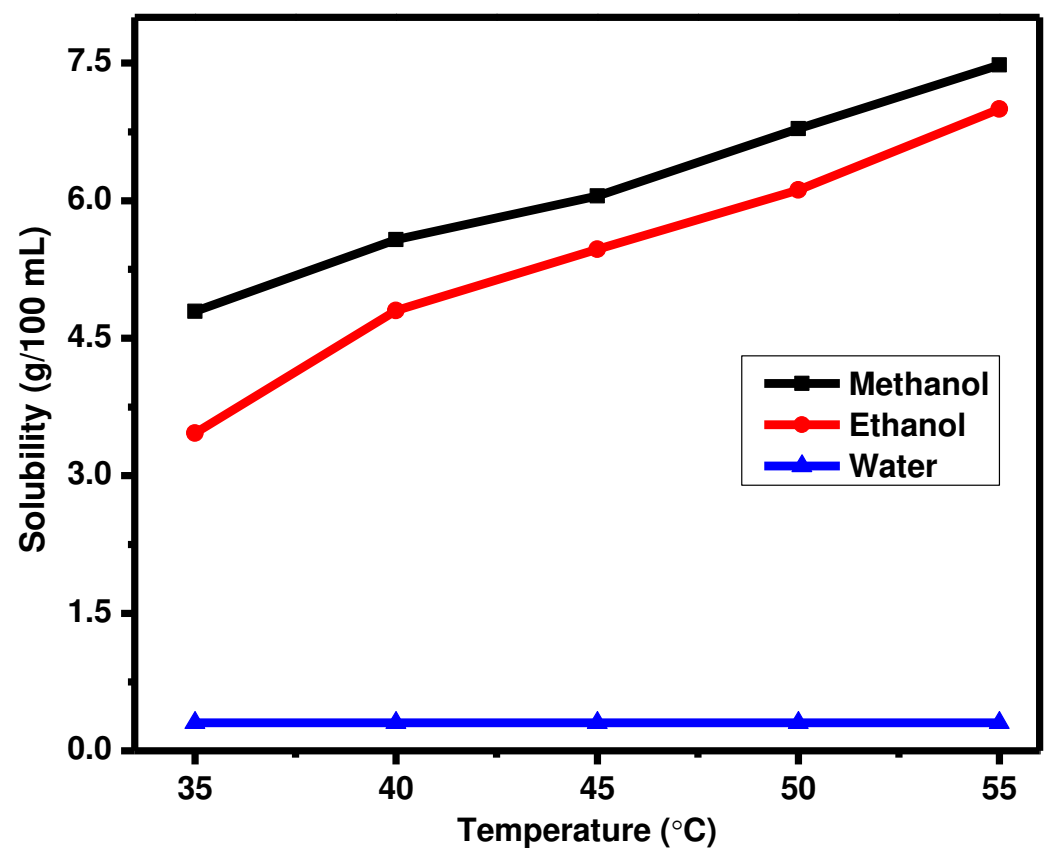

Figure 2. Solubility diagram for 2 A5NP4CBA crystal

It is observed that the title molecule shows increasing solubility in methanol and ethanol solvents with increasing temperature. The flat solubility is observed when using water as a solvent in the temperature range from $35-55^{\circ} \mathrm{C}$. Based on the solubility data, it is found that the solubility in methanol is higher than in the ethanol and water solvents. At room temperature, the solubility was found to be $4.7 \mathrm{~g} / 100 \mathrm{~mL}, 3.4 \mathrm{~g} / 100 \mathrm{~mL}, 0.3 \mathrm{~g} / 100 \mathrm{~mL}$ for methanol, ethanol and water solvents, respectively. Attempts have been made to grow 2A5NP4CBA single crystals using ethanol, methanol solvents by conventional SEST. Optically transparent and good quality single crystals were obtained only in methanol solvent. Particularly, the growth of title crystal was performed only in methanol solvent due to the reasonable solubility compared to the other two solvents. 


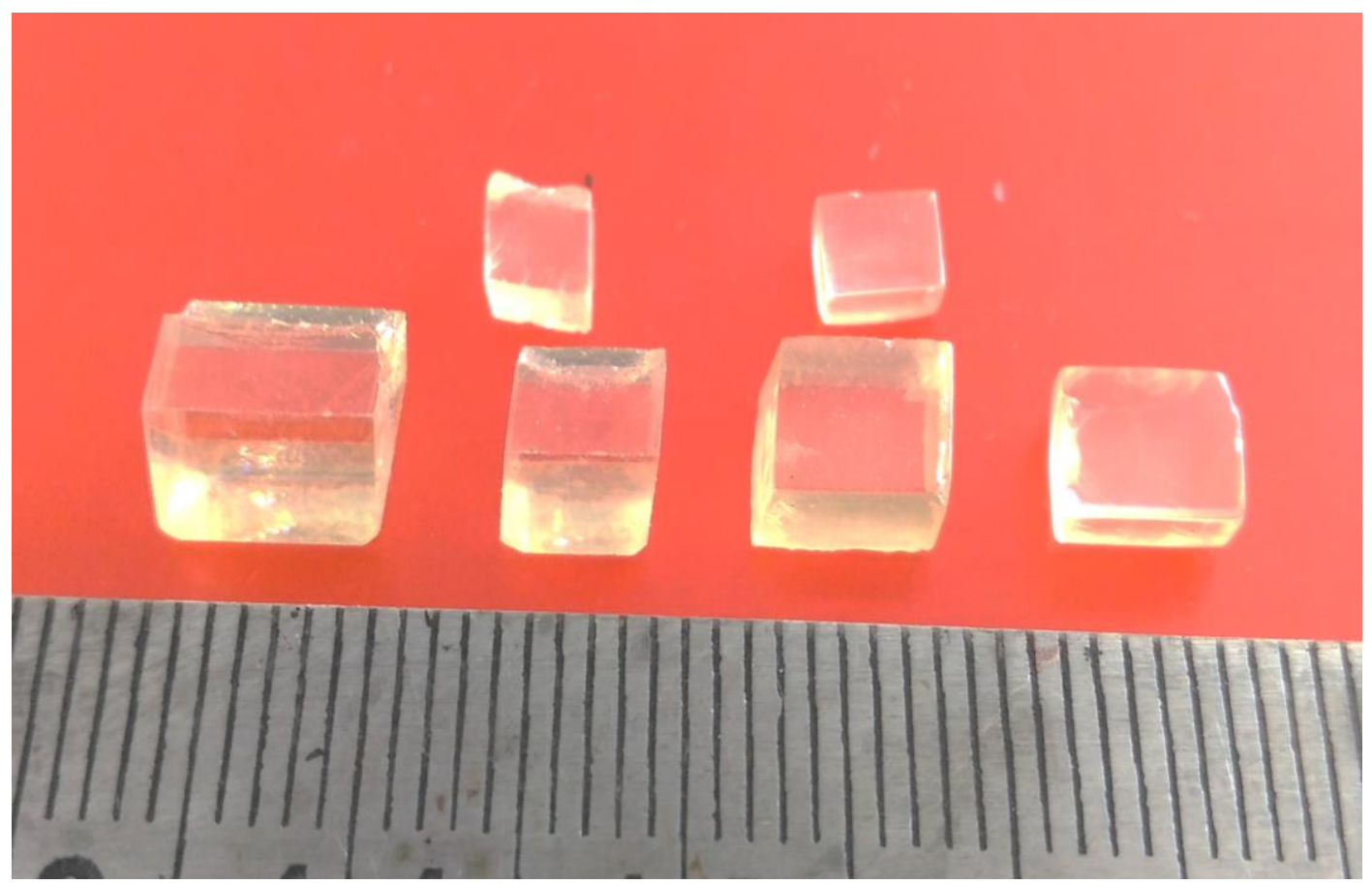

Figure 3. As grown 2A5NP4CBA adduct crystals

Based on the solubility data, the 2A5NP4CBA crystalline material was dissolved in methanol, and it was continuously stirred for 2 hours to obtain the homogeneous saturated solution. Then, the filtered solution was poured into a well-cleaned petri dish and covered with a thick polythene sheet to control the abundant solvent evaporation. A few hours later, very small pinholes were made on the polythene sheet to achieve the controlled solvent evaporation and it was housed in the $\mathrm{CTB}$ at $35^{\circ} \mathrm{C}$ for the crystal growth. Previously, several growth attempts have been carried out by SEST to obtain the definite morphology single crystal. The spurious nucleation was controlled during the crystal growth process by the controlled growth conditions. Optically transparent yellow color 2A5NP4CBA single crystals were harvested after 90 days with the maximum crystal dimension of $7 \times 5 \times 5 \mathrm{~mm}^{3}$. The photograph of as-grown crystals with definite morphology is shown in Figure 3. 


\section{Results and Discussion}

\subsection{X-ray diffraction (XRD) analysis}

The unit cell parameters and crystal structure of the 2A5NP4CBA single crystal were determined using a computer-aided single-crystal X-ray diffractometer (Model: Bruker AXS Kappa APEX II) at 296K. The instrument has the provision of graphite monochromator and MoKa radiation $(\lambda=0.71073 \AA)$. The CCD (charge-coupled device) detector was used to collect the intensity of the X-ray diffraction. The 2A5NP4CBA single crystal of dimension $0.3 \times 0.25 \times 0.2 \mathrm{~mm}^{3}$ was used for the analysis. The data collection, unit cell refinement, absorption correction and data reduction for the entire experiment were performed using APEX2 (Bruker, 2004), SAINT (Bruker, 2004) and SADABS software [24]. The three-dimensional molecular structure of this compound was determined by X-ray crystallography using SHELXS-97 and later refined by SHELXL-16 to a final R-value of $3.4 \%$.

From the SXRD analysis, it can be declared that the grown 2A5NP4CBA crystal has monoclinic with the centrosymmetric crystal structure. The determined space group, number of molecules per unit cell, molecular weight and density are found to be $\mathrm{P} 2{ }_{1} / \mathrm{n}, 4,295.68 \mathrm{~g} / \mathrm{mol}$ and $1.538 \mathrm{Mg} / \mathrm{m}^{3}$, respectively. With reference number 15111154 , crystallographic data of the title crystal has been deposited in the Cambridge Crystallographic Database (CCDC). Table 1. represents the crystallographic data of the title crystal. The asymmetric unit of the title salt comprises 2A5NP $\left(\mathrm{C}_{5} \mathrm{H}_{5} \mathrm{~N}_{3} \mathrm{O}_{2}\right)$ and 4-chlorobenzoic acid $\left(\mathrm{C}_{7} \mathrm{H}_{5} \mathrm{O}_{2} \mathrm{Cl}_{1}\right)$ are shown in Figure 4. 


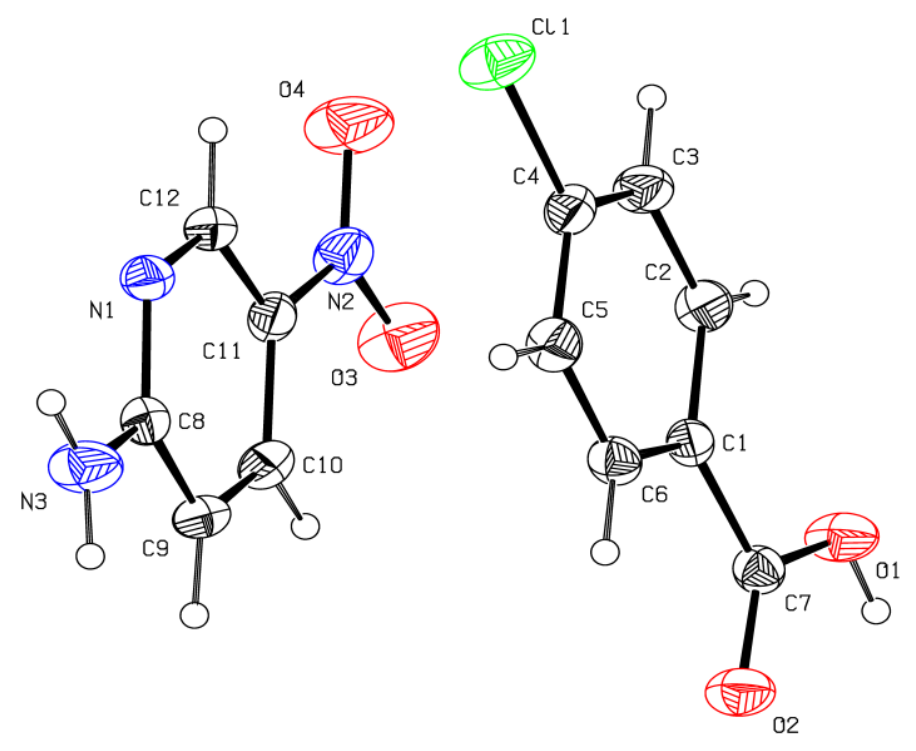

\section{Figure 4. Three-dimensional molecular structure of the title salt with the atom numbering scheme. Displacement ellipsoids are drawn at $30 \%$ probability level}

These two salts are forming parallel in the crystal structure with a distance of $3.65 \AA$ and the mean planes of the two salts are inclined to one another by $5.79(6)^{\circ}$. In nitrous oxide, the oxygen atoms are partially double-bonded in this structure with a bond distance of $1.22 \AA$. In the 4-chlorobenzoic acid, the oxygen atoms are mentioned that $\mathrm{O} 2$ is a double-bonded atom and $\mathrm{O} 1$ is the single-bonded atom from the distances of $1.216 \AA$ and $1.311 \AA$, respectively. The chlorine atom is attached to the phenyl ring with a bond distance of $1.735 \AA$, comparable with the values reported in the literature [25]. The crystal structure of the title salt involves a three-dimensional network of $\mathrm{N}-\mathrm{H} \ldots \mathrm{O}, \mathrm{O}-\mathrm{H} \ldots \mathrm{N}, \mathrm{C}-\mathrm{H} \ldots \mathrm{O}$ and $\pi-\pi$ interactions which contribute to the following supramolecular aggregation. In the crystal structure of 2A5NP4CBA, 2A5NP of nitrogen atom $(\mathrm{N} 3 \mathrm{~A})$ forming an intermolecular hydrogen bond interaction with the 4-chlorobenzoic acid of $\mathrm{O} 2$ atom $\left(\mathrm{N} 3-\mathrm{H} 3 \mathrm{~A} \ldots \mathrm{O} 2^{\mathrm{ii}}\right)$. The $\mathrm{O} 1$ oxygen atom is forming a hydrogen bond interaction with the nearest $\mathrm{N} 1$ nitrogen $\left(\mathrm{O} 1-\mathrm{H} 1 \mathrm{~A} \ldots \mathrm{N} 1^{\mathrm{i}}\right)$ of $2 \mathrm{~A} 5 \mathrm{NP}$ salt. These two hydrogen bond interactions are generating dimers with an $R_{2}^{2}(8)$ ring motif as shown in Figure 5 . 
The atomic coordinates and equivalent isotropic displacement parameters, bond lengths and angles, anisotropic displacement parameters, hydrogen coordinates and isotropic displacement parameters and selected torsion angles are given in section S1, electronic supplementary information (ESI) (Tables (S1-S5)).

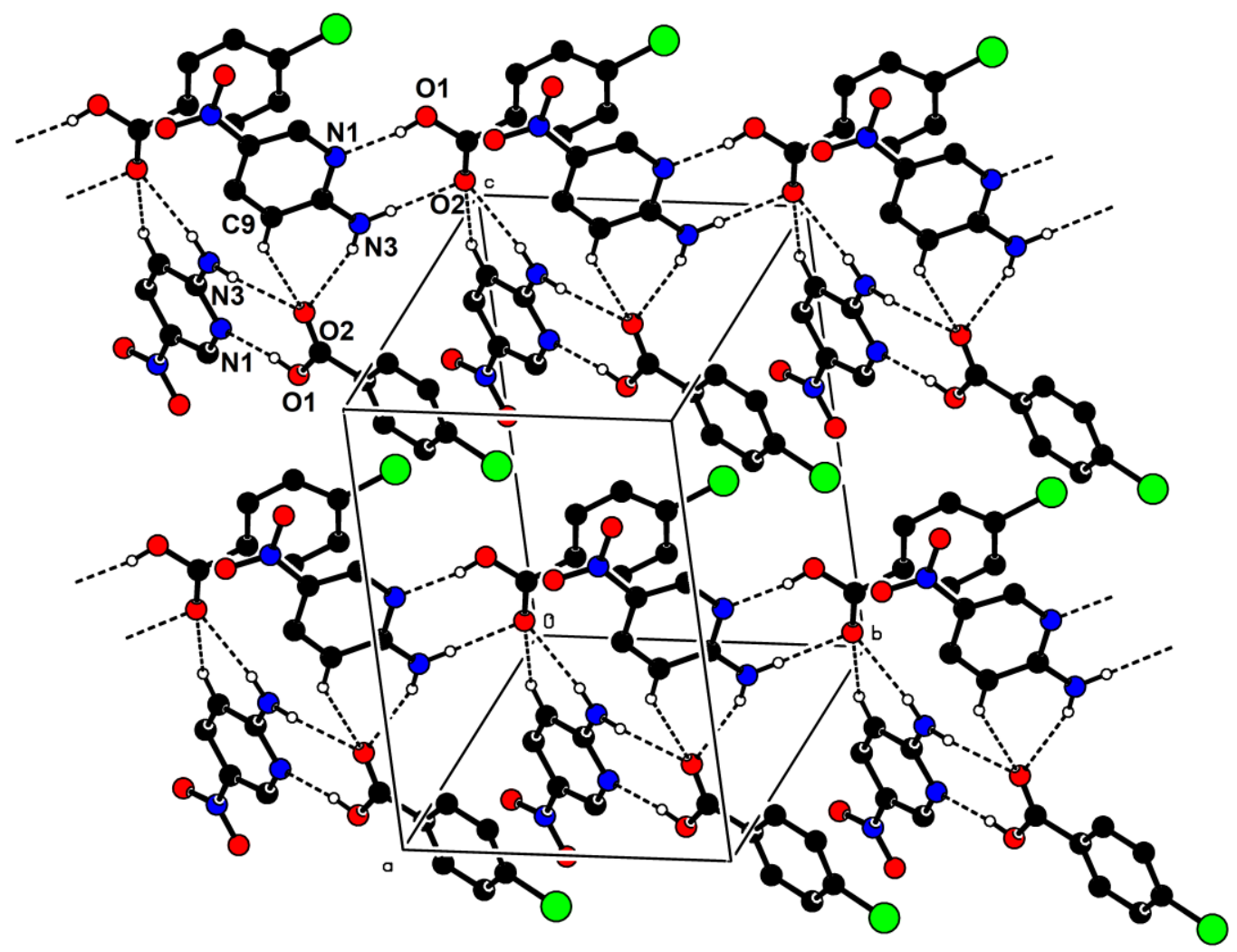

Figure 5. The O1-H1A...N1 ${ }^{\mathrm{i}}, \mathrm{N} 3-\mathrm{H} 3 \mathrm{~A} \ldots . . \mathrm{O} 2^{\mathrm{ii}}, \mathrm{N} 3-\mathrm{H} 3 \mathrm{~B} \ldots \mathrm{O} 2^{\mathrm{iii}}$ and $\mathrm{C} 9-\mathrm{H} 9 \ldots \mathrm{O}^{2 \mathrm{iii}}$ intermolecular hydrogen bonds

[Symmetry codes: (i) $x, y-1, z$, (ii) $x, y+1, z$ and (iii) $3 / 2-x, 1 / 2+y, 1 / 2-z$ ]

The N3 nitrogen atom act as a donor atom and also forming two hydrogen bond interaction with the nearest molecules in the crystal structure. The $\mathrm{N} 3-\mathrm{H} 3 \mathrm{~A} \ldots \mathrm{O} 2^{\mathrm{ii}}$ and $\mathrm{N} 3-\mathrm{H} 3 \mathrm{~B} \ldots \mathrm{O} 2^{\mathrm{iii}}$ intermolecular hydrogen bond interaction links the molecules into an infinite one-dimensional chain with the descriptor of $C(4)$ running parallel to " $b$ " axis. The $\mathrm{O} 2$ oxygen atom acts as an 
acceptor atom in the crystal structure and it's forming three acceptor hydrogen bond interactions. In the crystal structure, the $\mathrm{C} 9$ atom is forming hydrogen bond interaction with the 4-chlorobenzoic acid of $\mathrm{O} 2$ atom $\left(\mathrm{C} 9-\mathrm{H} 9 \ldots \mathrm{O} 2^{\mathrm{iii}}\right)$. The $\mathrm{N} 3-\mathrm{H} 3 \mathrm{~B} \ldots \mathrm{O} 2^{\mathrm{iii}}$ and $\mathrm{C} 9-\mathrm{H} 9 \ldots \mathrm{O} 2^{\mathrm{iii}}$ hydrogen bond interactions together form an $R_{2}{ }^{1}(6)$ graph-set ring motif as shown in Figure 5. The $\mathrm{C} 10-\mathrm{H} 10 \ldots \mathrm{O}^{\mathrm{iv}}$ intermolecular interactions form cyclic centrosymmetric inversion dimers with an $R_{2}^{2}(10)$ graph-set ring motif view down " $b$ " axis as shown in Figure 6.

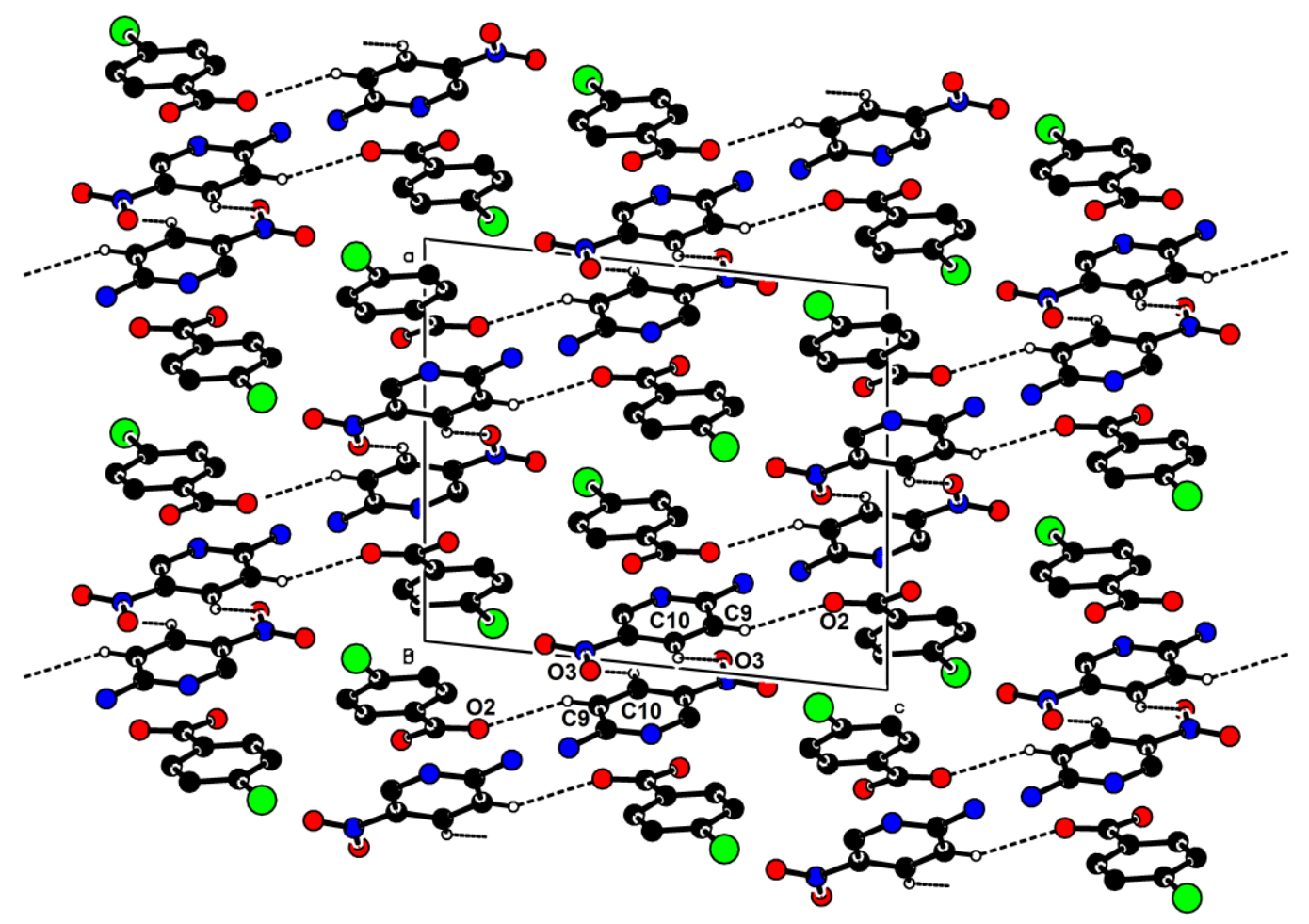

Figure 6. The $\mathrm{C} 9-\mathrm{H9} . . . \mathrm{O} 2^{\mathrm{iii}}$ and $\mathrm{C} 10-\mathrm{H10} \ldots \mathrm{O}^{\mathrm{iv}}$ hydrogen bond interactions

[Symmetry code: (iii) 3/2-x, 1/2+y, 1/2-z and (iv) 2-x, 1-y, 1-z]

Figure 7, represents the $2 \mathrm{~A} 5 \mathrm{NP}$ and 4-chlorobenzoic acid are forming the rectangular cavity in the three-dimensional structure in the crystal. In the crystal, the molecules are stacked in layers held together by $\pi-\pi$ interactions, with a distance of $\mathrm{Cg} 1 \cdots \operatorname{Cg} 2$ is $3.6663(11) \AA$, between the centroid of adjacent one phenyl ring and one nitropyridine ring. 


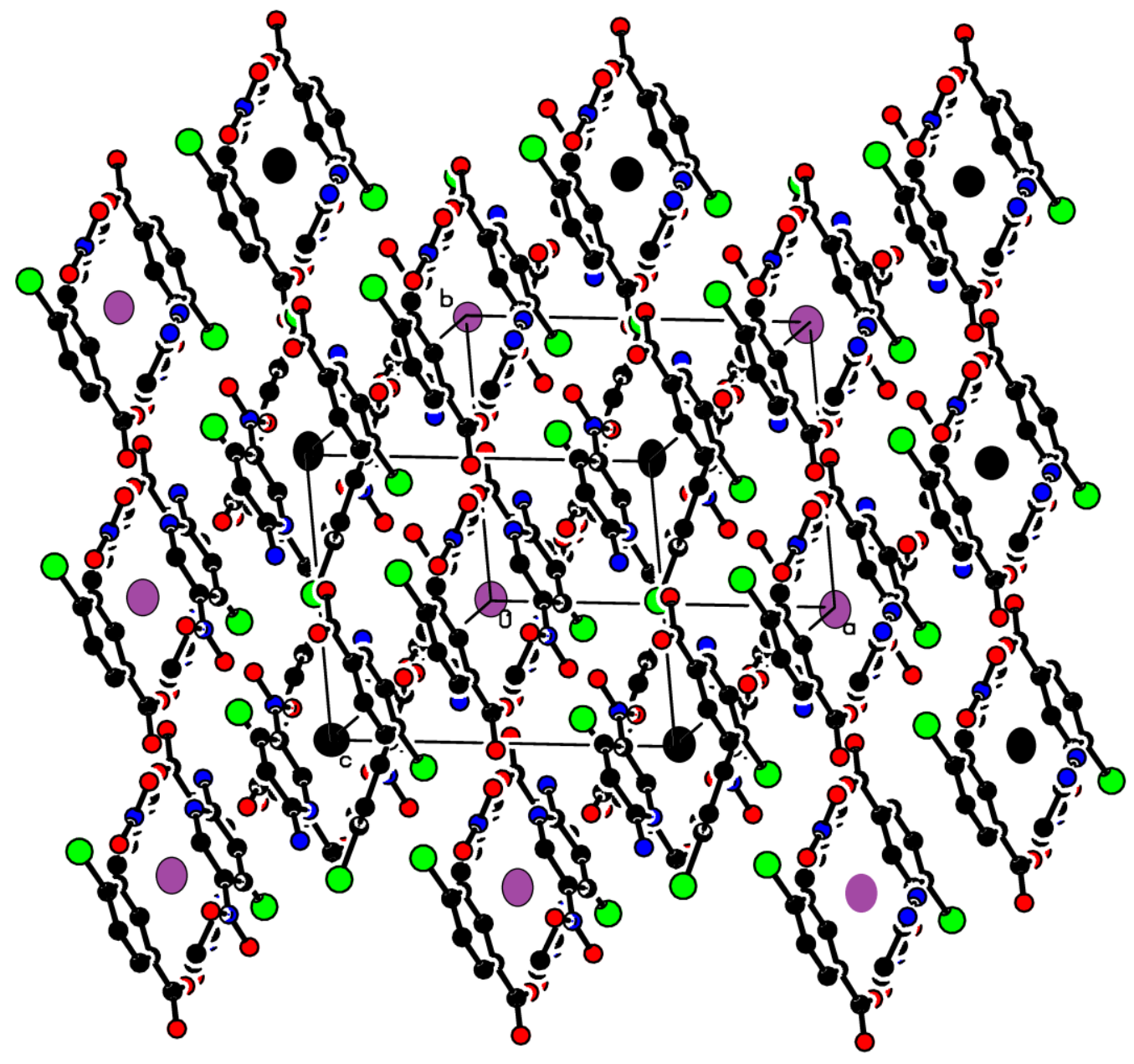

Figure 7. Three-dimensional crystal packing 
Table 1. Crystal data and particulars of the crystal refinement for the 2A5NP4CBA

\begin{tabular}{|c|c|c|}
\hline Identification code & \multicolumn{2}{|l|}{ 2A5NP4CBA } \\
\hline Empirical formula & \multicolumn{2}{|l|}{$\mathrm{C}_{12} \mathrm{H}_{10} \mathrm{Cl} \mathrm{N} \mathrm{O}_{4}$} \\
\hline Formula weight & \multicolumn{2}{|l|}{295.68} \\
\hline Temperature & \multicolumn{2}{|l|}{ 293(2) K } \\
\hline Wavelength & \multicolumn{2}{|l|}{$0.71073 \AA$} \\
\hline Crystal system & \multicolumn{2}{|l|}{ Monoclinic } \\
\hline Space group & \multicolumn{2}{|l|}{$\mathrm{P} 21 / \mathrm{n}$} \\
\hline \multirow[t]{3}{*}{ Unit cell dimensions } & $a=10.9490(5) \AA$ & $a=90^{\circ}$ \\
\hline & $\mathrm{b}=9.2108(4) \AA$ & $\beta=96.017(3)^{\circ}$ \\
\hline & $c=12.7294(6) \AA$ & $\gamma=90^{\circ}$ \\
\hline Volume & \multicolumn{2}{|l|}{$1276.68(10) \AA^{3}$} \\
\hline $\mathrm{Z}$ & \multicolumn{2}{|l|}{4} \\
\hline Density (calculated) & \multicolumn{2}{|l|}{$1.538 \mathrm{Mg} / \mathrm{m}^{3}$} \\
\hline Absorption coefficient & \multicolumn{2}{|l|}{$0.317 \mathrm{~mm}^{-1}$} \\
\hline $\mathrm{F}(000)$ & \multicolumn{2}{|l|}{608} \\
\hline Crystal size & \multicolumn{2}{|c|}{$0.300 \times 0.250 \times 0.200 \mathrm{~mm}^{3}$} \\
\hline Theta range for data collection & \multicolumn{2}{|c|}{2.336 to $25.996^{\circ}$} \\
\hline Index ranges & \multicolumn{2}{|c|}{$-13<=\mathrm{h}<=13,-11<=\mathrm{k}<=11,-15<=\mathrm{l}<=15$} \\
\hline Reflections collected & \multicolumn{2}{|c|}{13709} \\
\hline Independent reflections & \multicolumn{2}{|c|}{$2520[\mathrm{R}$ (int) $=0.0239]$} \\
\hline Completeness to theta $=25.242^{\circ}$ & \multicolumn{2}{|c|}{$100.0 \%$} \\
\hline Absorption correction & \multicolumn{2}{|c|}{ Semi-empirical from equivalents } \\
\hline Max. and min. transmission & \multicolumn{2}{|l|}{0.7462 and 0.6894} \\
\hline Refinement method & \multicolumn{2}{|c|}{ Full-matrix least-squares on $\mathrm{F}^{2}$} \\
\hline Data / restraints / parameters & \multicolumn{2}{|l|}{$2520 / 3 / 190$} \\
\hline Goodness-of-fit on $\mathrm{F}^{2}$ & \multicolumn{2}{|l|}{1.071} \\
\hline Final $\mathrm{R}$ indices $[\mathrm{I}>2 \operatorname{sigma}(\mathrm{I})]$ & \multicolumn{2}{|c|}{$\mathrm{R} 1=0.0349, \mathrm{wR} 2=0.0827$} \\
\hline $\mathrm{R}$ indices (all data) & \multicolumn{2}{|c|}{$\mathrm{R} 1=0.0508, \mathrm{wR} 2=0.0968$} \\
\hline Extinction coefficient & \multicolumn{2}{|c|}{$0.0064(11)$} \\
\hline Largest diff. peak and hole & \multicolumn{2}{|c|}{0.201 and -0.237 e. $\AA^{-3}$} \\
\hline
\end{tabular}


Using the crystallographic data, the packing diagram of the title molecule was simulated by the Mercury 3.9 program [26] and it is presented in Figure 8 (a). Besides, the morphology of the as-grown crystal has been predicted by the SXRD diffractometer (Model: Bruker AXS Kappa APEX II) with MoK $\alpha$ radiation $(\lambda=0.71073 \AA)$ at room temperature. Based on the SXRD results, the morphology of the 2A5NP4CBA crystal has been drawn by the WinXMorph software [26] (which is similar to the results obtained from the SXRD) and it is shown in Figure 8 (b). The details of hydrogen bonding for the 2A5NP4CBA are described in Table 2 .

Table 2. Hydrogen bonds for 2A5NP4CBA [ A $^{\text {and }}{ }^{\circ}$ ]

\begin{tabular}{lcccc} 
D-H...A & d(D-H) & d(H...A) & d(D...A) & $<$ (DHA) \\
\hline $\mathrm{O}(1)-\mathrm{H}(1 \mathrm{~A}) \ldots \mathrm{N}(1)^{(\mathrm{i})}$ & 0.82 & 1.85 & $2.6565(19)$ & 166.7 \\
$\mathrm{~N}(3)-\mathrm{H}(3 \mathrm{~A}) \ldots \mathrm{O}(2)^{(\mathrm{ii})}$ & $0.859(15)$ & $2.290(16)$ & $3.101(2)$ & $157(2)$ \\
$\mathrm{N}(3)-\mathrm{H}(3 \mathrm{~B}) \ldots \mathrm{O}(2)^{(\mathrm{iii})}$ & $0.887(15)$ & $2.219(16)$ & $3.081(2)$ & $164(2)$ \\
$\mathrm{C}(9)-\mathrm{H}(9) \ldots \mathrm{O}(2)^{(\mathrm{iii})}$ & 0.93 & 2.59 & $3.360(2)$ & 140.0 \\
$\mathrm{C}(10)-\mathrm{H}(10) \ldots \mathrm{O}(3)^{(\mathrm{iiv})}$ & 0.93 & 2.39 & $3.213(2)$ & 147.1 \\
& & & & \\
\hline
\end{tabular}

Symmetry transformations used to generate equivalent atoms: $x, y-1, z$, (ii) $x, y+1, z$, (iii) $3 / 2-x, 1 / 2+y, 1 / 2-z$ and (iv) $2-x, 1-y, 1-z$ 

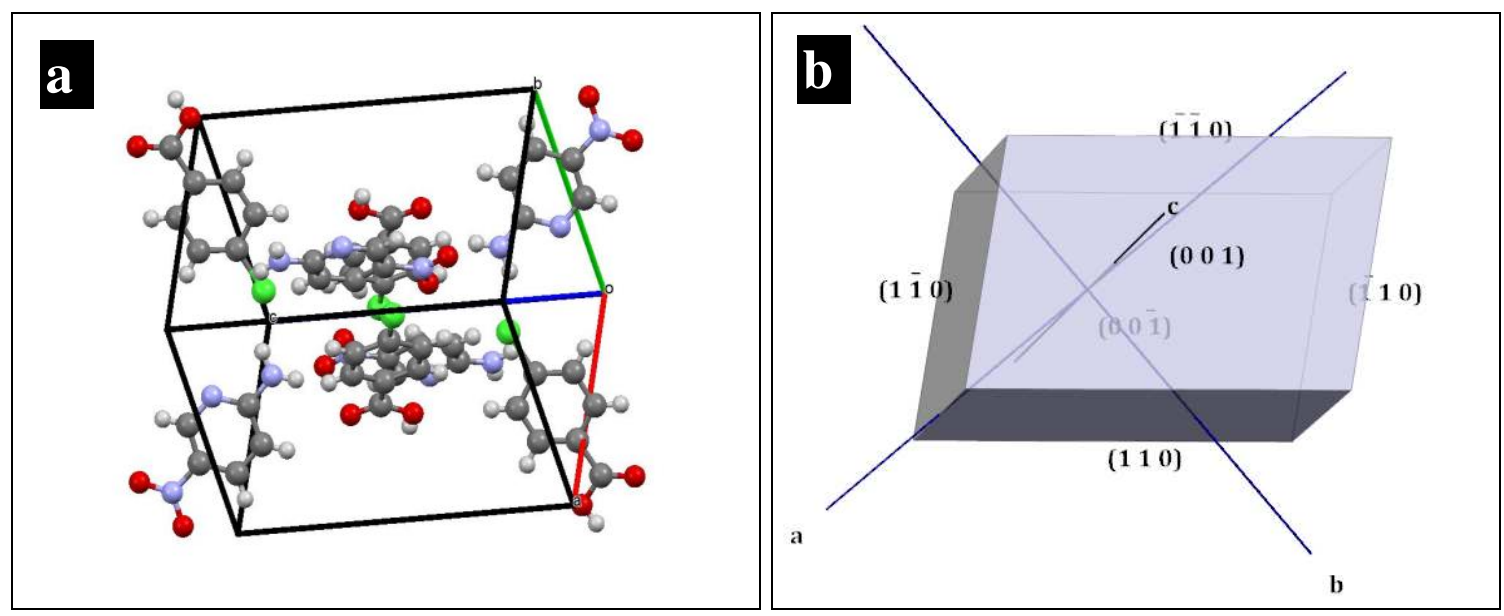

Figure 8 (a) The packing diagram and (b) morphology of the as-grown 2A5NP4CBA crystal deduced by the SXRD analysis

To claim phase purity of the crystallinity of title material, the powder XRD analysis has been carried out at room temperature in the $2 \theta$ scanning range of $10-50^{\circ}$. The PANAnalytic XPERT PRO X-ray diffractometer with $\mathrm{CuK} \alpha_{1}$ radiation of wavelength $1.54059 \AA$ has been used for this experiment. Also, the PXRD spectrum has been simulated from the SXRD data and the obtained hkl planes were matched by the Mercury 3.9 software [26]. The comparison of the simulated and the experimentally obtained PXRD spectra are presented in Figure 9. It is observed that both the PXRD spectra seem to be almost identical. The well-defined sharp peaks at $2 \theta$ angle evidence that the grown crystal has good crystallinity with high purity. The obtained predominant hkl planes are: (110), (002), (20-1), (201), (003), (202), (022), (221), (31-2), (32-2), (412) and (106). 


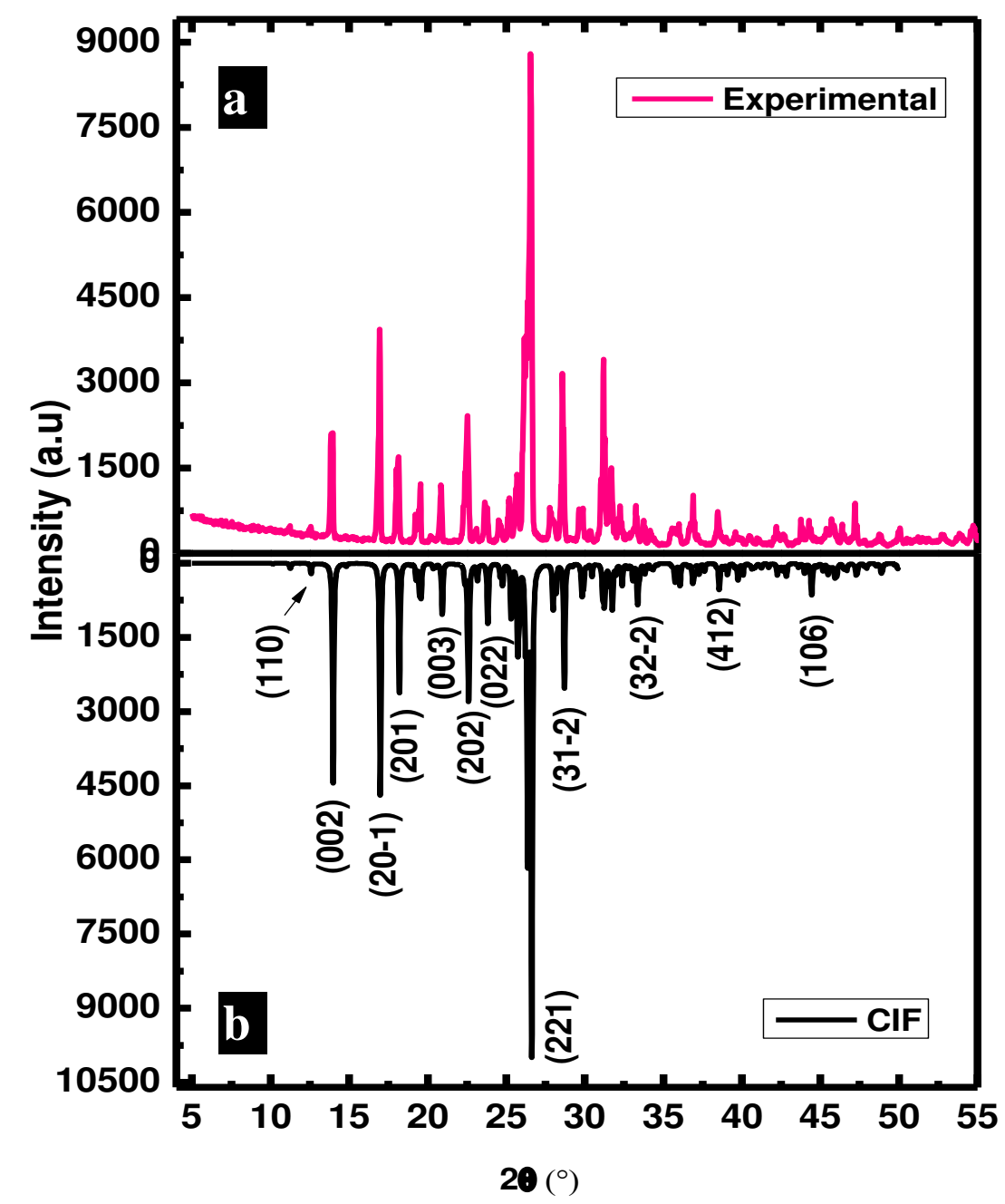

Figure 9. Comparative PXRD spectra of 2A5NP4CBA (a) experimental data and (b) simulated data

The crystalline superiority of the grown crystal was evaluated by the HRXRD analysis using PANanalytical X'pert PRO MRD high-resolution X-ray diffractometer with $\mathrm{CuK \alpha _{1 }}$ radiation. The rocking curve was recorded for as-grown 2A5NP4CBA single crystal along (001) plane and it is presented in Figure 10. The rocking curve shows the single peak with the FWHM of 36 arc-s and it indicates that the grown crystal has good crystalline perfection [27]. The obtained low value of FWHM for the title crystal is found to be almost close to the plane wave 
theory of dynamical X-ray diffraction for ideal crystal [28-29].

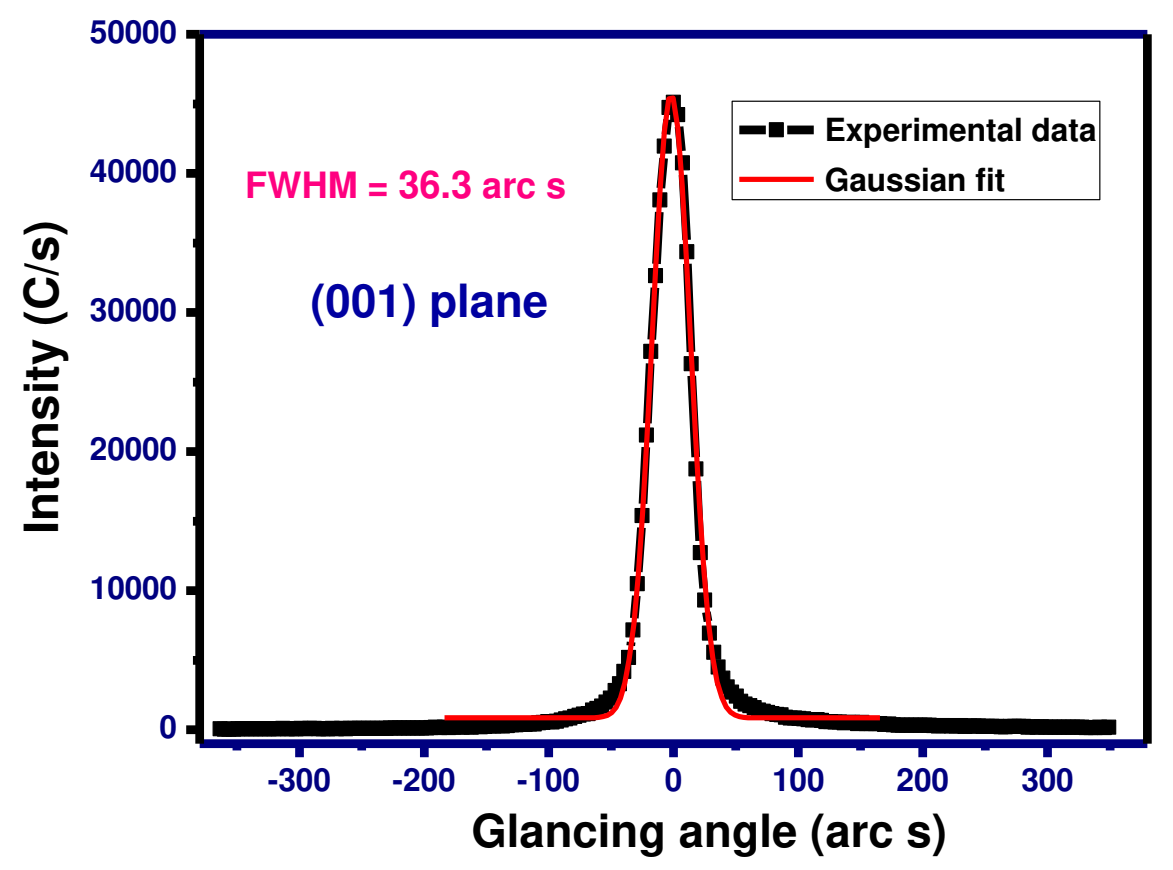

Figure 10. HRXRD rocking curve of 2A5NP4CBA single crystal measured at (001) plane

\subsection{FTIR spectroscopy analysis}

To identify the presence of multifarious functional groups in the 2A5NP4CBA adduct crystal, the FTIR spectrum was recorded in the scanning range between 4000 to $500 \mathrm{~cm}^{-1}$. The experiment was done using the $\mathrm{KBr}$ pellet method by the Perkin-Elmer instrument at room atmosphere. Figure 11. represents the FTIR spectrum of the title adduct compound. The title molecule is known as an unprotonated molecule where the moieties such as 2A5NP and 4-chlorobenzoic acid bonded together with the interactions of hydrogen bonds. The obtained vibrational bands and their assignments are presented in Table 3. 


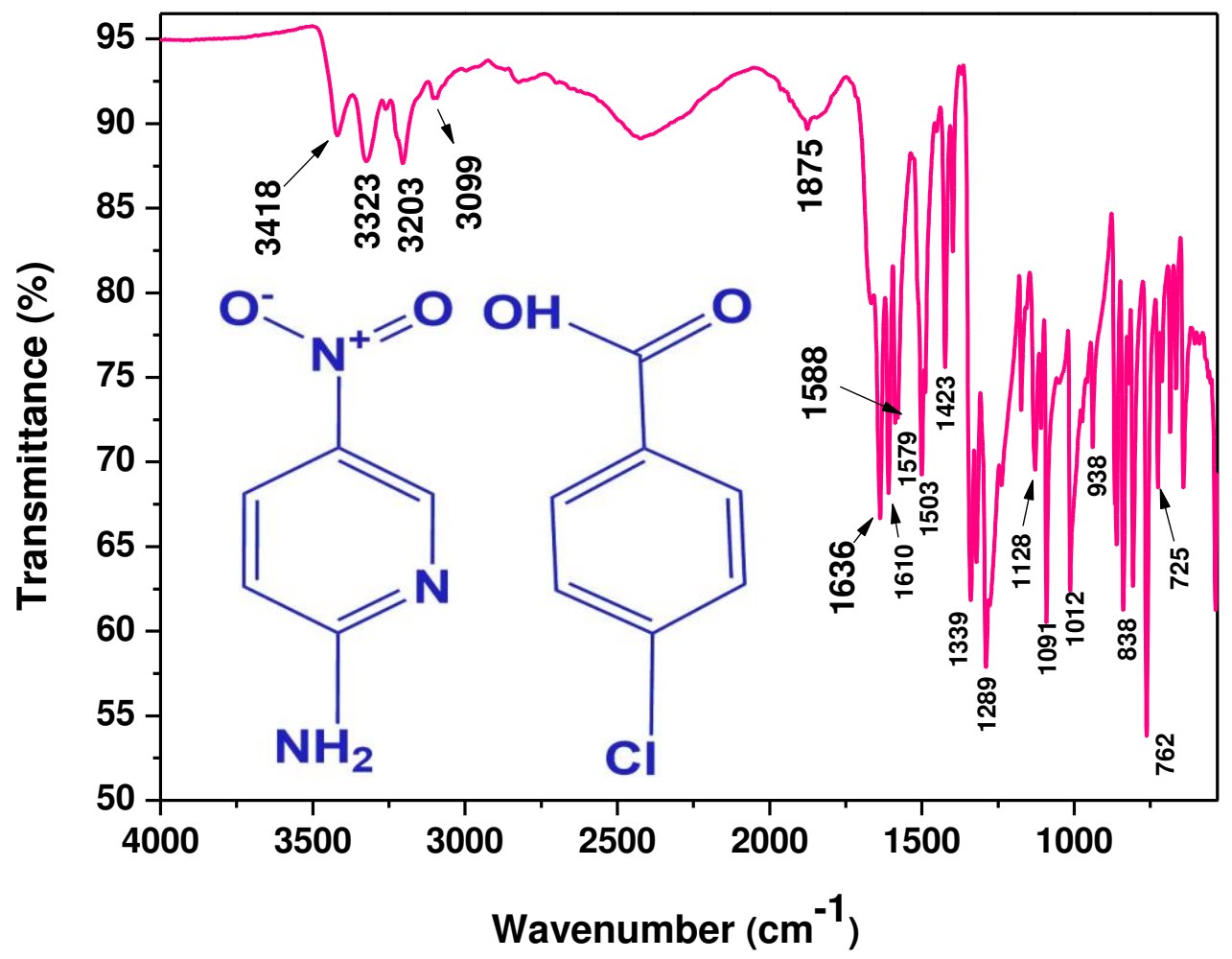

Figure 11. FTIR spectrum of 2A5NP4CBA

The vibrational bands appearing at $3418 \mathrm{~cm}^{-1}$ and $3323 \mathrm{~cm}^{-1}$ correspond to the asymmetric and symmetric stretching vibrations of the $\mathrm{N}-\mathrm{H}$ group for the primary amine, respectively. The peak appearing at $3203 \mathrm{~cm}^{-1}$ is due to the presence of $\mathrm{O}-\mathrm{H}$ stretching vibration, which indicates the occurrence of a hydrogen-bonded $\mathrm{COOH}$ group for the title compound. The medium intensity peak at $3099 \mathrm{~cm}^{-1}$ represents the C-H stretching vibration of the aromatic compound. The vibrational band at $1503 \mathrm{~cm}^{-1}$ is due to the $\mathrm{NO}_{2}$ asymmetric stretching vibration for the $2 \mathrm{~A} 5 \mathrm{NP}$ moiety and the corresponding symmetric stretching vibration is observed at $1339 \mathrm{~cm}^{-1}$. The N-H in-plane bending vibration for the primary amine produces a band at $1588 \mathrm{~cm}^{-1}$. The $\mathrm{C}=\mathrm{O}$ stretching vibration for the $\mathrm{COOH}$ group and $\mathrm{C}=\mathrm{C}$ stretching vibration of the phenyl nucleus produce the vibrational peaks at $1636 \mathrm{~cm}^{-1}$ and $1610 \mathrm{~cm}^{-1}$, respectively. The vibrational band at $1423 \mathrm{~cm}^{-1}$ is attributed to the coupled band vibrations of the $\mathrm{O}-\mathrm{H}$ in-plane 
bending and $\mathrm{C}-\mathrm{O}$ stretching for the title 2A5NP4CBA molecule.

Table 3. FTIR spectral bands and their assignments for the 2A5NP4CBA compound

\begin{tabular}{|c|c|}
\hline Wavenumber $\left(\mathrm{cm}^{-1}\right)$ & Mode of vibrations \\
\hline 3418 & $\begin{array}{c}\text { N-H asymmetric stretching } \\
\text { Vibrations }\end{array}$ \\
\hline 3323 & $\begin{array}{c}\text { N-H symmetric stretching } \\
\text { Vibrations }\end{array}$ \\
\hline 3203 & $\begin{array}{c}\text { O-H stretching } \\
\text { Vibrations }\end{array}$ \\
\hline 3099 & $\mathrm{C}-\mathrm{H}$ stretching vibrations \\
\hline 1636 & $\mathrm{C}=\mathrm{O}$ stretching vibrations \\
\hline 1610 & $\mathrm{C}=\mathrm{C}$ stretching vibrations \\
\hline 1588 & $\mathrm{~N}-\mathrm{H}$ in-plane bending vibrations \\
\hline 1579 & $\mathrm{C}=\mathrm{N}$ stretching vibrations \\
\hline 1503 & $\mathrm{~N}-\mathrm{O}_{2}$ asymmetric stretching vibrations \\
\hline 1423 & $\begin{array}{l}\text { Coupled vibrations of } \mathrm{O}-\mathrm{H} \text { in-plane } \\
\text { bending and } \mathrm{C}-\mathrm{O} \text { stretching }\end{array}$ \\
\hline 1339 & $\mathrm{~N}-\mathrm{O}_{2}$ symmetric stretching vibrations \\
\hline 1128 & $\mathrm{C}-\mathrm{H}$ in-plane bending vibrations \\
\hline 938 & O-H out of plane bending vibrations \\
\hline 860 & C-N aromatic stretching vibrations \\
\hline 838 & C-H out of plane bending vibrations \\
\hline 762 & C-H out of plane bending vibrations \\
\hline 725 & C-Cl stretching vibrations \\
\hline
\end{tabular}

The presence of a pyridine compound in the title molecule produces the vibrational peak at $1579 \mathrm{~cm}^{-1}$ in the form of $\mathrm{C}=\mathrm{N}$ stretching vibrations. The $\mathrm{C}-\mathrm{H}$ in-plane bending vibration is observed at $1128 \mathrm{~cm}^{-1}$ and $\mathrm{O}-\mathrm{H}$ out of plane bending vibration of the $\mathrm{COOH}$ group is observed at 
$938 \mathrm{~cm}^{-1}$. The vibrational band at $860 \mathrm{~cm}^{-1}$ is due to the presence of aromatic C-N stretching vibration which is originated from the vibrations of the aromatic $\mathrm{NO}_{2}$ group. The $\mathrm{C}-\mathrm{H}$ out of plane bending vibration for the presence of 1,4 disubstituted benzene ring and the $\mathrm{C}-\mathrm{Cl}$ stretching vibration for the presence of aromatic monochlorinated compounds are assigned for the occurrence of vibrational bands at $838 \mathrm{~cm}^{-1}$ and $725 \mathrm{~cm}^{-1}$, respectively. The existence of a 2-substituted pyridine ring produces the vibrational band at $762 \mathrm{~cm}^{-1}$ in the form of $\mathrm{C}-\mathrm{H}$ out of plane bending vibrations. All the vibrational peaks and their corresponding assignments were done with the help of standard literature [30].

\subsection{Linear optical studies}

The determination of the linear optical characteristics of the grown crystal helps to identify its utility in optoelectronics and nonlinear optical device applications. This is because the grown crystal could be of utility if it possesses a wide range of optical transmittance without having any absorption at the fundamental wavelength region [31]. Usually, the single crystal with a wide optical window and high transmittance are the essential parameters for the transmission of second and third harmonic generation [32]. The linear optical study also provides important information on the electronic band structure of the grown crystal. Here, the absorption of light involves the excitation of electrons from the ground state to the higher energy states [33]. To determine the linear optical characteristics of the grown crystal, the optical absorption and transmittance analyses have been carried out using the UV-vis-NIR spectrophotometer (Model: Perkin-Elmer Lambda 35) in the scanning range of $200 \mathrm{~nm}$ to $1100 \mathrm{~nm}$. The well-polished 2A5NP4CBA single crystal with the crystal thickness of $2 \mathrm{~mm}$ was subjected to the absorption and transmittance analysis and the recorded spectra are shown in Figure 12. 


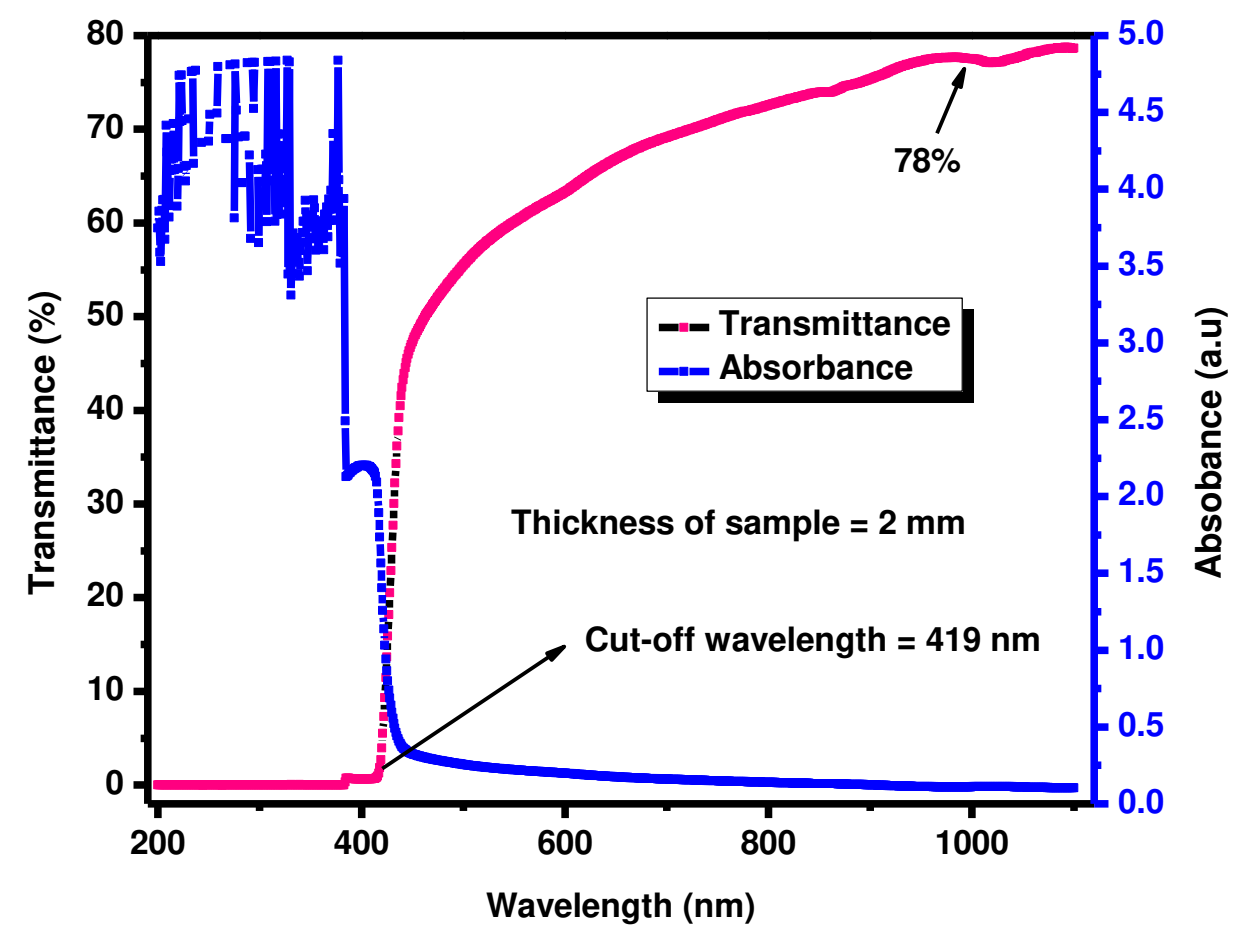

Figure 12. The UV-vis-NIR spectra of 2A5NP4CBA single crystal

The resultant transmission spectrum illustrates that the grown crystal has a cut-off edge at $419 \mathrm{~nm}$ which facilitates it to be a good candidate for frequency conversion applications. It has been inferred from the figure that the transmittance of the grown crystal has more than $70 \%$ in the visible and near-infrared region. The comparison of cut-off wavelength for 2A5NP derivative single crystals is presented in Table 4. Such good optical transmittance in the grown crystal is attributed to the minimized intrinsic structural and crystalline defects like line defects, point defects, vacancies, voids and low angle grain boundaries [34]. If the density of defects is high, the optical loss may be induced in the optical medium owing to the occurrence of increased scattering centers. In the present case, the grown crystal has good optical transmittance and this is due to the occurrence of required optical properties such as less absorption and the less scattering centers within the crystal medium. Hence, it is noticed that the optical transmittance of 
the grown crystal seems to be quite good and this property leads to the positive sign for its usefulness in the linear and nonlinear optical device applications [35].

The absorption spectrum clearly shows that the grown crystal possesses strong absorption in the scanning range between $200 \mathrm{~nm}$ to $419 \mathrm{~nm}$, which is due to the presence of various optically active chromophores such as $\mathrm{NO}_{2}, \mathrm{NH}_{2}, \mathrm{NH}^{+}$and $\mathrm{COOH}$ in the title molecule. These chromophores are also responsible for the appearance of yellow color in the title crystal. The absorption edge in the title molecule is attributed to the $\pi-\pi^{*}$ transitions [36]. The optical constants such as the absorption coefficient, bandgap and refractive index play an important role in the fabrication of photonics and optoelectronic device applications. Hence, such optical constants were determined for the 2A5NP4CBA crystal from the UV-Vis NIR analysis using some standard formulae and the details are presented in section S2 (ESI).

Normally, the wide bandgap materials are utilized in the photonic and optoelectronic device applications because of the less chances for the promotion of spontaneous emission or absorption at the fundamental region during the frequency conversion [37]. Based on the Tauc's plot relation, the bandgap of the 2A5NP4CBA crystal was $2.9 \mathrm{eV}$. The value of ' $\mathrm{m}$ ' indicates the presence of direct allowed transition in the grown crystal. The refractive index and extinction coefficient of the grown crystal was found to be 1.66 at $532 \mathrm{~nm}$. The Tauc's plot, refractive index spectra of the grown crystal are presented in Figure 13 (a and b), respectively. Thus, the obtained results show that the grown crystal has excellent optical properties such as good optical transmittance (more than $70 \%$ in the visible and NIR region), lower cut-off wavelength (419 $\mathrm{nm})$, wide bandgap $(2.9 \mathrm{eV})$ and a direct allowed electronic transition $(\mathrm{m}=1 / 2)$. Hence, the obtained results lead to conclude that the grown crystal can be utilized in the fabrication of linear and nonlinear optical applications. 

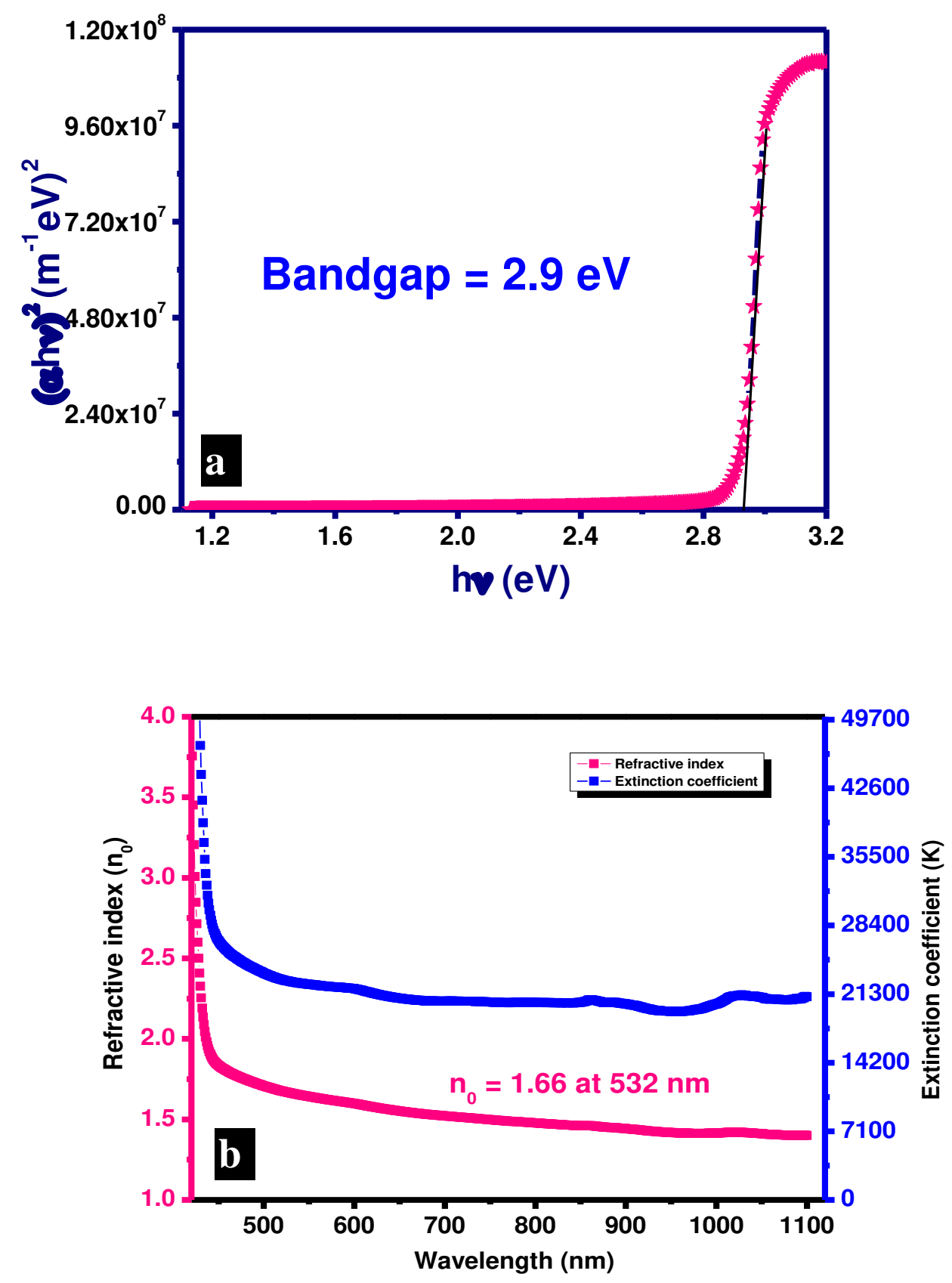

Figure 13. (a) Tauc's plot (b) refractive index and extinction coefficient spectra of 2A5NP4CBA crystal 


\subsection{Thermal analysis}

The efficiency of nonlinear optical materials strongly depends on their thermal stability. Usually, the high-power radiation induces a considerable amount of heat in the NLO medium which reduces the overall performance of the optical device. Hence, the discovery of new thermally stable nonlinear optical materials is always engaged in recent days due to its huge technological importance. The grown 2A5NP4CBA crystal has been subjected to thermal analysis using the instrument (model-Perkin Elmer Diamond TG-DTA) in the temperature range of $30^{\circ} \mathrm{C}$ to $350^{\circ} \mathrm{C}$. A small piece of crystal sample weighing $7.2 \mathrm{mg}$ was placed in the platinum crucible and it was subjected to heat with the heating rate of $10.0^{\circ} \mathrm{C} / \mathrm{min}$. During the experiment, an inert atmosphere has been maintained using nitrogen gas with a flow rate of $100 \mathrm{ml} / \mathrm{min}$. Figure 14. shows the simultaneous TG-DTA spectra of 2A5NP4CBA single crystal.

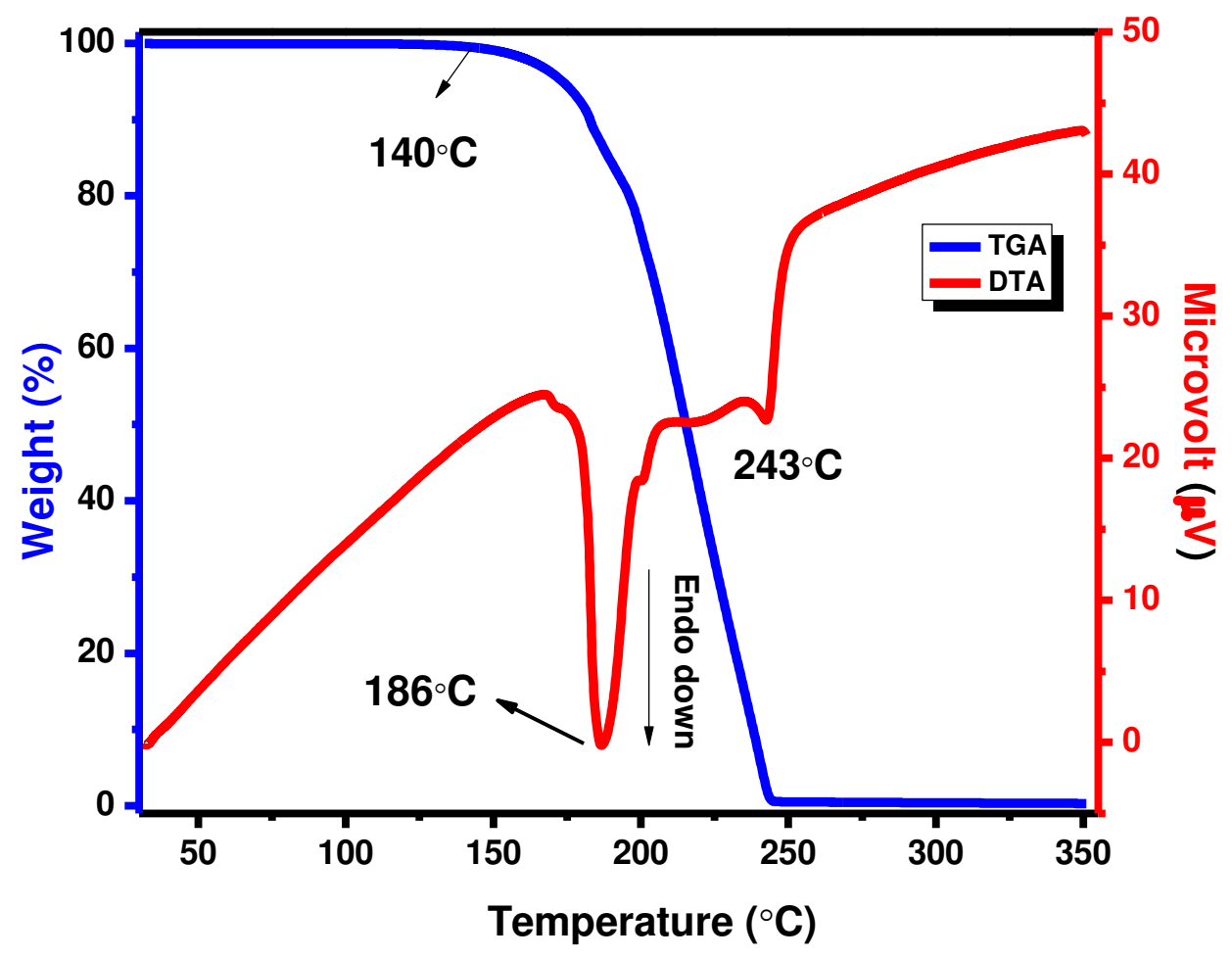

Figure 14. TG-DTA spectrum of 2A5NP4CBA single crystal 
The TG spectrum shows that there is a single-stage weight loss occurring in the grown crystal when increasing the temperature upto $350^{\circ} \mathrm{C}$. It is observed that there is no peak in the temperature range between $30^{\circ} \mathrm{C}$ to $140^{\circ} \mathrm{C}$ which evidences the absence of moisture in the grown crystal. The dissociation occurred in the temperature range between $140^{\circ} \mathrm{C}$ to $243^{\circ} \mathrm{C}$ in the form of volatile gaseous products. The sharp endothermic peak was observed in the DTA spectrum at $186^{\circ} \mathrm{C}$ which reveals the good crystalline quality and phase purity of the grown crystal. The nonexistence of endothermic or exothermic peaks in the temperature range from $30^{\circ} \mathrm{C}$ to $180^{\circ} \mathrm{C}$ reveals the absence of any structural changes in the grown crystal.

The sharp endothermic peak was observed at $186^{\circ} \mathrm{C}$ in the DTA curve which coincides with the weight loss observed in the TG curve. This is an indication of the simultaneous melting and complex decomposition of the 2A5NP4CBA crystal. The obtained thermal stability is quite good compared to some 2A5NP derivative single crystals and the details are presented in Table 4. The good thermal stability of the grown crystal is due to the presence of multiple hydrogen bond interactions between 2A5NP and 4-chlorobenzoic acid moieties.

Table 4. The cut-off wavelength and thermal stability for 2A5NP derivative single crystals

\begin{tabular}{|c|c|c|c|c|}
\hline Crystal name & $\begin{array}{c}\text { Crystal system } \\
\text { \& Space group }\end{array}$ & $\begin{array}{c}\text { Cut-off } \\
\text { wavelength } \\
(\mathbf{n m})\end{array}$ & $\begin{array}{c}\text { Thermal } \\
\text { stability } \\
\left({ }^{\circ} \mathbf{C}\right)\end{array}$ & Reference \\
\hline 2A5NPP & Orthorhombic- Pna2 1 & 408 & 200 & {$[15]$} \\
\hline 2A5NPBr & Monoclinic- P2 1 & 408 & 188 & {$[38,39]$} \\
\hline 2A5NP4CBA & Monoclinic- P21/n & $\mathbf{4 1 9}$ & $\mathbf{1 8 6}$ & Present work \\
\hline 2A5NPLT & Monoclinic- P2 1 & 410 & 181 & {$[20]$} \\
\hline 2A5NPDP & Orthorhombic- Pna2 1 & 410 & 175 & {$[40]$} \\
\hline 2A5NPN & Monoclinic- P2 $1 / 1 \mathrm{n}$ & 404 & 175 & {$[41]$} \\
\hline 2A5NPTB & Orthorhombic- Fdd2 & 420 & 145 & {$[18]$} \\
\hline 2A5NPTFA & Monoclinic- P2 ${ }_{1 / \mathrm{c}}$ & 430 & 125 & {$[11]$} \\
\hline
\end{tabular}




\subsection{Laser damage threshold (LDT) analysis}

For the selection of an effective crystal for nonlinear optical applications, the crystal should have the ability to withstand high-power lasers. It is one of the major criteria is considered for NLO device fabrication. In addition, the investigation of the LDT for the newly grown single crystal with high power laser becomes crucial for the crystal growers to perform as potential material for the NLO and optoelectronic device applications. In general, the origin of the LDT is a complex process and majorly depends on the material's nature and various parameters of the experimental setup. When the laser beam is irradiated onto the crystal surface, the part of incident light induces the rise in temperature by the absorption and it leads to the temperature gradient. If the temperature gradient occurs, the corresponding thermal expansion coefficient is also induced in the crystal sample. Due to the anisotropic nature of the thermal expansion coefficient, the damage is induced in the case of light-absorbing optical materials [17]. Hence, it can be correlated that the thermal effect is one of the major reasons to induce the damage in the 2A5NP4CBA crystal with the exposure of a high-power laser beam. In another way, material's intrinsic factors like multi-photon absorption, electron avalanche effect, photochemical dissociation and photo-ionization may be responsible for the light-induced laser damage threshold [23]. Apart from that, the laser-induced damage can be persuaded by a great number of intrinsic factors like crystal quality, thermal stability, the density of crystal defects and the nature of the crystal surface. The experimental parameters like the wavelength of the laser, pulse width, repetition rate, intensity of the laser, longitudinal and transverse mode structures and beam size also influence the development of damage in the crystal sample [42]. Apart from that, the laser-induced damage may occur due to the existence of various nonlinear optical factors such as the self-focusing and multi or two-photon absorption behavior of the material [43-44]. 
The LDT measurement of the 2A5NP4CBA single crystal was carried out under the irradiation of Nd: YAG laser (Make Litron Lasers, UK) of wavelength $1064 \mathrm{~nm}$. The laser was operated at a $10 \mathrm{~Hz}$ repetition rate with a pulse width of $10 \mathrm{~ns}$ and $\mathrm{TM}_{00}$ mode. The laser beam diameter was fixed as $1 \mathrm{~mm}$. The variable attenuator was used to control the energy of the output laser. The focal point of the laser was attained with the help of a converging lens with a focal length of $35 \mathrm{~cm}$. The as-grown single crystal with a flat surface was placed at the focal point for the experiment. In doing so, the laser beam falls onto the crystal's surface and the occurrence of visible damage can be seen when exceeding the threshold for the grown crystal with the exposure of high-power laser irradiation. During this process, the damage was determined by the visible microdot/fracture onto the crystal surface and the corresponding input intensity of the laser was measured by the power meter. For the experiment, different intensity $(5 \mathrm{~mJ}, 10 \mathrm{~mJ}, 20 \mathrm{~mJ}, 30 \mathrm{~mJ}$ and $40 \mathrm{~mJ}$ ) was irradiated onto the crystal surface and the corresponding damage was noticed under an optical microscope. When the intensity of the laser was reached $5 \mathrm{~mJ}$, there is no damage observed on the crystal surface. However, when the intensity is gradually increased to $10 \mathrm{~mJ}$, a small circular dot appeared on the crystal surface. Usually, the laser damage threshold is determined by the lowest intensity of the laser in which the visible damage occurs on the surface of the crystal. 

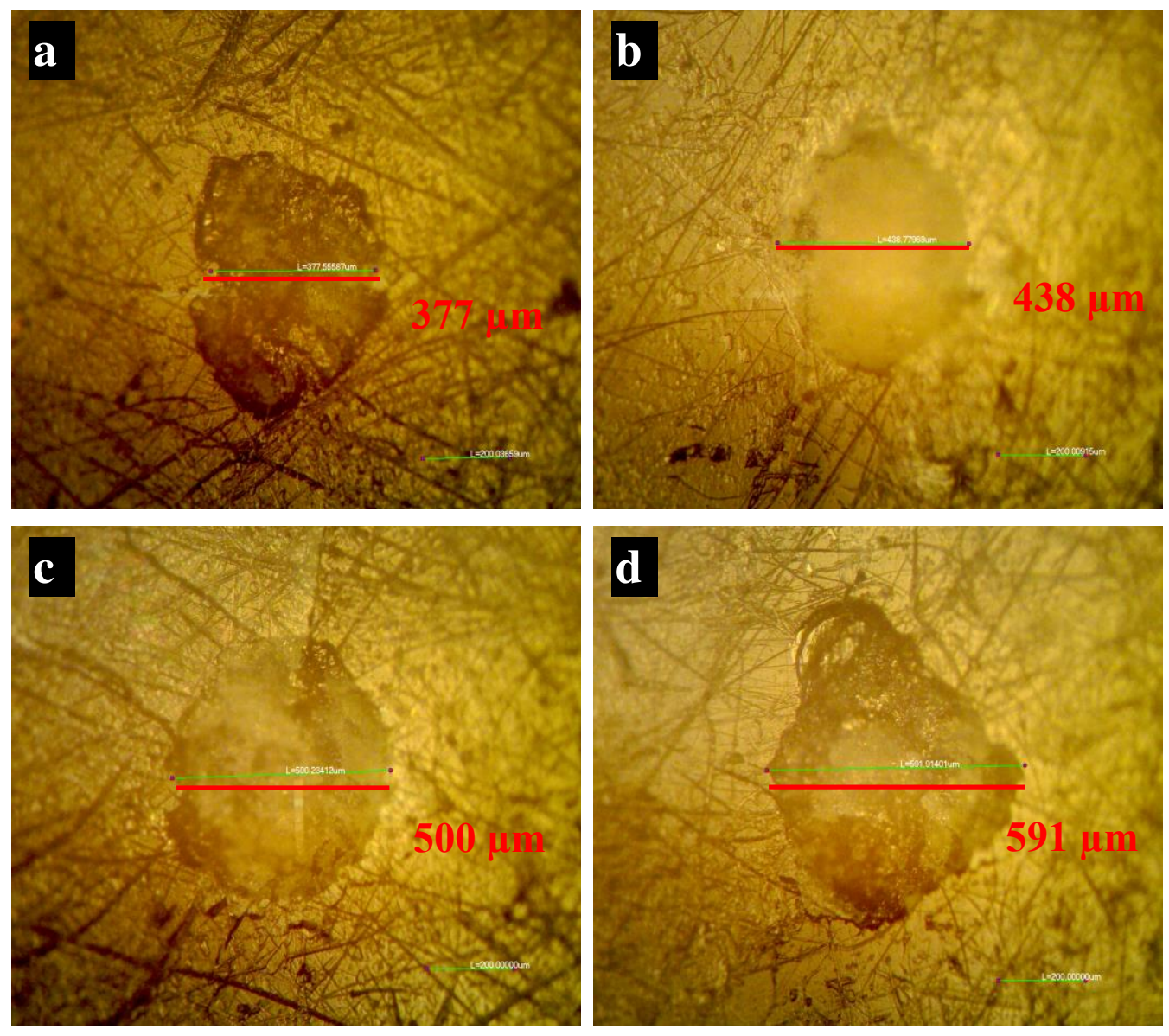

Figure 15 (a-d). Laser damage patterns of 2A5NP4CBA single crystal with the irradiation of

\section{different intensity of the laser beam}

Figure 15 (a-d). show the damaged patterns of the 2A5N4CBA single crystal with different intensities of the laser irradiation such as $10 \mathrm{~mJ}, 20 \mathrm{~mJ}, 30 \mathrm{~mJ}$ and $40 \mathrm{~mJ}$, respectively. Here we noticed that the size of the damaged pattern increases when increasing the intensity of the laser radiation. Based on the above laser parameters, the grown crystal withstands the laser radiation upto $10 \mathrm{~mJ}$. The crystal's LDT was determined by the following expression [45].

$$
\text { Power density }\left(P_{d}\right)=\frac{E}{\tau \pi r^{2}} \mathrm{GW} / \mathrm{cm}^{2}
$$

where, E is the energy of the laser beam (which is measured when the visible damage occurred on the crystal surface), $\tau$ is the pulse width $(10 \mathrm{~ns})$ and $\omega_{0}$ is the radius of the beam waist at the 
focal point which is measured by the following expression.

$$
2 \omega_{0}=\left(\frac{4 \lambda}{\pi}\right)\left(\frac{f}{d}\right)
$$

where $\lambda$ is the wavelength of the laser, $\mathrm{f}$ is the focal length of the convex lens and $\mathrm{d}$ is the diameter of the laser beam. From the above relation, the value of $\omega_{\mathrm{o}}$ was calculated and it was found to be $0.237 \mathrm{~mm}$.

Table 5. Comparison of laser damage threshold of 2A5NP4CBA crystal with some known NLO single crystals

\begin{tabular}{|c|c|c|c|c|}
\hline Crystal name & $\begin{array}{c}\text { Wavelength } \\
(\mathbf{n m})\end{array}$ & $\begin{array}{c}\text { Pulse width } \\
\text { (ns) }\end{array}$ & $\begin{array}{c}\mathrm{LDT} \\
\left(\mathrm{GW} / \mathrm{cm}^{2}\right)\end{array}$ & Reference \\
\hline Potassium pentaborate (KB5) & 1064 & 12 & $>0.08$ & {$[46]$} \\
\hline $\begin{array}{l}\text { Lithium format monohydrate } \\
\text { (LFMH) }\end{array}$ & 1064 & 11 & 1.5 & {$[46]$} \\
\hline Potassium titanyl phosphate (KTP) & 1064 & 11 & $>1.5-2.2$ & {$[46]$} \\
\hline L-arginine trifluoroacetate (LATF) & 1064 & 10 & 3.5 & {$[1]$} \\
\hline $\begin{array}{l}\text { 2-amino-5-nitropyridinium nitrate } \\
\qquad(2 \mathrm{~A} 5 \mathrm{NPN})\end{array}$ & 1064 & 10 & 4 & {$[41]$} \\
\hline $\begin{array}{l}\text { Potassium dihydrogen phosphate } \\
\qquad(\mathrm{KDP})\end{array}$ & 1064 & 1 & 5 & {$[47]$} \\
\hline $\begin{array}{l}\text { Diguanidinium phosphate } \\
\text { monohydrate }(\mathrm{G} 2 \mathrm{HP})\end{array}$ & 1064 & 10 & 5.2 & {$[1]$} \\
\hline 2A5NP4CBA & 1064 & 10 & 6.2 & $\begin{array}{c}\text { Present } \\
\text { work }\end{array}$ \\
\hline
\end{tabular}

From the above equations, the value of LDT for the grown crystal was calculated to be 6.2 $\mathrm{GW} / \mathrm{cm}^{2}$. The obtained results are compared with literature reports and the details are 
presented in Table 5. Based on the obtained result, the significant large LDT can be attributed to the good quality and the stable molecular structure of the 2A5NP4CBA single crystal. Hence, the result shows that the grown crystal is a potential candidate for the high-power laser and NLO device applications.

\subsection{Nonlinear optical analyses}

The fabrication of optoelectronic devices strongly depends on the development of efficient NLO single crystals. For the usage of the grown crystal to the application, it is important to determine the quantitative information about their third-order nonlinear characteristics such as nonlinear absorption coefficient $(\beta)$, nonlinear refractive index $\left(\mathrm{n}_{2}\right)$ and nonlinear susceptibility $\left(\chi^{(3)}\right)$. Numerous characterization techniques such as four-wave mixing [48], nonlinear interferometry [49], nonlinear ellipse rotation [50], beam-distortion [51] and the single beam Z-scan [52-53] are available to determine $\beta$ and $\mathrm{n}_{2}$ of the optical materials. However, the single-beam Z-scan is a widely accepted technique by the scientific community because of its reliability, simplicity and high accuracy [53-54].

To determine the third-order nonlinearity of 2A5NP4CBA single crystal, a diode laser of wavelength $532 \mathrm{~nm}$ has been used with the power of $100 \mathrm{~mW}$. The sample size should be considered less than the Rayleigh length (ZR) during the experiment. It is found that the crystal thickness (L) is less than the ZR, and hence basic criteria are found to be satisfied for the Z-scan measurement. The value of $\mathrm{L}$ and $\mathrm{ZR}$ are calculated to be $0.83 \mathrm{~mm}$ and $1.32 \mathrm{~mm}$, respectively. For this experiment, the Gaussian beam was focused onto the 2A5NP4CBA crystal and then the crystal sample was moved along the $-\mathrm{Z}$ and $+\mathrm{Z}$ direction with the propagation direction of the laser. For each translation, the intensity of the transmitted light was measured as a function of sample position. Based on the $\beta$ and $\mathrm{n}_{2}$ characteristics of the grown crystal, the sign and magnitude of the transmitted beam will be varied for open/closed aperture measurements. For the 
case of closed aperture measurement, the intensity of the source light was recorded by the photodetector by fixing an aperture radius of $2 \mathrm{~mm}$.

In the case of open aperture measurement, the entire transmitted light obtained through the sample was recorded without placing any aperture at the detector. Accordingly, the interesting nonlinear effects like self-focusing and self-defocussing behavior of the nonlinear medium can be identified while the signature of $\mathrm{n}_{2}$ is found to be positive and negative, respectively [55]. The normalized open aperture spectrum of the 2A5NP4CBA crystal is shown in Figure 16 (a). Here, the transmittance is found to be maximum at the focus $(\mathrm{Z}=0)$ when increasing optical intensity, which indicates the nonlinear saturable absorption (SA) and positive absorption coefficient of the grown crystal. Also, the maximum transmittance (peak) at focus $(Z=0)$ in the open aperture spectrum reveals the photon absorption in the 2A5NP4CBA single crystal [56].

The recorded closed aperture spectrum is presented in Figure 16 (b). The spectrum clearly shows that the grown crystal possesses the configuration of the pre-focal peak to postfocal valley in transmitted intensity which indicates the occurrence of negative nonlinear refractive index and it is facilitating the self-defocusing effect. Arising of the self-defocusing effect owing to the local change of refraction with temperature. Such a class of materials is more desirable for the development of the protection of optical sensors particularly for night vision devices [57]. 

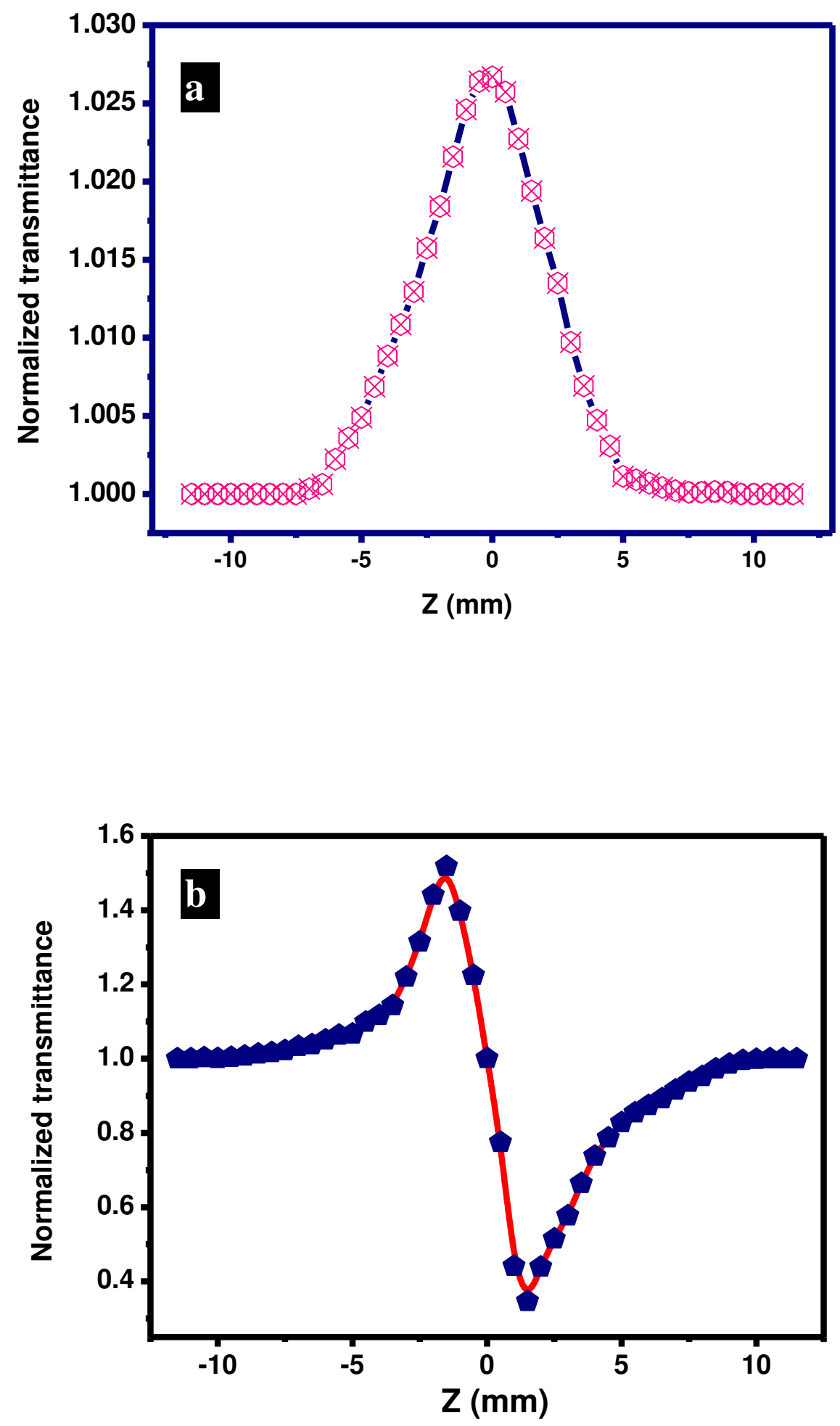

Figure 16. (a) Normalized open and (b) closed aperture spectrum of 2A5NP4CBA single crystal 
To determine absolute third-order nonlinear parameters such as $n_{2}, \beta$ and $\chi^{(3)}$ of the grown crystal, the standard nonlinear transmission equations have been used and the details are described in the literature $[40,58]$. The calculated value of $\mathrm{n}_{2}, \beta$ and $\chi^{(3)}$ values are found to be $6.042 \times 10^{-8} \mathrm{~cm}^{2} / \mathrm{W}, 0.019 \times 10^{-4} \mathrm{~cm} / \mathrm{W}$ and $2.958 \times 10^{-6} \mathrm{esu}$, respectively. The obtained $\chi^{(3)}$ is found to be good compared to some know NLO single crystal and the details are presented in Table 6 . Hence, the obtained result leads to conclude that the grown crystal is a potential competitor in optoelectronic and NLO fields.

In recent days, extensive research is being carried out to develop efficient optical limiters for the protection of optical elements from high-intensity light [59]. This interesting phenomenon can be observed in NLO materials where the transmitted intensity of the optical medium remains constant at a particular point with increasing intensity or fluence [60]. In the present work, a similar Z-scan setup with a solid-state laser of wavelength $532 \mathrm{~nm}$ was used to determine the optical limiting property of the 2A5NP4CBA single crystal. The intensity of the incident laser was systematically increased using a polarizer-analyzer (PA) setup and the corresponding transmitted intensity of light was recorded through the aperture by the photodetector. The measured OL response of the title crystal is shown in Figure 17. 


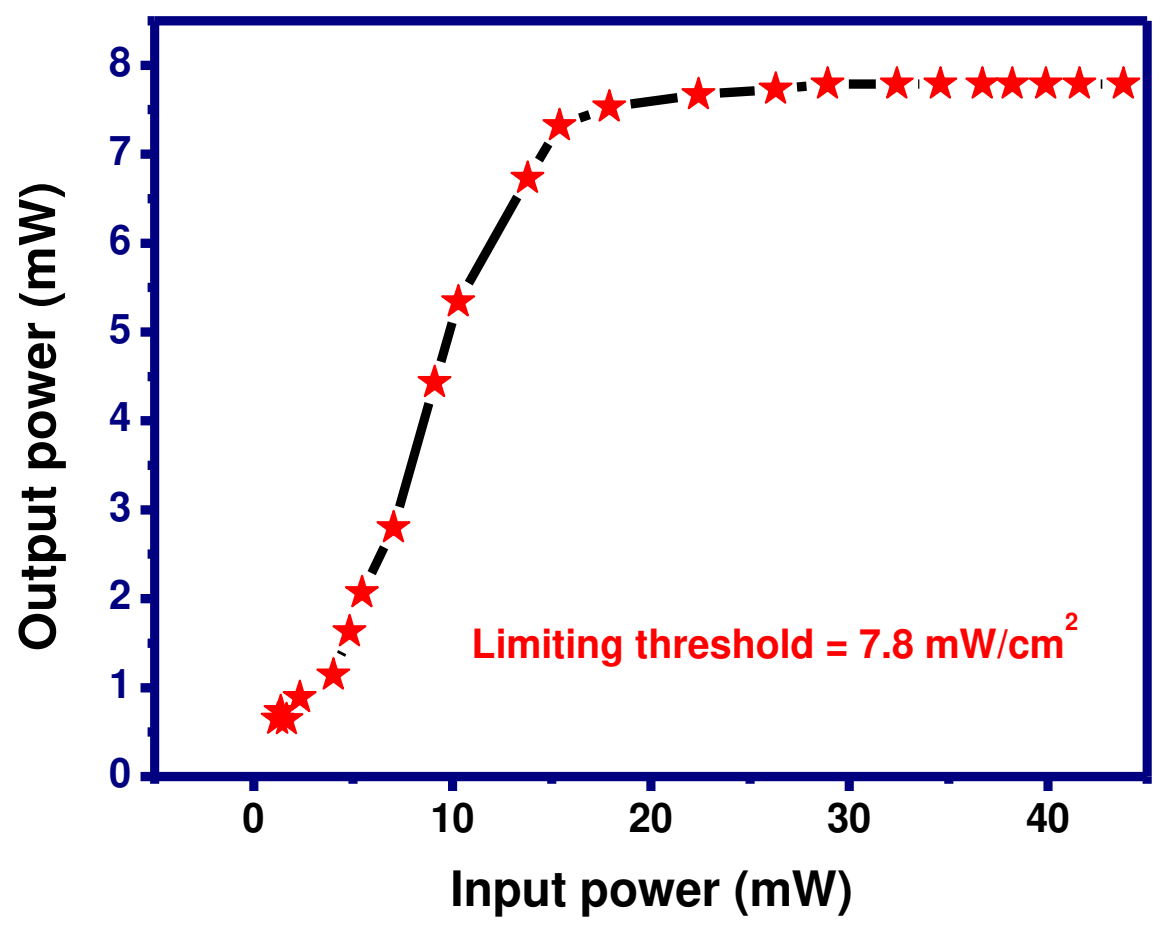

Figure 17. OL spectrum of 2A5N4CBA single crystal

Interestingly, the intensity of the transmitted light is linearly increased at low input power and then it saturates beyond the $7.8 \mathrm{~mW} / \mathrm{cm}^{2}$. This result indicates the existence of noticeable optical limiting characteristics of the 2A5NP4CBA single crystal. This is due to the strong nonlinearity of the grown title single crystal which may be originated by its molecular structure. Also, it can be correlated with the existence of third-order nonlinear properties such as negative refraction and strong saturable absorption of the 2A5NP4CBA single crystal. In general, the origin of the optical limiting is a complex process, however, it may be correlated with important factors such as nonlinear optical refraction (or thermal effect), nonlinear optical absorption and nonlinear optical scattering [61]. Hence, the obtained result satisfies the essential requirement of optical limiters. 
Table 6. Comparison of $\chi^{(3)}$ for the title crystal and other NLO single crystals

\begin{tabular}{|c|c|c|c|c|}
\hline $\begin{array}{c}\text { Crystal } \\
\text { name }\end{array}$ & $\begin{array}{c}\boldsymbol{\beta} \\
(\mathbf{m} / \mathbf{W})\end{array}$ & $\begin{array}{c}\mathbf{n}^{2} \\
\left(\mathbf{m}^{\mathbf{2}} / \mathbf{W}\right)\end{array}$ & $\begin{array}{c}\chi^{(\mathbf{3})} \\
(\mathbf{e . s . u})\end{array}$ & Reference \\
\hline 2 ADPTS & $0.311 \times 10^{-2}$ & $3.22 \times 10^{-6}$ & $3.143 \times 10^{-4}$ & {$[62]$} \\
\hline VSNS & $5.954 \times 10^{-5}$ & $5.214 \times 10^{-12}$ & $6.564 \times 10^{-5}$ & {$[58]$} \\
\hline $\mathbf{2 A 5 N P 4 C B A}$ & $\mathbf{0 . 0 1 0 1 9 \times 1 0 ^ { - 4 }}$ & $\mathbf{0 . 6 0 4 2} \times \mathbf{1 0}^{-8}$ & $\mathbf{2 . 9 5 8 \times 1 0 ^ { - 6 }}$ & Present work \\
\hline BCBA & $-2.065 \times 10^{-3}$ & $-1.816 \times 10^{-10}$ & $4.853 \times 10^{-7}$ & {$[63]$} \\
\hline 2 A5NPN & $1.2 \times 10^{4}$ & $2.442 \times 10^{-11}$ & $2.42 \times 10^{-8}$ & {$[41]$} \\
\hline AAP & - & - & $6.2 \times 10^{-9}$ & {$[64]$} \\
\hline VMST & $1.1 \times 10^{-5}$ & $1.5 \times 10^{-13}$ & $9.6 \times 10^{-12}$ & {$[65]$} \\
\hline KBBT & - & $1.75 \times 10^{-18}$ & $0.99 \times 10^{-13}$ & {$[66]$} \\
\hline KDP & - & $2.54 \times 10^{-11}$ & $4.02 \times 10^{-14}$ & {$[67]$} \\
\hline
\end{tabular}

\section{Conclusion}

The 2A5NP4CBA single crystals with well-faceted morphology have been successfully grown by the SEST for the first time. The centrosymmetric structure of the grown crystal was confirmed by SXRD analysis. The low FWHM has been observed in HRXRD analysis which reveals the grown crystal has greater crystalline perfection. The functional groups in the title molecule have been identified by the FTIR spectroscopy analysis. The UV -vis -NIR analysis shows the good optical quality (transmittance observed is more than $70 \%$ ) with the absorption edge occurs at $419 \mathrm{~nm}$. Based on the UV result, various linear optical parameters have been analyzed. The simultaneous TG and DTA analysis of 2A5NP4CBA single crystal revealed high thermal stability. The grown crystal exhibiting a good LDT value $\left(6.2 \mathrm{GW} / \mathrm{cm}^{2}\right)$ compared to other NLO single crystals with irradiation of Q-switched Nd: YAG laser. The open and closed 
aperture Z-scan analysis proved that the grown crystal has a negative nonlinear refractive index and a self-defocusing nature. The obtained large $\chi^{(3)}$ value $\left(2.958 \times 10^{-6}\right.$ esu $)$ and good optical limiting threshold $\left(7.8 \mathrm{~mW} / \mathrm{cm}^{2}\right)$ imply that the grown crystal is a potential candidate for the fabrication of optical limiting and photonic devices in the future. The interesting properties exhibited by this kind of 2A5NP based single crystal can motivate the crystal growth researchers involved with modern optoelectronic devices.

\section{Acknowledgment}

The authors are grateful to Sri Sivasubramaniya Nadar College of Engineering for the excellent characterization facilities and financial support. We also acknowledge Dr. Vinitha Gandhiraj, School of Advanced Sciences, VIT University (Chennai Campus) for providing the NLO facility and Dr. Soma Venugopal Rao, Advanced Center of Research in High Energy Materials, University of Hyderabad for the LDT facility. One of the authors Sivasubramani Vediyappan thank the SSN management for providing a postdoctoral fellowship.

\section{References:}

1. Liu, X., Wang, X., Yin, X., Liu, S., He, W., Zhu, L., Zhang, G. and Xu, D., 2014. Bulk growth and physical properties of diguanidinium phosphate monohydrate (G2HP) as a multifunctional crystal. CrystEngComm, 16(5), pp.930-938.

2. Munn, R.W. and Ironside, C.N. eds., 1993. Principles and applications of nonlinear optical materials (pp. 20-34). London: Blackie Academic \& Professional.

3. Marder, S.R., Perry, J.W. and Yakymyshyn, C.P., 1994. Organic salts with large second-order optical nonlinearities. Chemistry of materials, 6(8), pp.1137-1147.

4. Rath, H., Sankar, J., PrabhuRaja, V., Chandrashekar, T.K., Nag, A. and Goswami, D., 2005. Core-modified expanded porphyrins with large third-order nonlinear optical response. Journal 
of the American Chemical Society, 127(33), pp.11608-11609.

5. Evans, C.C., Bagieu-Beucher, M., Masse, R. and Nicoud, J.F., 1998. Nonlinearity enhancement by solid-state proton transfer: a new strategy for the design of nonlinear optical materials. Chemistry of materials, 10(3), pp.847-854.

6. Lee, S.H., Jazbinsek, M., Hauri, C.P. and Kwon, O.P., 2016. Recent progress in acentric core structures for highly efficient nonlinear optical crystals and their supramolecular interactions and terahertz applications. CrystEngComm, 18(38), pp.7180-7203.

7. Marder, S.R., Kippelen, B., Jen, A.K.Y. and Peyghambarian, N., 1997. Design and synthesis of chromophores and polymers for electro-optic and photorefractive applications. Nature, 388(6645), pp.845-851.

8. Yang, Z., Mutter, L., Stillhart, M., Ruiz, B., Aravazhi, S., Jazbinsek, M., Schneider, A., Gramlich, V. and Guenter, P., 2007. Large-size bulk and thin-film stilbazolium-salt single crystals for nonlinear optics and $\mathrm{THz}$ generation. Advanced Functional Materials, 17(13), pp.2018-2023.

9. Ennaceur, N. and Ledoux-Rak, I., 2018. Reinvestigation of the crystal structure, vibrational spectroscopic studies and DFT calculations of 4, 4'-bipyridinium dinitrate: An efficient SHG material for electro-optic devices. Journal of Physics and Chemistry of Solids, 120, pp.223-230.

10. Thirunavukkarsu, A., Sujatha, T., Umarani, P.R., Mohideen, M.N., Silambarasan, A. and Kumar, R.M., 2017. Growth aspects, structural, optical, thermal and mechanical properties of benzotriazole pyridine-2-carboxylic acid single crystal. Journal of Crystal Growth, 460, pp.4247.

11. Jovita, J.V., Ramanand, A., Sagayaraj, P., Boopathi, K. and Ramasamy, P., 2015. Studies on growth and characterization of 2-amino-5-nitropyridinium trifluoroacetate single crystals. Optik, 126(2), pp.265-269. 
12. Kothavale, S., Katariya, S. and Sekar, N., 2018. NLOphoric rigid pyrazino-phenanthroline donor- $\pi$-acceptor compounds: Investigation of structural and solvent effects on non-linear optical properties using computational methods. Optical Materials, 75, pp.379-389.

13. Zaccaro, J., Salvestrini, J.P., Ibanez, A., Ney, P. and Fontana, M.D., 2000. Electric-field frequency dependence of Pockels coefficients in 2-amino-5-nitropyridium dihydrogen phosphate organic-inorganic crystals. JOSA B, 17(3), pp.427-432.

14. Zaccaro, J. and Ibanez, A., 2000. Hybrid organic-inorganic crystals for quadratic nonlinear optics. Journal of Optoelectronics and Advanced Materials, 2(5), pp.515-524.

15. Sivasubramani, V., Mohankumar, V., Pandian, M.S. and Ramasamy, P., 2017. Synthesis, crystal growth, physicochemical properties and quantum chemical investigations of a D- $\pi-\mathrm{A}$ type organic single crystal: 2-amino-5-nitropyridinium p-phenolsulfonate (2A5NPP) for nonlinear optical (NLO) applications. CrystEngComm, 19(37), pp.5662-5678.

16. Horiuchi, N., Lefaucheux, F., Ibanez, A., Josse, D. and Zyss, J., 1999. An organic-inorganic crystal for blue SHG: crystal growth and quadratic optical effect of 2-amino-5-nitropyridinium chloride. Optical Materials, 12(2-3), pp.351-356.

17. Babu, G.A., Ramasamy, P. and Philip, J., 2011. Studies on the growth and physical properties of nonlinear optical crystal: 2-amino-5-nitropyridinium-toluenesulfonate. Materials Research Bulletin, 46(5), pp.631-634.

18. Manivannan, S., Dhanuskodi, S., Kirschbaum, K. and Tiwari, S.K., 2005. Design of an efficient solution grown semiorganic NLO crystal for short wavelength generation: 2-amino-5nitropyridinium tetrafluoroborate. Crystal growth \& design, 5(4), pp.1463-1468.

19. Pecaut, J., Levy, J.P. and Masse, R., 1993. Structural evidence in 2-amino-5-nitropyridinium halides $(\mathrm{Cl}-, \mathrm{Br}-)$ of herringbone motifs favourable to efficient quadratic non-linear optical properties. Journal of Materials Chemistry, 3(10), pp.999-1003. 
20. Manikandan, S. and Dhanuskodi, S., 2007. EPR of $\gamma$-irradiated single crystals of 2-amino-5nitro pyridinium 1-tartrate: a NLO material. Spectrochimica Acta Part A: Molecular and Biomolecular Spectroscopy, 67(1), pp.160-165.

21. Kotler, Z., Hierle, R., Josse, D., Zyss, J. and Masse, R., 1992. Quadratic nonlinear-optical properties of a new transparent and highly efficient organic-inorganic crystal: 2-amino-5nitropyridinium-dihydrogen phosphate (2A5NPDP). JOSA B, 9(4), pp.534-547.

22. Zaccaro, J., Salvestrini, J.P., Ibanez, A., Ney, P. and Fontana, M.D., 2000. Electric-field frequency dependence of Pockels coefficients in 2-amino-5-nitropyridium dihydrogen phosphate organic-inorganic crystals. JOSA B, 17(3), pp.427-432.

23. Babu, G.A., Ramasamy, P. and Chandramohan, A., 2011. Studies on the synthesis, structure, growth and physical properties of an organic NLO crystal: 2-Amino-5-nitropyridinium Phenolsulfonate. Materials Research Bulletin, 46(12), pp.2247-2251.

24. Bruker, APEX2, SAINT and SADABS. Bruker AXS Inc., Madison, Wisconsin, USA, 2004

25. Allen, F.H., Kennard, O., Watson, D.G., Brammer, L., Orpen, A.G. and Taylor, R., 1987. Tables of bond lengths determined by X-ray and neutron diffraction. Part 1. Bond lengths in organic compounds. Journal of the Chemical Society, Perkin Transactions 2, (12), pp.S1-S19.

26. Kaminsky, W., 2007. From CIF to virtual morphology using the WinXMorph program. Journal of Applied Crystallography, 40(2), pp.382-385.

27. Lal, K. and Bhagavannarayana, G., 1989. A high-resolution diffuse X-ray scattering study of defects in dislocation-free silicon crystals grown by the float-zone method and comparison with Czochralski-grown crystals. Journal of Applied Crystallography, 22(3), pp.209-215.

28. Pandian, M.S., Boopathi, K., Ramasamy, P. and Bhagavannarayana, G., 2012. The growth of benzophenone crystals by Sankaranarayanan-Ramasamy (SR) method and slow evaporation solution technique (SEST): a comparative investigation. Materials Research Bulletin, 47(3), 
pp.826-835.

29. Bhagavannarayana, G., Ananthamurthy, R.V., Budakoti, G.C., Kumar, B. and Bartwal, K.S., 2005. A study of the effect of annealing on Fe-doped LiNbO3 by HRXRD, XRT and FT-IR. Journal of Applied Crystallography, 38(5), pp.768-771.

30. Mohan, J 2011, 'Organic Spectroscopy Principles and Applications, 2 ed., Narosa Publishers, New Delhi.

31. Priyadharshini, A. and Kalainathan, S., 2017. Synthesis, structure and characterization of new promising organic NLO crystal: thiosemicarbazide 4-hydroxybenzenesulfonate monohydrate (THBSM). Journal of Materials Science: Materials in Electronics, 28(10), pp.7401-7412.

32. Ramajothi, J. and Dhanuskodi, S., 2007. Crystal growth, thermal and optical studies on a semiorganic nonlinear optical material for blue-green laser generation. Spectrochimica Acta Part A: Molecular and Biomolecular Spectroscopy, 68(5), pp.1213-1219.

33. Dalal, J., Sinha, N., Yadav, H. and Kumar, B., 2015. Structural, electrical, ferroelectric and mechanical properties with Hirshfeld surface analysis of novel NLO semiorganic sodium pnitrophenolate dihydrate piezoelectric single crystal. RSC advances, 5(71), pp.57735-57748.

34. Pandian, M.S., Pattanaboonmee, N., Ramasamy, P. and Manyum, P., 2011. Studies on conventional and Sankaranarayanan-Ramasamy (SR) method grown ferroelectric glycine phosphite (GPI) single crystals. Journal of crystal growth, 314(1), pp.207-212.

35. Horiuchi, N., Kodaira, T., Watanabe, A. and Matsuda, M., 1997. Protonation and solventinteraction effects on the first hyperpolarizability of 2-amino-5-nitropyridine. Chemical physics letters, 276(1-2), pp.92-96.

36. Anandan, P., Parthipan, G., Saravanan, T., Kumar, R.M., Bhagavannarayana, G. and Jayavel, R., 2010. Crystal growth, structural and optical characterization of a semi-organic single crystal for frequency conversionapplications. Physica B: Condensed Matter, 405(24), pp.4951-4956. 
37. Dalal, J. and Kumar, B., 2016. Bulk crystal growth, optical, mechanical and ferroelectric properties of new semiorganic nonlinear optical and piezoelectric Lithium nitrate monohydrate oxalate single crystal. Optical Materials, 51, pp.139-147.

38. Vediyappan, S., Arumugam, R., Pichan, K., Kasthuri, R., Muthu, S.P. and Perumal, R., 2017. Crystal growth and characterization of semi-organic 2-amino-5-nitropyridinium bromide (2A5NPBr) single crystals for third-order nonlinear optical (NLO) applications. Applied Physics A, 123(12), p.780.

39. Dhanuskodi, S., Jeyakumari, A.P. and Manivannan, S., 2005. Semiorganic NLO material for short-wavelength generation 2-amino-5-nitropyridinium bromide. Journal of crystal growth, 282(1-2), pp.72-78.

40. Vediyappan, Sivasubramani, Anil Kumar Chaudhary, Venkatesh Mottamchetty, Raja Arumugam, Vinitha Gandhiraj, Muthu Senthil Pandian, and Ramasamy Perumalsamy. "Evaluation of Linear and Nonlinear Optical Properties of $\mathrm{D}-\pi-\mathrm{A}$ Type 2-Amino-5Nitropyridinium Dihydrogen Phosphate (2A5NPDP) Single Crystal Grown by the Modified Sankaranarayanan-Ramasamy (SR) Method for Terahertz Generation." Crystal Growth \& Design 19, no. 12 (2019): 6873-6892.

41. Sivasubramani, V., Senthil Pandian, M., Boopathi, K. and Ramasamy, P., 2018. Crystal growth, structural, optical, thermal and dielectric studies of non-linear optical 2-amino-5nitropyridinium nitrate $(2 \mathrm{~A} 5 \mathrm{NPN})$ single crystals. Materials research innovations, 22(3), pp.128-136.

42. Boling, N.L., Crisp, M.D. and Dube, G., 1973. Laser induced surface damage. Applied Optics, 12(4), pp.650-660.

43. Brant, J.A., Clark, D.J., Kim, Y.S., Jang, J.I., Weiland, A. and Aitken, J.A., 2015. Outstanding laser damage threshold in Li2MnGeS4 and tunable optical nonlinearity in 
diamond-like semiconductors. Inorganic Chemistry, 54(6), pp.2809-2819.

44. Bhar, G.C., Chaudhary, A.K. and Kumbhakar, P., 2000. Study of laser induced damage threshold and effect of inclusions in some nonlinear crystals. Applied surface science, 161(1-2), pp.155-162.

45. Era, P., Jauhar, R.M., Vinitha, G. and Murugakoothan, P., 2018. Synthesis, growth, structural modeling and physio-chemical properties of a charge transfer molecule: guanidinium tosylate. Optics \& Laser Technology, 101, pp.127-137.

46. Daniel, D.J. and Ramasamy, P., 2014. Studies on semi-organic non linear optical single crystal: Lithium formate monohydrate (HCO2Li· H2O). Optical materials, 36(5), pp.971-976.

47. Ji, C., Chen, T., Sun, Z., Ge, Y., Lin, W., Luo, J., Shi, Q. and Hong, M., 2013. Bulk crystal growth and characterization of imidazolium L-tartrate (IMLT): a novel organic nonlinear optical material with a high laser-induced damage threshold. CrystEngComm, 15(11), pp.2157-2162.

48. Friberg, S.T.E.P.H.E.N.R. and Smith, P.E.T.E.R.W., 1987. Nonlinear optical glasses for ultrafast optical switches. IEEE journal of quantum electronics, 23(12), pp.2089-2094.

49. Weber, M.J., Milam, D. and Smith, W.L., 1978. Nonlinear refractive index of glasses and crystals. Optical Engineering, 17(5), p.175463.

50. Owyoung, A., 1973. Ellipse rotation studies in laser host materials. IEEE Journal of Quantum Electronics, 9(11), pp.1064-1069.

51. Williams, W.E., Soileau, M.J. and Van Stryland, E.W., 1984. Optical switching and n2 measurements in CS2. Optics communications, 50(4), pp.256-260.

52. Sheik-Bahae, M., Said, A.A. and Van Stryland, E.W., 1989. High-sensitivity, single-beam n 2 measurements. Optics letters, 14(17), pp.955-957.

53. Sheik-Bahae, M., Said, A.A., Wei, T.H., Hagan, D.J. and Van Stryland, E.W., 1990. Sensitive measurement of optical nonlinearities using a single beam. IEEE journal of quantum 
electronics, 26(4), pp.760-769.

54. Mian, S.M., Taheri, B. and Wicksted, J.P., 1996. Effects of beam ellipticity on Z-scan measurements. JOSA B, 13(5), pp.856-863.

55. Wen, S., Wu, J., Tang, K., Su, W., Fu, X. and Fan, D., 2005, January. Self-focusing and selfdefocusing of the optical beam propagation in a nonlinear negative-refractive-index material. In High-Power Lasers and Applications III (Vol. 5627, pp. 71-75). International Society for Optics and Photonics.

56. Jauhar, R.M., Viswanathan, V., Vivek, P., Vinitha, G., Velmurugan, D. and Murugakoothan, P., 2016. A new organic NLO material isonicotinamidium picrate (ISPA): crystal structure, structural modeling and its physico-chemical properties. RSC advances, 6(63), pp.57977-57985. 57. Zhou, Yun-shan, En-bo Wang, Jun Peng, Jie Liu, Chang-wen Hu, Ru-dan Huang, and Xiaozeng You. "Synthesis and the third-order optical nonlinearities of two novel charge-transfer complexes of a heteropoly blue type (C9H7NO) 4 H7PMo12O40.3H2O (C9H7NO= quinolin8-ol) and (phen) 3 H7PMo12O40. CH3CN. H2O (phen= 1, 10-phenanthroline)." Polyhedron 18, no. 10 (1999): 1419-1423.

58. Senthil, K., Kalainathan, S., Kumar, A.R. and Aravindan, P.G., 2014. Investigation of synthesis, crystal structure and third-order NLO properties of a new stilbazolium derivative crystal: a promising material for nonlinear optical devices. Rsc Advances, 4(99), pp.5611256127.

59. Whittall, I.R., McDonagh, A.M., Humphrey, M.G. and Samoc, M., 1999. Organometallic complexes in nonlinear optics II: third-order nonlinearities and optical limiting studies. Advances in organometallic chemistry, 43, pp.349-405.

60. Sutherland, R.L., 2003. Handbook of nonlinear optics. CRC press.

61. Feng, W., Yi, W., Wu, H., Ozaki, M. and Yoshino, K., 2005. Enhancement of third-order 
optical nonlinearities by conjugated polymer-bonded carbon nanotubes. Journal of applied physics, 98(3), p.034301.

62. Jauhar, R.M., Kalainathan, S. and Murugakoothan, P., 2015. Three dimensional organic framework of 2-amino 4, 6 dimethoxypyrimidine p-toluenesulfonic acid monohydrate: synthesis, single crystal growth and its properties. Journal of Crystal Growth, 424, pp.42-48.

63. Subashini, A., Kumaravel, R., Leela, S., Evans, H.S., Sastikumar, D. and Ramamurthi, K., 2011. Synthesis, growth and characterization of 4-bromo-4' chloro benzylidene aniline-A third order non linear optical material. Spectrochimica Acta Part A: Molecular and Biomolecular Spectroscopy, 78(3), pp.935-941.

64. Arunkumar, A. and Ramasamy, P., 2014. Bulk single crystals of ammonium acid phthalate grown by the Sankaranarayanan-Ramasamy method for optical limiting applications. Journal of crystal growth, 401, pp.195-199.

65. Kumar, P.R., Ravindrachary, V., Janardhana, K. and Poojary, B., 2012. Structural and optical properties of a new chalcone single crystal. Journal of crystal growth, 354(1), pp.182-187.

66. Li, F.Q., Zong, N., Zhang, F.F., Yang, J., Yang, F., Peng, Q.J., Cui, D.F., Zhang, J.Y., Wang, X.Y., Chen, C.T. and Xu, Z.Y., 2012. Investigation of third-order optical nonlinearity in KBe 2 BO 3 F 2 crystal by Z-scan. Applied Physics B, 108(2), pp.301-305.

67. Wang, D., Li, T., Wang, S., Wang, J., Wang, Z., Xu, X. and Zhang, F., 2016. Study on nonlinear refractive properties of KDP and DKDP crystals. Rsc Advances, 6(18), pp.1449014495. 
Synthesis, crystal growth, structure, crystalline perfection, thermal, linear and nonlinear optical investigations on 2-amino-5-nitropyridine 4-chlorobenzoic acid (1:1): A novel organic single crystal for NLO and optical limiting optical applications

Sivasubramani Vediyappan ${ }^{a^{*}}$, Arumugam Raja ${ }^{\mathrm{a}}$, RO. MU. Jauhara, Ramachandran Kasthuri ${ }^{\mathrm{a}}$, Viswanathan Vijayan ${ }^{\mathrm{b}}$, Muthu Senthil Pandian ${ }^{\mathrm{a}}$, Ramasamy Perumalsamy ${ }^{\mathrm{a}}$

aNadar Research Centre, Sri Sivasubramaniya Nadar College of Engineering, Kalavakkam-603 110, Chennai, Tamil Nadu, India

bDepartment of Biophysics, All India Institute of Medical Sciences (AIIMS), New Delhi110 029, India

Electronic supplementary information:

S1. Single crystal X-ray diffraction analysis

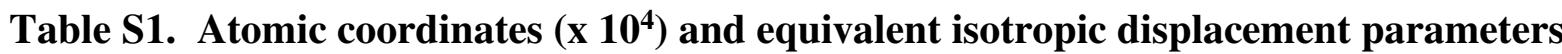
$\left(\AA^{2} \times 10^{3}\right)$ for $2 A 5 N P 4 C B A . U(e q)$ is defined as one-third of the trace of the orthogonalized $\mathrm{U}^{\mathrm{ij}}$ tensor.

\begin{tabular}{|c|c|c|c|c|}
\hline & $\mathrm{x}$ & $\mathrm{y}$ & $\mathrm{z}$ & $\mathrm{U}(\mathrm{eq})$ \\
\hline $\mathrm{C}(1)$ & $-3209(2)$ & $-119(2)$ & $10213(1)$ & $32(1)$ \\
\hline $\mathrm{C}(2)$ & $-3007(2)$ & $183(2)$ & $11283(1)$ & $40(1)$ \\
\hline $\mathrm{C}(3)$ & $-3354(2)$ & $1498(2)$ & $11674(2)$ & $43(1)$ \\
\hline $\mathrm{C}(4)$ & $-3920(2)$ & $2508(2)$ & $10983(2)$ & $38(1)$ \\
\hline$C(5)$ & $-4125(2)$ & $2238(2)$ & $9915(1)$ & $39(1)$ \\
\hline$C(6)$ & $-3769(2)$ & $920(2)$ & $9533(1)$ & $36(1)$ \\
\hline$C(7)$ & $-2874(2)$ & $-1548(2)$ & $9780(1)$ & $35(1)$ \\
\hline $\mathrm{C}(8)$ & $-1717(2)$ & $4358(2)$ & $8923(1)$ & $37(1)$ \\
\hline $\mathrm{C}(9)$ & $-1142(2)$ & $3022(2)$ & $8764(2)$ & $42(1)$ \\
\hline$C(10)$ & $-627(2)$ & $2263(2)$ & $9608(2)$ & $41(1)$ \\
\hline
\end{tabular}




$\begin{array}{lrrrr}\mathrm{C}(11) & -673(2) & 2851(2) & 10609(1) & 36(1) \\ \mathrm{C}(12) & -1204(2) & 4178(2) & 10716(1) & 37(1) \\ \mathrm{N}(1) & -1717(1) & 4935(2) & 9896(1) & 37(1) \\ \mathrm{N}(2) & -166(2) & 2068(2) & 11536(1) & 47(1) \\ \mathrm{N}(3) & -2273(2) & 5121(2) & 8119(1) & 55(1) \\ \mathrm{O}(1) & -2479(1) & -2492(1) & 10509(1) & 51(1) \\ \mathrm{O}(2) & -2960(1) & -1820(2) & 8840(1) & 51(1) \\ \mathrm{O}(3) & 297(2) & 879(2) & 11421(1) & 69(1) \\ \mathrm{O}(4) & -243(2) & 2608(2) & 12404(1) & 76(1) \\ \mathrm{Cl}(1) & -4382(1) & 4150(1) & 11480(1) & 58(1)\end{array}$


Table S2. Bond lengths $[\AA]$ and angles $\left[{ }^{\circ}\right]$ for 2 A5NP4CBA

\begin{tabular}{ll}
\hline $\mathrm{C}(1)-\mathrm{C}(2)$ & $1.385(2)$ \\
$\mathrm{C}(1)-\mathrm{C}(6)$ & $1.389(2)$ \\
$\mathrm{C}(1)-\mathrm{C}(7)$ & $1.488(2)$ \\
$\mathrm{C}(2)-\mathrm{C}(3)$ & $1.379(3)$ \\
$\mathrm{C}(2)-\mathrm{H}(2)$ & 0.9300 \\
$\mathrm{C}(3)-\mathrm{C}(4)$ & $1.381(3)$ \\
$\mathrm{C}(3)-\mathrm{H}(3)$ & 0.9300 \\
$\mathrm{C}(4)-\mathrm{C}(5)$ & $1.378(3)$ \\
$\mathrm{C}(4)-\mathrm{Cl}(1)$ & $1.7355(18)$ \\
$\mathrm{C}(5)-\mathrm{C}(6)$ & $1.379(3)$ \\
$\mathrm{C}(5)-\mathrm{H}(5)$ & 0.9300 \\
$\mathrm{C}(6)-\mathrm{H}(6)$ & 0.9300 \\
$\mathrm{C}(7)-\mathrm{O}(2)$ & $1.216(2)$ \\
$\mathrm{C}(7)-\mathrm{O}(1)$ & $1.311(2)$ \\
$\mathrm{C}(8)-\mathrm{N}(3)$ & $1.335(2)$ \\
$\mathrm{C}(8)-\mathrm{N}(1)$ & $1.348(2)$ \\
$\mathrm{C}(8)-\mathrm{C}(9)$ & $1.407(3)$ \\
$\mathrm{C}(9)-\mathrm{C}(10)$ & $1.355(3)$ \\
$\mathrm{C}(9)-\mathrm{H}(9)$ & 0.9300 \\
$\mathrm{C}(10)-\mathrm{C}(11)$ & $1.390(3)$ \\
$\mathrm{C}(10)-\mathrm{H}(10)$ & 0.9300 \\
$\mathrm{C}(11)-\mathrm{C}(12)$ & $1.366(3)$ \\
$\mathrm{C}(11)-\mathrm{N}(2)$ & $1.443(2)$ \\
$\mathrm{C}(12)-\mathrm{N}(1)$ & $1.329(2)$ \\
$\mathrm{C}(12)-\mathrm{H}(12)$ & 0.9300 \\
$\mathrm{~N}(2)-\mathrm{O}(4)$ & $1.222(2)$ \\
$\mathrm{N}(2)-\mathrm{O}(3)$ & $1.222(2)$ \\
$\mathrm{N}(3)-\mathrm{H}(3 \mathrm{~B})$ & $0.859(15)$ \\
$\mathrm{N}(3)-\mathrm{H}(3 \mathrm{~A})$ & $0.887(15)$ \\
$\mathrm{O}(1)-\mathrm{H}(1 \mathrm{~A})$ & 0.8200 \\
&
\end{tabular}




\begin{tabular}{|c|c|}
\hline$C(2)-C(1)-C(6)$ & $119.28(16)$ \\
\hline$C(2)-C(1)-C(7)$ & $121.44(16)$ \\
\hline$C(6)-C(1)-C(7)$ & $119.25(16)$ \\
\hline$C(3)-C(2)-C(1)$ & $120.63(17)$ \\
\hline $\mathrm{C}(3)-\mathrm{C}(2)-\mathrm{H}(2)$ & 119.7 \\
\hline $\mathrm{C}(1)-\mathrm{C}(2)-\mathrm{H}(2)$ & 119.7 \\
\hline $\mathrm{C}(2)-\mathrm{C}(3)-\mathrm{C}(4)$ & $118.99(17)$ \\
\hline $\mathrm{C}(2)-\mathrm{C}(3)-\mathrm{H}(3)$ & 120.5 \\
\hline $\mathrm{C}(4)-\mathrm{C}(3)-\mathrm{H}(3)$ & 120.5 \\
\hline$C(5)-C(4)-C(3)$ & $121.54(17)$ \\
\hline $\mathrm{C}(5)-\mathrm{C}(4)-\mathrm{Cl}(1)$ & $119.55(14)$ \\
\hline $\mathrm{C}(3)-\mathrm{C}(4)-\mathrm{Cl}(1)$ & $118.91(14)$ \\
\hline$C(4)-C(5)-C(6)$ & $118.90(17)$ \\
\hline $\mathrm{C}(4)-\mathrm{C}(5)-\mathrm{H}(5)$ & 120.5 \\
\hline $\mathrm{C}(6)-\mathrm{C}(5)-\mathrm{H}(5)$ & 120.5 \\
\hline$C(5)-C(6)-C(1)$ & $120.65(16)$ \\
\hline $\mathrm{C}(5)-\mathrm{C}(6)-\mathrm{H}(6)$ & 119.7 \\
\hline $\mathrm{C}(1)-\mathrm{C}(6)-\mathrm{H}(6)$ & 119.7 \\
\hline $\mathrm{O}(2)-\mathrm{C}(7)-\mathrm{O}(1)$ & $123.07(17)$ \\
\hline $\mathrm{O}(2)-\mathrm{C}(7)-\mathrm{C}(1)$ & $123.33(16)$ \\
\hline $\mathrm{O}(1)-\mathrm{C}(7)-\mathrm{C}(1)$ & $113.60(15)$ \\
\hline $\mathrm{N}(3)-\mathrm{C}(8)-\mathrm{N}(1)$ & $116.92(17)$ \\
\hline $\mathrm{N}(3)-\mathrm{C}(8)-\mathrm{C}(9)$ & $121.68(17)$ \\
\hline $\mathrm{N}(1)-\mathrm{C}(8)-\mathrm{C}(9)$ & $121.39(17)$ \\
\hline$C(10)-C(9)-C(8)$ & $119.47(17)$ \\
\hline $\mathrm{C}(10)-\mathrm{C}(9)-\mathrm{H}(9)$ & 120.3 \\
\hline $\mathrm{C}(8)-\mathrm{C}(9)-\mathrm{H}(9)$ & 120.3 \\
\hline $\mathrm{C}(9)-\mathrm{C}(10)-\mathrm{C}(11)$ & $118.32(17)$ \\
\hline $\mathrm{C}(9)-\mathrm{C}(10)-\mathrm{H}(10)$ & 120.8 \\
\hline $\mathrm{C}(11)-\mathrm{C}(10)-\mathrm{H}(10)$ & 120.8 \\
\hline$C(12)-C(11)-C(10)$ & $119.77(17)$ \\
\hline $\mathrm{C}(12)-\mathrm{C}(11)-\mathrm{N}(2)$ & $119.74(16)$ \\
\hline $\mathrm{C}(10)-\mathrm{C}(11)-\mathrm{N}(2)$ & $120.49(16)$ \\
\hline $\mathrm{N}(1)-\mathrm{C}(12)-\mathrm{C}(11)$ & $122.70(16)$ \\
\hline $\mathrm{N}(1)-\mathrm{C}(12)-\mathrm{H}(12)$ & 118.7 \\
\hline $\mathrm{C}(11)-\mathrm{C}(12)-\mathrm{H}(12)$ & 118.7 \\
\hline $\mathrm{C}(12)-\mathrm{N}(1)-\mathrm{C}(8)$ & $118.26(15)$ \\
\hline $\mathrm{O}(4)-\mathrm{N}(2)-\mathrm{O}(3)$ & $122.82(18)$ \\
\hline
\end{tabular}




$\begin{array}{ll}\mathrm{O}(4)-\mathrm{N}(2)-\mathrm{C}(11) & 118.62(17) \\ \mathrm{O}(3)-\mathrm{N}(2)-\mathrm{C}(11) & 118.53(17) \\ \mathrm{C}(8)-\mathrm{N}(3)-\mathrm{H}(3 \mathrm{~B}) & 120.1(16) \\ \mathrm{C}(8)-\mathrm{N}(3)-\mathrm{H}(3 \mathrm{~A}) & 118.5(15) \\ \mathrm{H}(3 \mathrm{~B})-\mathrm{N}(3)-\mathrm{H}(3 \mathrm{~A}) & 121(2) \\ \mathrm{C}(7)-\mathrm{O}(1)-\mathrm{H}(1 \mathrm{~A}) & 109.5\end{array}$

Symmetry transformations used to generate equivalent atoms: 
Table S3. Anisotropic displacement parameters $\left(\AA^{2} \times 10^{3}\right)$ for 2 A5NP4CBA. The anisotropic displacement factor exponent takes the form: $-2 p^{2}\left[h^{2} a^{* 2} U^{11}+\ldots+2 h k\right.$ $\mathbf{a}^{*} \mathbf{b}^{*} \mathrm{U}^{12}$ ]

$\begin{array}{llllll}\mathrm{U}^{11} & \mathrm{U}^{22} & \mathrm{U}^{33} & \mathrm{U}^{23} & \mathrm{U}^{13} & \mathrm{U}^{12}\end{array}$

\begin{tabular}{lcccccc}
\hline $\mathrm{C}(1)$ & $32(1)$ & $32(1)$ & $31(1)$ & $2(1)$ & $4(1)$ & $-3(1)$ \\
$\mathrm{C}(2)$ & $50(1)$ & $34(1)$ & $34(1)$ & $6(1)$ & $-2(1)$ & $3(1)$ \\
$\mathrm{C}(3)$ & $55(1)$ & $41(1)$ & $31(1)$ & $-1(1)$ & $1(1)$ & $-1(1)$ \\
$\mathrm{C}(4)$ & $39(1)$ & $31(1)$ & $43(1)$ & $-2(1)$ & $4(1)$ & $-2(1)$ \\
$\mathrm{C}(5)$ & $42(1)$ & $36(1)$ & $38(1)$ & $7(1)$ & $-2(1)$ & $3(1)$ \\
$\mathrm{C}(6)$ & $39(1)$ & $40(1)$ & $29(1)$ & $4(1)$ & $1(1)$ & $-1(1)$ \\
$\mathrm{C}(7)$ & $37(1)$ & $36(1)$ & $33(1)$ & $2(1)$ & $4(1)$ & $-1(1)$ \\
$\mathrm{C}(8)$ & $42(1)$ & $35(1)$ & $34(1)$ & $1(1)$ & $6(1)$ & $-6(1)$ \\
$\mathrm{C}(9)$ & $55(1)$ & $37(1)$ & $34(1)$ & $-9(1)$ & $7(1)$ & $-5(1)$ \\
$\mathrm{C}(10)$ & $49(1)$ & $30(1)$ & $45(1)$ & $-6(1)$ & $6(1)$ & $-1(1)$ \\
$\mathrm{C}(11)$ & $40(1)$ & $31(1)$ & $35(1)$ & $2(1)$ & $1(1)$ & $-6(1)$ \\
$\mathrm{C}(12)$ & $46(1)$ & $35(1)$ & $30(1)$ & $-4(1)$ & $6(1)$ & $-4(1)$ \\
$\mathrm{N}(1)$ & $47(1)$ & $32(1)$ & $33(1)$ & $-1(1)$ & $8(1)$ & $1(1)$ \\
$\mathrm{N}(2)$ & $55(1)$ & $41(1)$ & $43(1)$ & $2(1)$ & $-5(1)$ & $-4(1)$ \\
$\mathrm{N}(3)$ & $79(1)$ & $51(1)$ & $34(1)$ & $2(1)$ & $-1(1)$ & $10(1)$ \\
$\mathrm{O}(1)$ & $80(1)$ & $37(1)$ & $36(1)$ & $1(1)$ & $4(1)$ & $19(1)$ \\
$\mathrm{O}(2)$ & $74(1)$ & $44(1)$ & $34(1)$ & $-2(1)$ & $4(1)$ & $8(1)$ \\
$\mathrm{O}(3)$ & $89(1)$ & $46(1)$ & $68(1)$ & $7(1)$ & $-8(1)$ & $19(1)$ \\
$\mathrm{O}(4)$ & $118(2)$ & $67(1)$ & $38(1)$ & $-1(1)$ & $-11(1)$ & $11(1)$ \\
$\mathrm{Cl}(1)$ & $73(1)$ & $40(1)$ & $61(1)$ & $-11(1)$ & $1(1)$ & $12(1)$
\end{tabular}


Table S4. Hydrogen coordinates $\left(x 1^{4}\right)$ and isotropic displacement parameters $\left(\AA^{2} \times 10^{3}\right)$ for $2 \mathrm{~A} 5 \mathrm{NP} 4 \mathrm{CBA}$

\begin{tabular}{lcccc}
\hline & & & & \\
$x$ & $y$ & $z$ & $U(e q)$ & \\
& & & & \\
\hline$H(2)$ & -2634 & -509 & 11742 & 48 \\
$H(3)$ & -3210 & 1703 & 12391 & 51 \\
$H(5)$ & -4498 & 2934 & 9458 & 47 \\
$H(6)$ & -3906 & 724 & 8814 & 43 \\
$H(9)$ & -1115 & 2663 & 8084 & 50 \\
$H(10)$ & -252 & 1371 & 9521 & 49 \\
$H(12)$ & -1205 & 4568 & 11389 & 45 \\
$H(1 A)$ & -2303 & -3254 & 10227 & 77 \\
$H(3 B)$ & $-2360(20)$ & $4760(20)$ & $7494(14)$ & $68(8)$ \\
$H(3 A)$ & $-2620(20)$ & $5960(20)$ & $8257(17)$ & $69(8)$ \\
& & & & \\
\hline
\end{tabular}


Table S5. Torsion angles $\left[{ }^{\circ}\right]$ for $2 \mathrm{A5NP4CBA}$

\begin{tabular}{lc}
\hline $\mathrm{C}(6)-\mathrm{C}(1)-\mathrm{C}(2)-\mathrm{C}(3)$ & $-0.1(3)$ \\
$\mathrm{C}(7)-\mathrm{C}(1)-\mathrm{C}(2)-\mathrm{C}(3)$ & $-178.17(17)$ \\
$\mathrm{C}(1)-\mathrm{C}(2)-\mathrm{C}(3)-\mathrm{C}(4)$ & $0.7(3)$ \\
$\mathrm{C}(2)-\mathrm{C}(3)-\mathrm{C}(4)-\mathrm{C}(5)$ & $-1.1(3)$ \\
$\mathrm{C}(2)-\mathrm{C}(3)-\mathrm{C}(4)-\mathrm{Cl}(1)$ & $178.84(14)$ \\
$\mathrm{C}(3)-\mathrm{C}(4)-\mathrm{C}(5)-\mathrm{C}(6)$ & $0.9(3)$ \\
$\mathrm{Cl}(1)-\mathrm{C}(4)-\mathrm{C}(5)-\mathrm{C}(6)$ & $-179.09(14)$ \\
$\mathrm{C}(4)-\mathrm{C}(5)-\mathrm{C}(6)-\mathrm{C}(1)$ & $-0.3(3)$ \\
$\mathrm{C}(2)-\mathrm{C}(1)-\mathrm{C}(6)-\mathrm{C}(5)$ & $-0.1(3)$ \\
$\mathrm{C}(7)-\mathrm{C}(1)-\mathrm{C}(6)-\mathrm{C}(5)$ & $177.96(16)$ \\
$\mathrm{C}(2)-\mathrm{C}(1)-\mathrm{C}(7)-\mathrm{O}(2)$ & $-174.87(17)$ \\
$\mathrm{C}(6)-\mathrm{C}(1)-\mathrm{C}(7)-\mathrm{O}(2)$ & $7.1(3)$ \\
$\mathrm{C}(2)-\mathrm{C}(1)-\mathrm{C}(7)-\mathrm{O}(1)$ & $5.2(2)$ \\
$\mathrm{C}(6)-\mathrm{C}(1)-\mathrm{C}(7)-\mathrm{O}(1)$ & $-172.82(16)$ \\
$\mathrm{N}(3)-\mathrm{C}(8)-\mathrm{C}(9)-\mathrm{C}(10)$ & $-177.71(19)$ \\
$\mathrm{N}(1)-\mathrm{C}(8)-\mathrm{C}(9)-\mathrm{C}(10)$ & $3.2(3)$ \\
$\mathrm{C}(8)-\mathrm{C}(9)-\mathrm{C}(10)-\mathrm{C}(11)$ & $-0.9(3)$ \\
$\mathrm{C}(9)-\mathrm{C}(10)-\mathrm{C}(11)-\mathrm{C}(12)$ & $-1.5(3)$ \\
$\mathrm{C}(9)-\mathrm{C}(10)-\mathrm{C}(11)-\mathrm{N}(2)$ & $178.42(17)$ \\
$\mathrm{C}(10)-\mathrm{C}(11)-\mathrm{C}(12)-\mathrm{N}(1)$ & $1.8(3)$ \\
$\mathrm{N}(2)-\mathrm{C}(11)-\mathrm{C}(12)-\mathrm{N}(1)$ & $-178.08(16)$ \\
$\mathrm{C}(11)-\mathrm{C}(12)-\mathrm{N}(1)-\mathrm{C}(8)$ & $0.4(3)$ \\
$\mathrm{N}(3)-\mathrm{C}(8)-\mathrm{N}(1)-\mathrm{C}(12)$ & $177.96(17)$ \\
$\mathrm{C}(9)-\mathrm{C}(8)-\mathrm{N}(1)-\mathrm{C}(12)$ & $-2.9(3)$ \\
$\mathrm{C}(12)-\mathrm{C}(11)-\mathrm{N}(2)-\mathrm{O}(4)$ & $1.2(3)$ \\
$\mathrm{C}(10)-\mathrm{C}(11)-\mathrm{N}(2)-\mathrm{O}(4)$ & $-178.72(19)$ \\
$\mathrm{C}(12)-\mathrm{C}(11)-\mathrm{N}(2)-\mathrm{O}(3)$ & $179.58(18)$ \\
$\mathrm{C}(10)-\mathrm{C}(11)-\mathrm{N}(2)-\mathrm{O}(3)$ & $-0.3(3)$ \\
\hline & \\
\hline & \\
&
\end{tabular}

Symmetry transformations used to generate equivalent atoms: 


\section{S2. Determination of linear optical parameters:}

The optical absorption coefficient of the 2A5NP4CBA single crystal was calculated by the following equation.

$$
\alpha=\frac{2.303 \times \log (1 / T)}{t}
$$

where, $\alpha$ is the optical absorption coefficient, $\mathrm{T}$ is the optical transmittance and $\mathrm{t}$ is the thickness of the sample. The bandgap was calculated by the following Tauc's plot relation.

$$
(\alpha h v)=A\left(h v-E_{g}\right)^{m}
$$

where, $v$ is the frequency of incident photons, A is optical constant. The tauc's plot was drawn between the photon energy $(h v)$ versus $(\alpha h v)^{2}$ and the bandgap of the grown 2A5NP4CBA crystal was found to be $2.9 \mathrm{eV}$. In equation 2 , the value of $\mathrm{m}$ describes the electronic structure of the 2A5NP4CBA molecule. Here, the value of $\mathrm{m}$ is found to be $1 / 2$, which indicates the direct allowed transition behavior of the title crystal. The reflectance (R) was evaluated using the following relation.

$$
R=\frac{\exp (-\alpha t) \pm \sqrt{\exp (-\alpha t) T-\exp (-3 \alpha t) T+\exp (-2 \alpha t) T^{2}}}{\exp (-\alpha t)+\exp (-2 \alpha t) T}
$$

The parameters such as $\alpha$ and wavelength $(\lambda)$ were used to calculate the extinction coefficient $(\mathrm{K})$ of the 2A5NP4CBA single crystal and the relevant equation is given below.

$$
K=\frac{\alpha \lambda}{4 \pi}
$$

The refractive index $\left(n_{0}\right)$ was calculated by the following equation.

$$
n_{0}=\frac{-(R+1) \pm 2 \sqrt{R}}{(R-1)}
$$


Figures

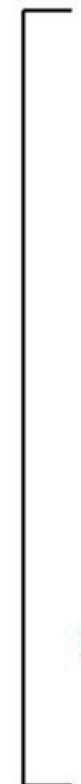

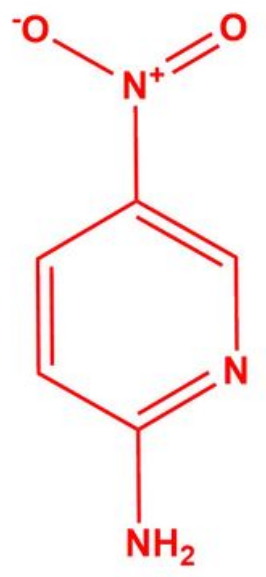

$\oplus$

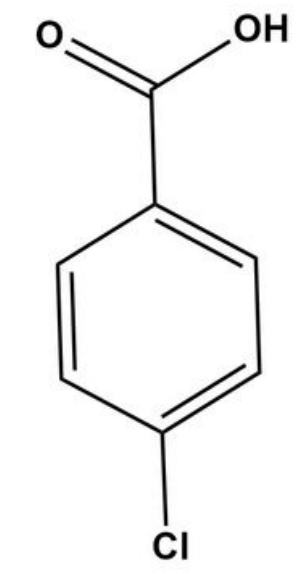

2-Amino-5-Nitropyridine

\section{4-Chlorobenzoic Acid}
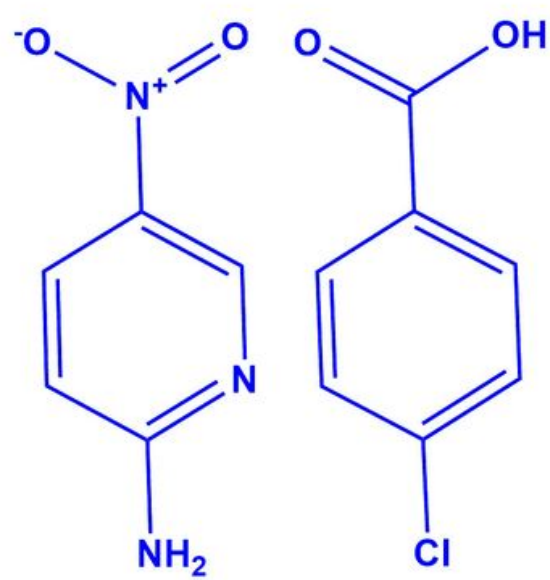

2-Amino-5-Nitropyridine 4-Chlorobenzoic Acid (1:1)

Figure 1

Reaction scheme of 2A5NP with 4-chlorobenzoic acid 


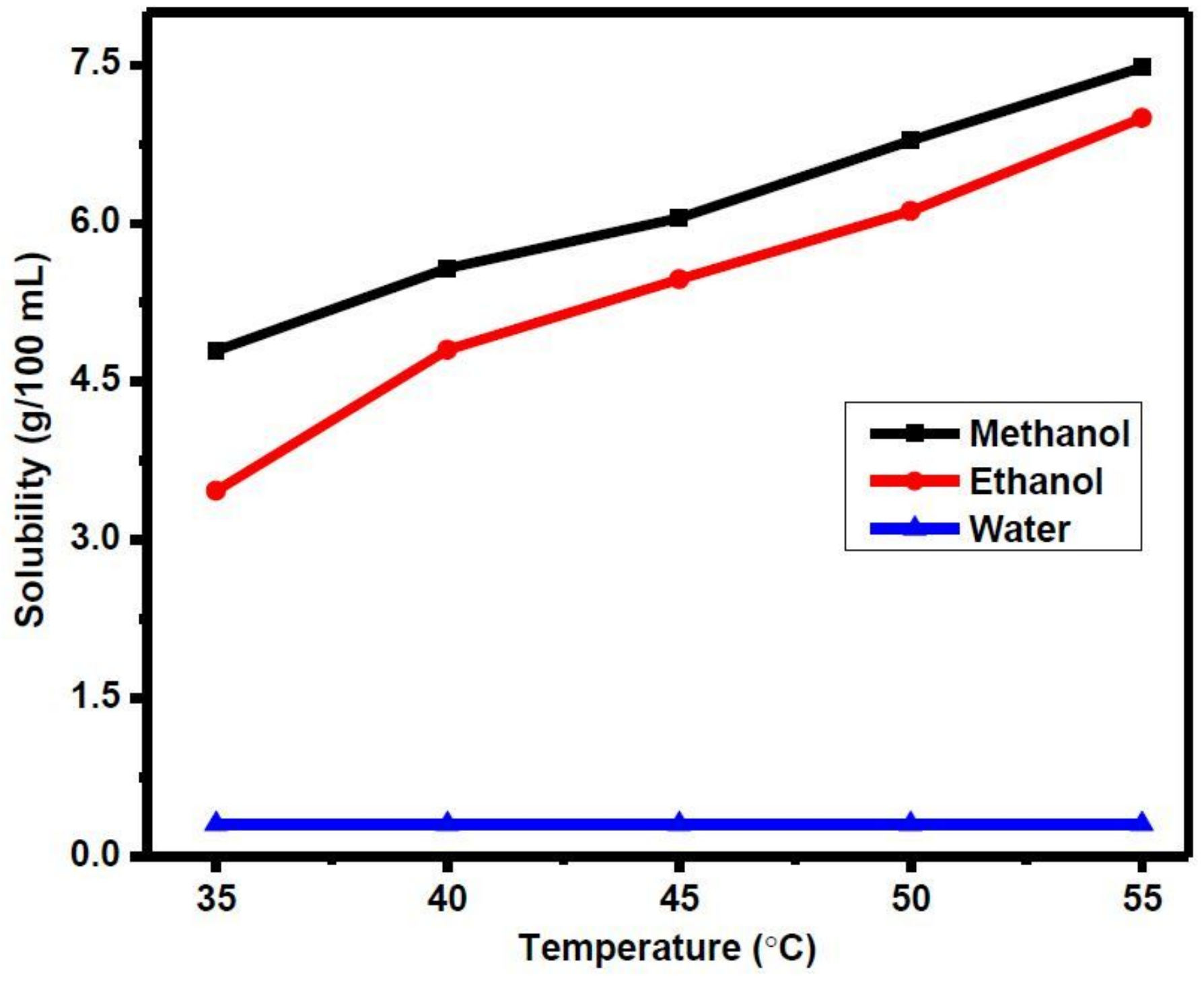

Figure 2

Solubility diagram for 2A5NP4CBA crystal 


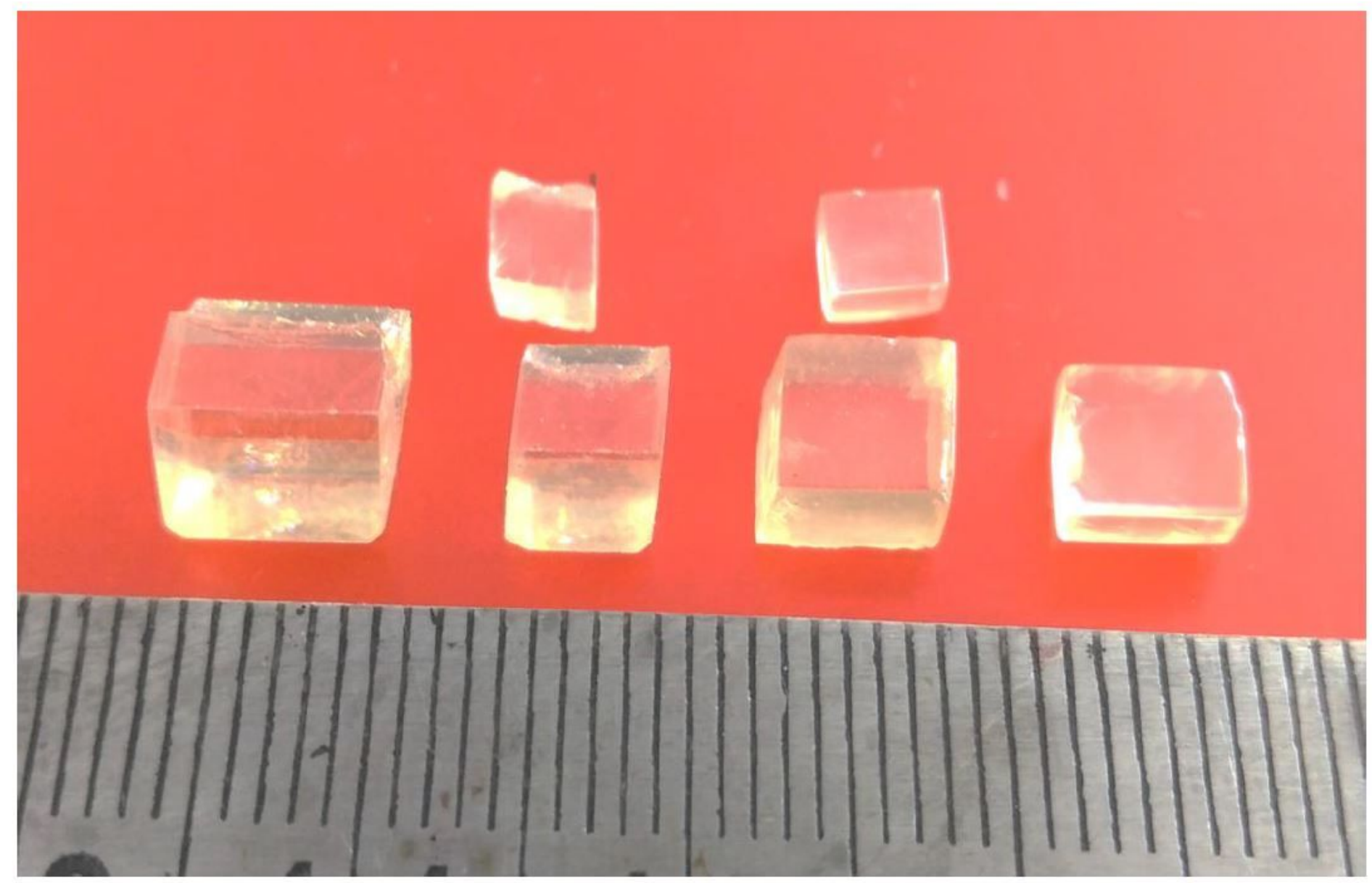

Figure 3

As grown 2A5NP4CBA adduct crystals 


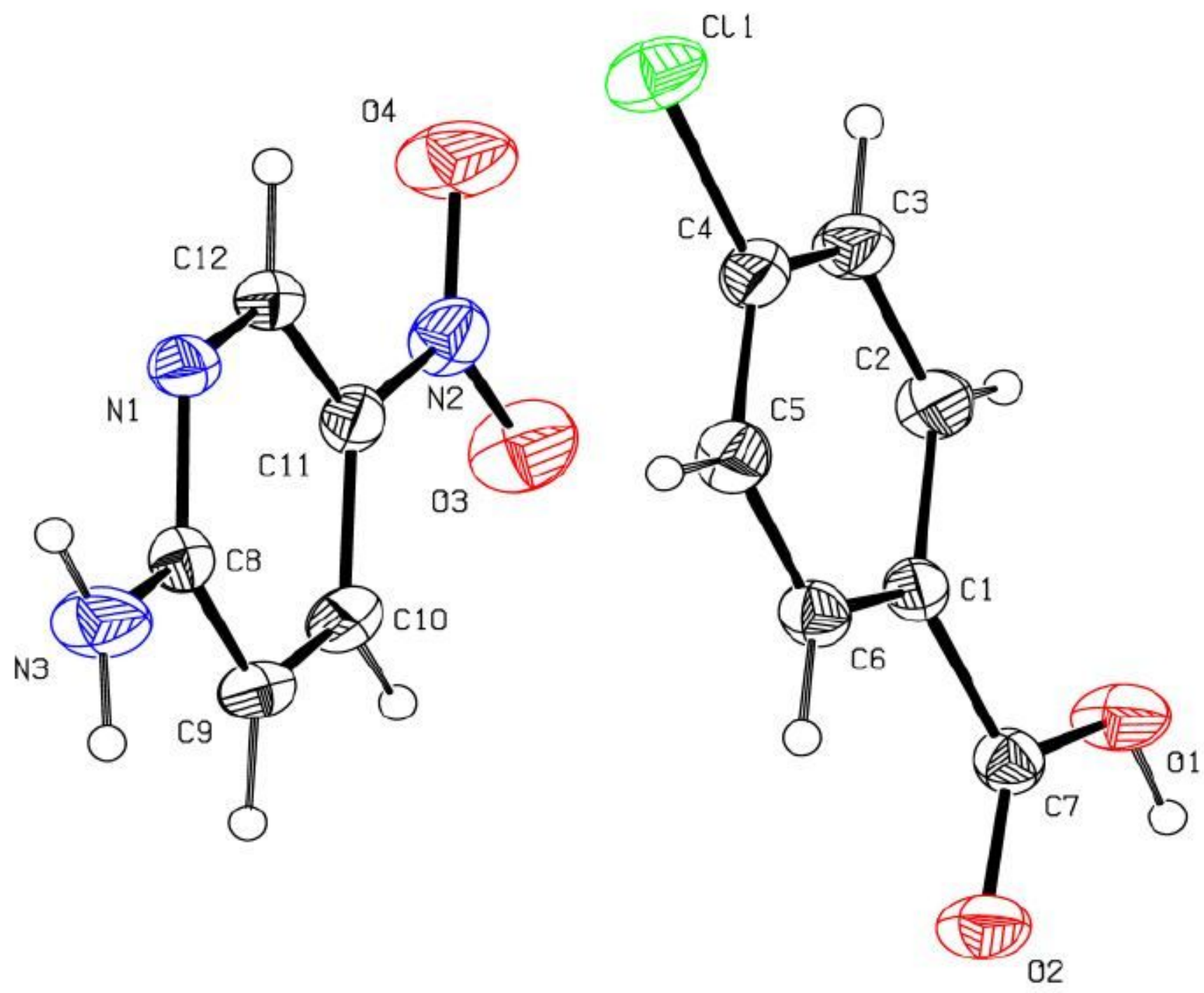

Figure 4

Three-dimensional molecular structure of the title salt with the atom numbering scheme. Displacement ellipsoids are drawn at 30\% probability level 


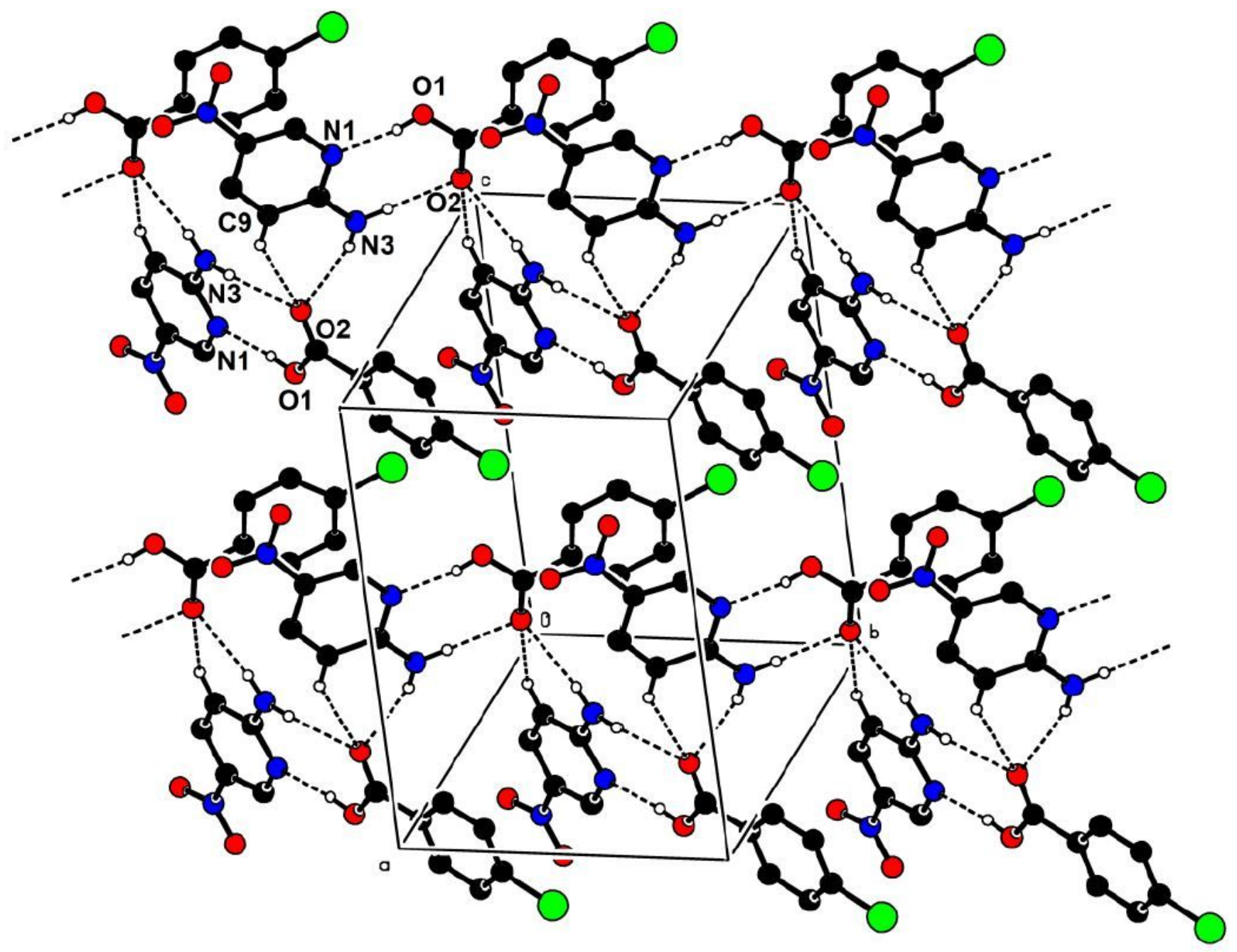

Figure 5

The 01-H1A...N1i, N3-H3A...02ii, N3-H3B...02iii and $\mathrm{C} 9-\mathrm{H} 9 . . .02 i i i$ intermolecular hydrogen bonds [Symmetry codes: (i) $x, y-1, z$, (ii) $x, y+1, z$ and (iii) $3 / 2-x, 1 / 2+y, 1 / 2-z$ ] 


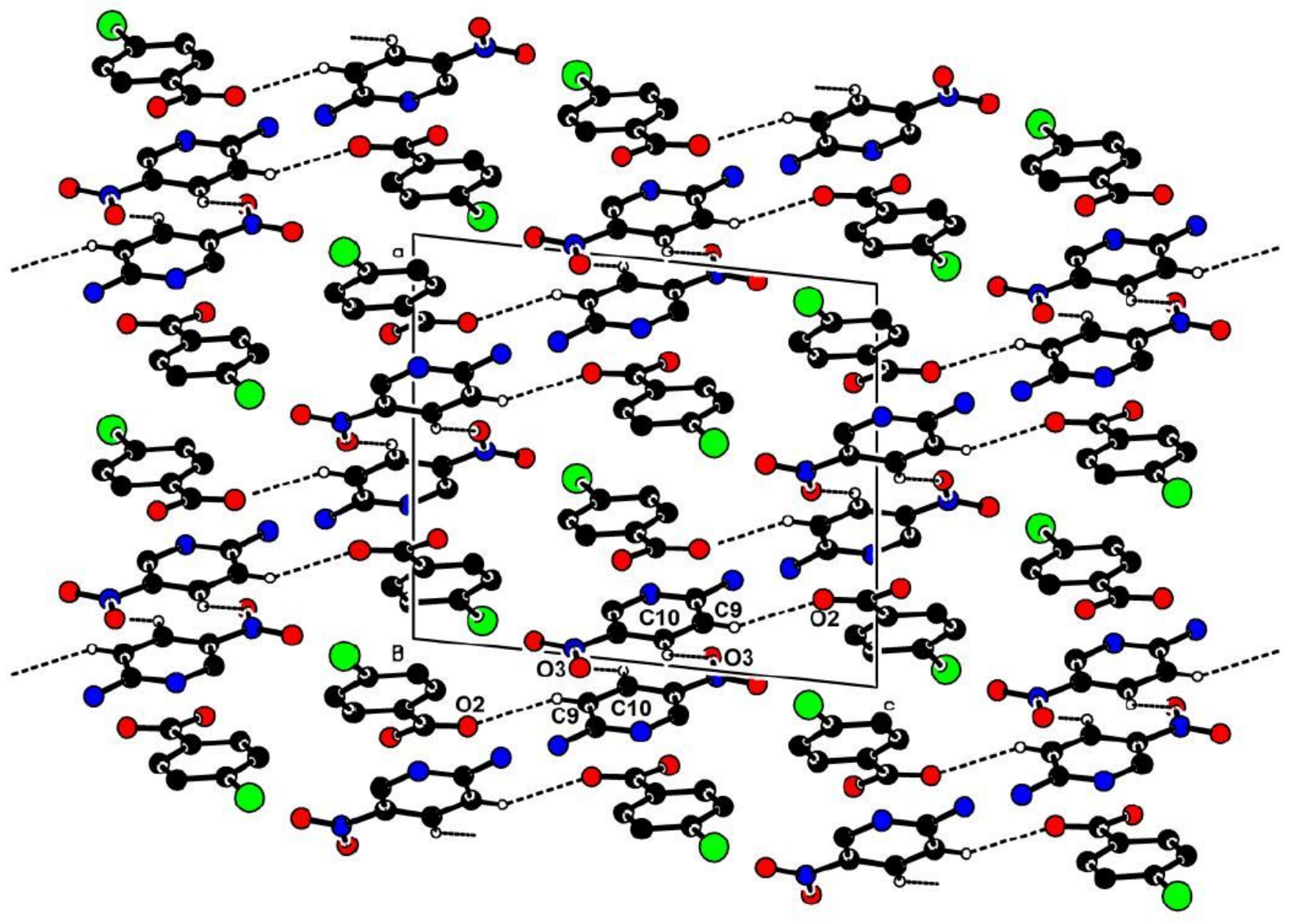

Figure 6

The $\mathrm{C} 9-\mathrm{H} 9 \ldots . \mathrm{O} 2 \mathrm{iii}$ and $\mathrm{C} 10-\mathrm{H} 10$...O3iv hydrogen bond interactions [Symmetry code: (iii) $3 / 2-\mathrm{x}, 1 / 2+\mathrm{y}, 1 / 2-\mathrm{z}$ and (iv) $2-x, 1-y, 1-z]$ 


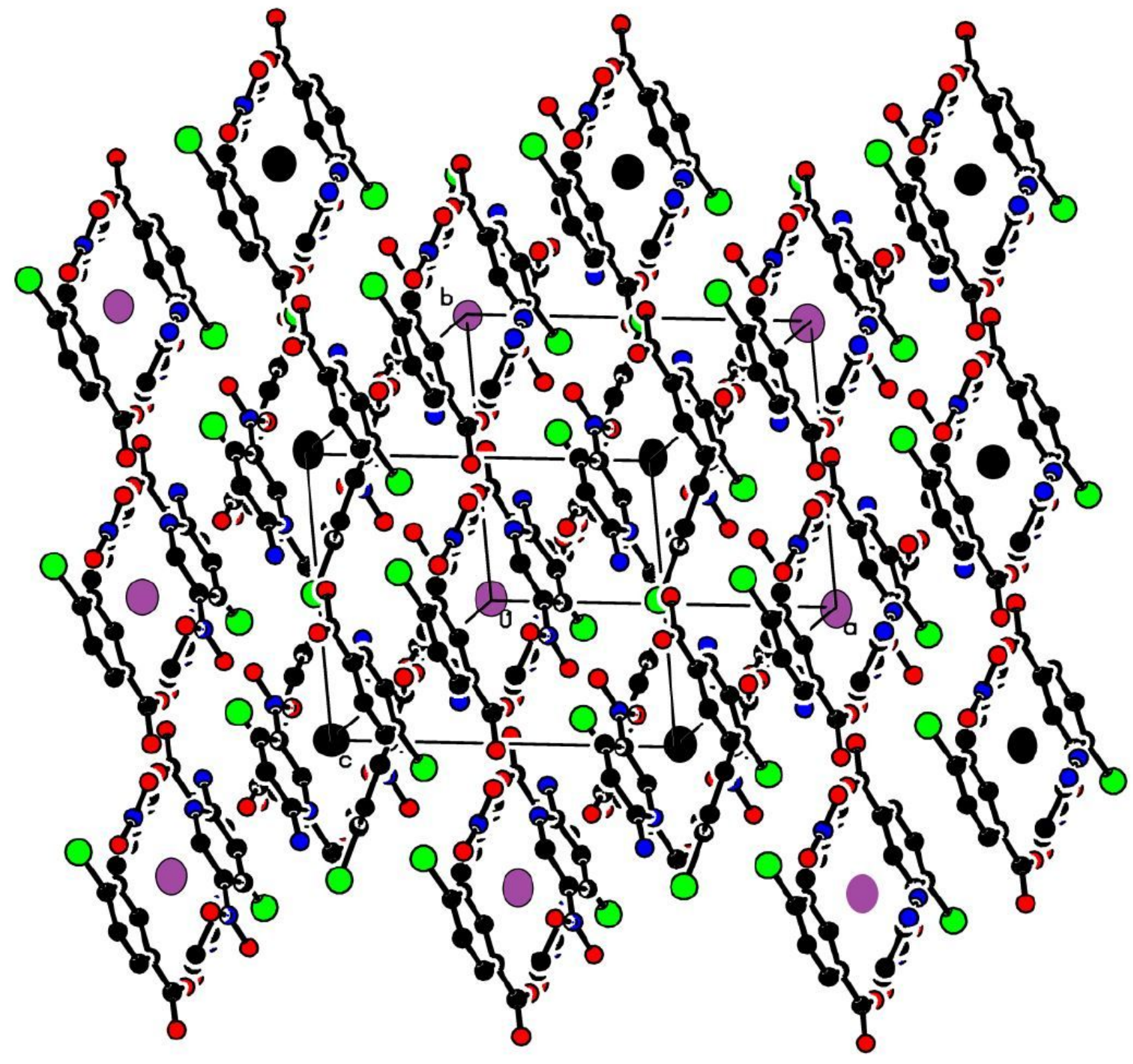

Figure 7

Three-dimensional crystal packing 

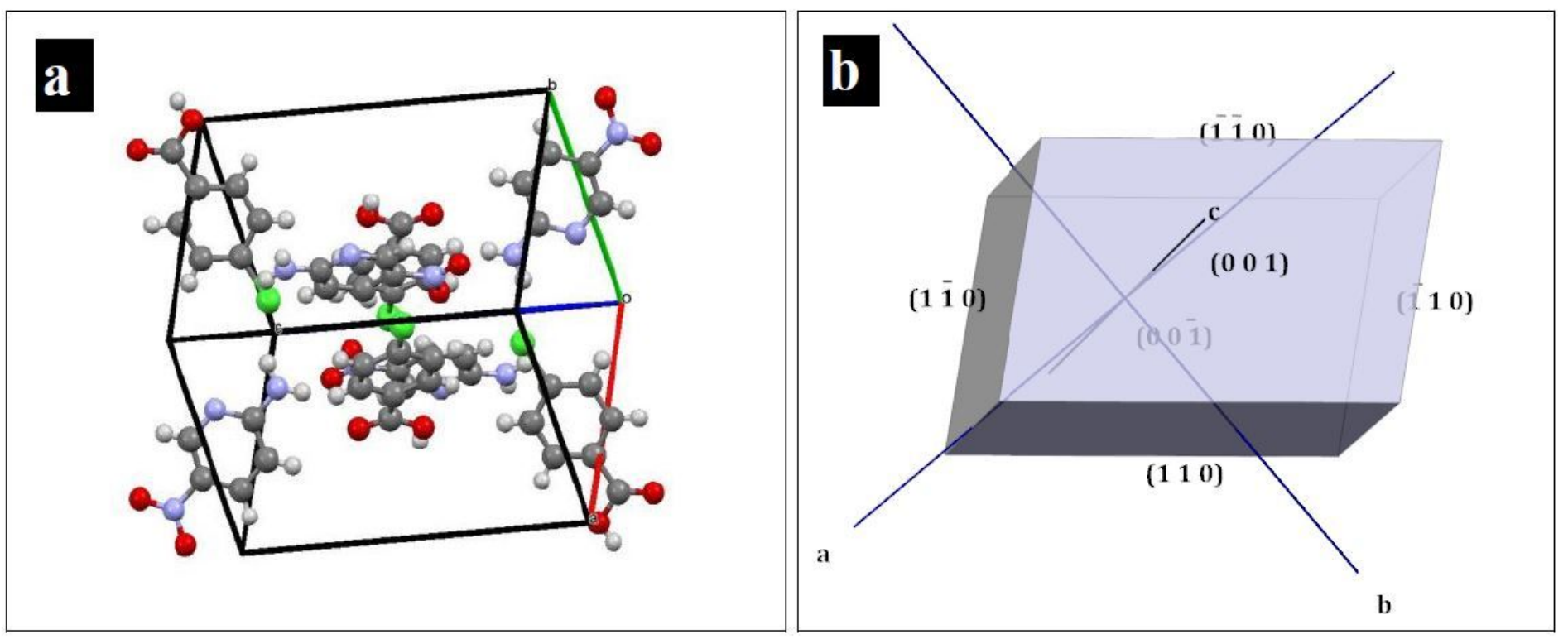

Figure 8

(a) The packing diagram and (b) morphology of the as-grown 2A5NP4CBA crystal deduced by the SXRD analysis 


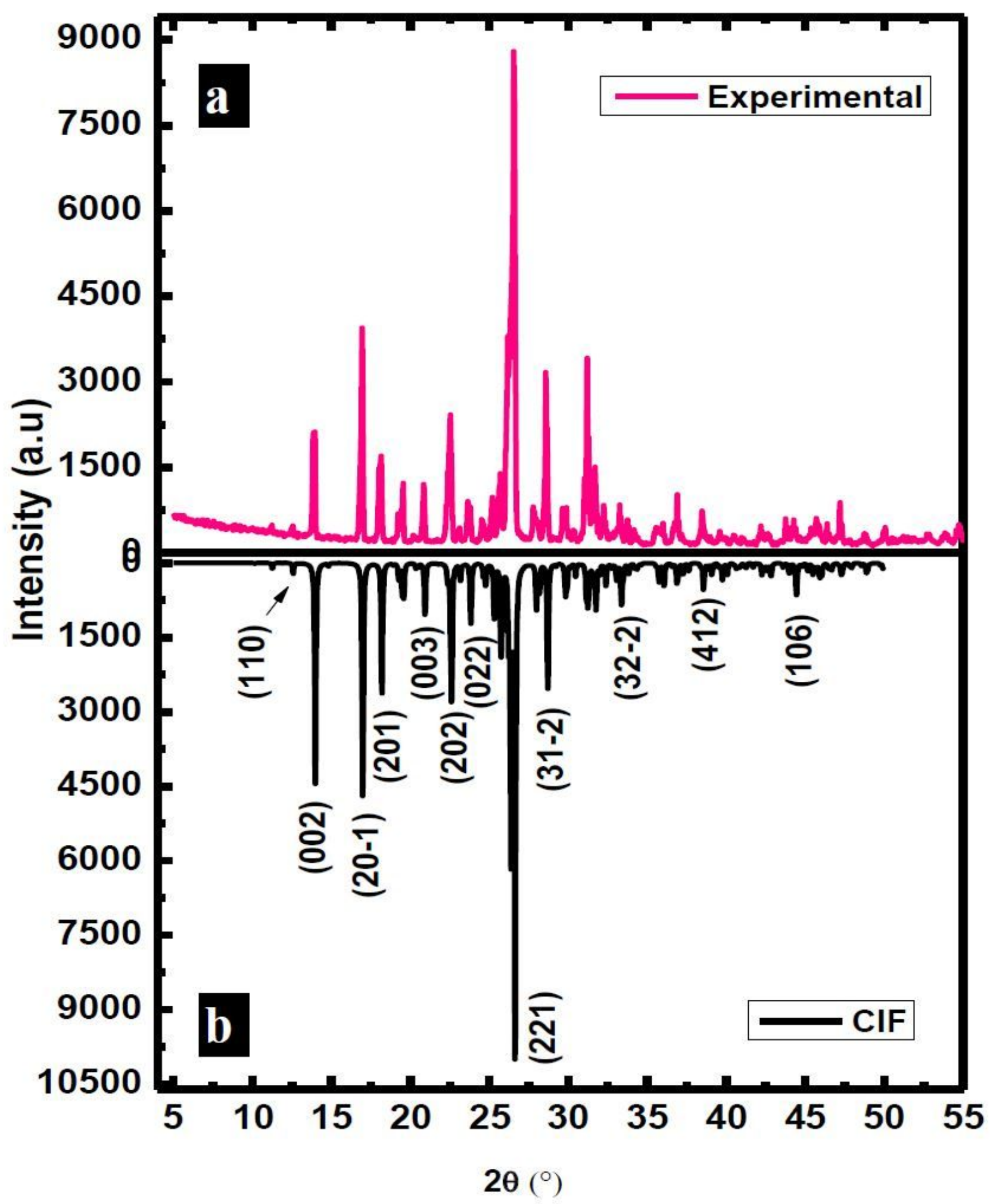

Figure 9

Comparative PXRD spectra of 2A5NP4CBA (a) experimental data and (b) simulated data 


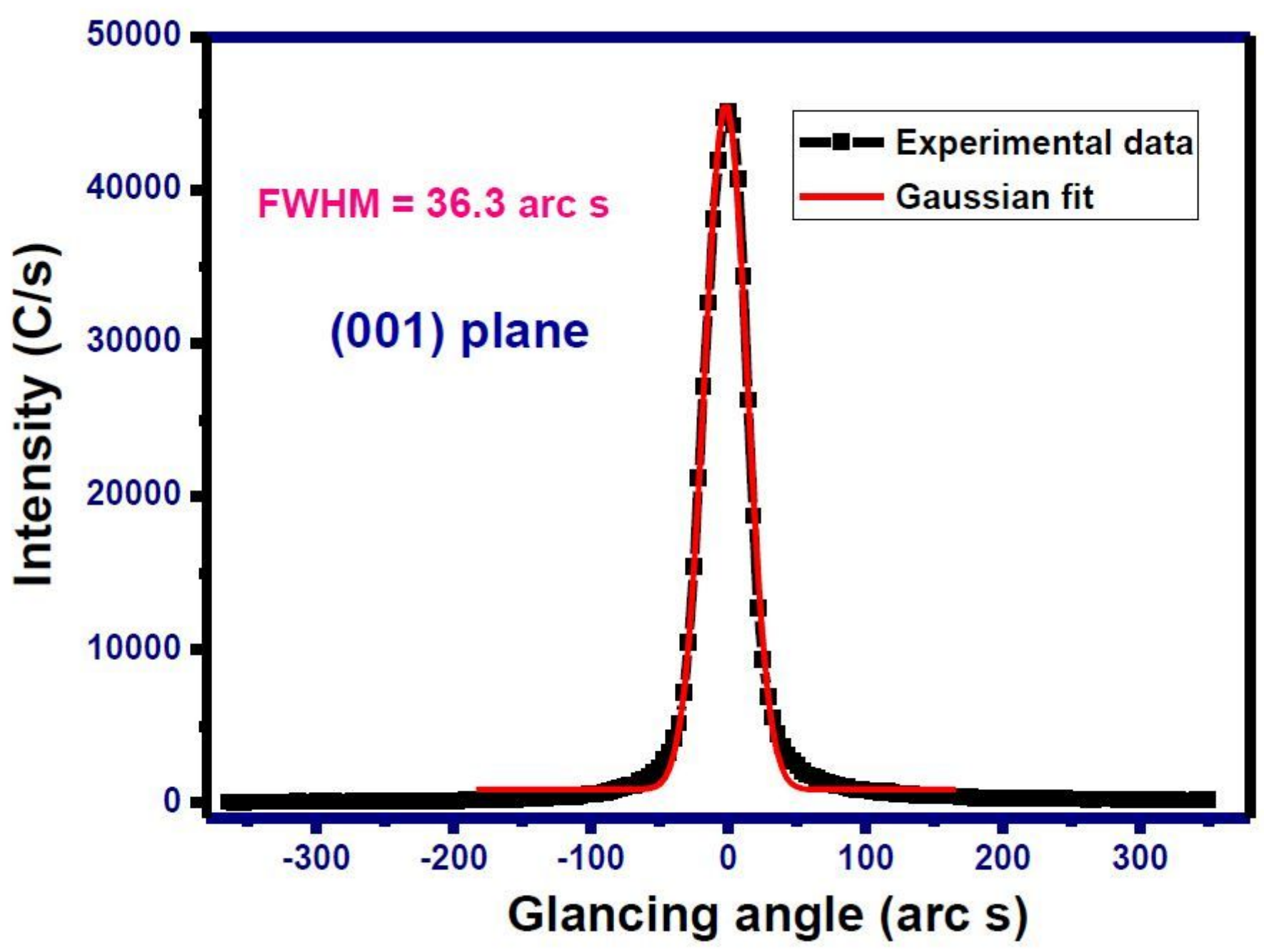

Figure 10

HRXRD rocking curve of 2A5NP4CBA single crystal measured at (001) plane 


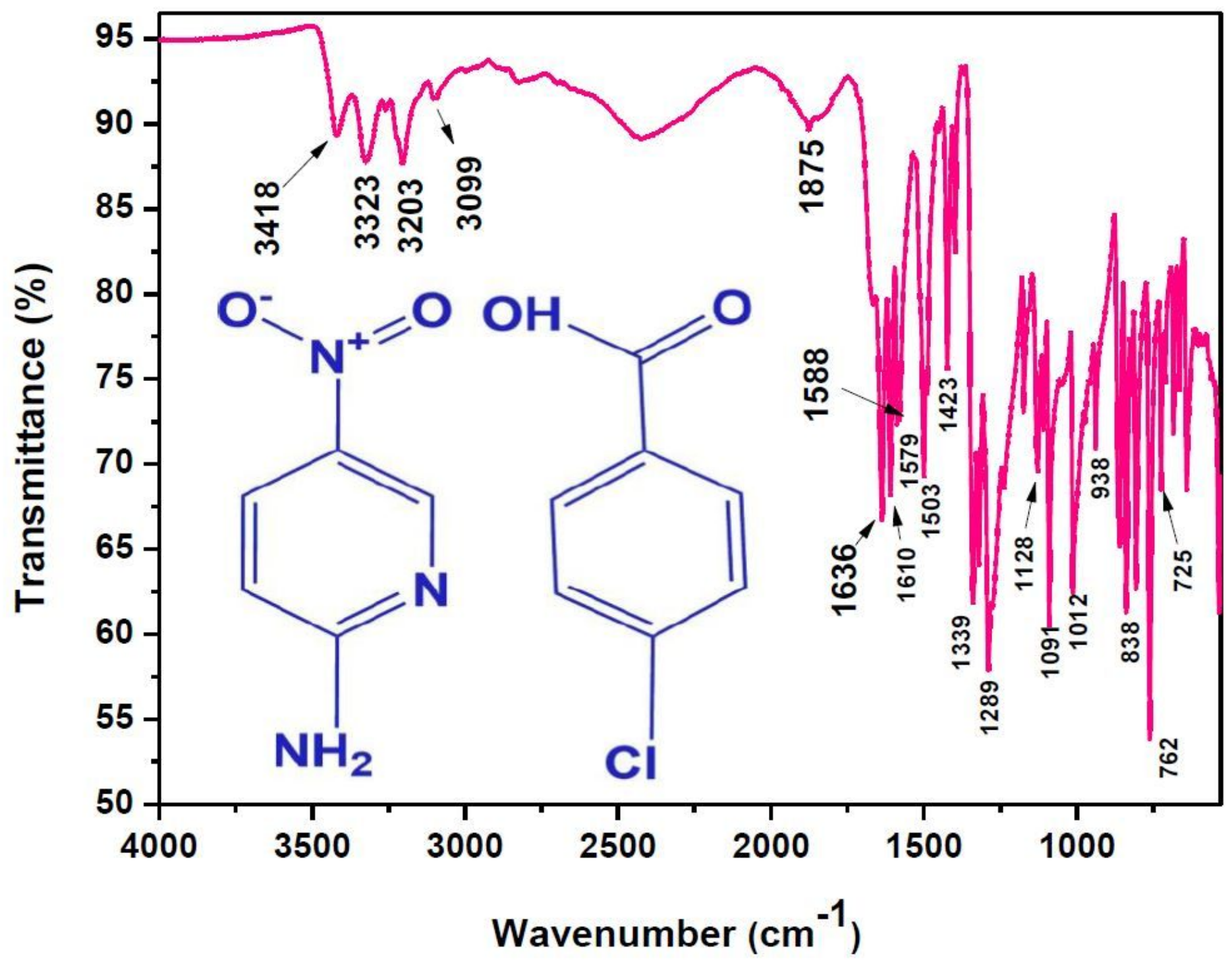

Figure 11

FTIR spectrum of 2A5NP4CBA 


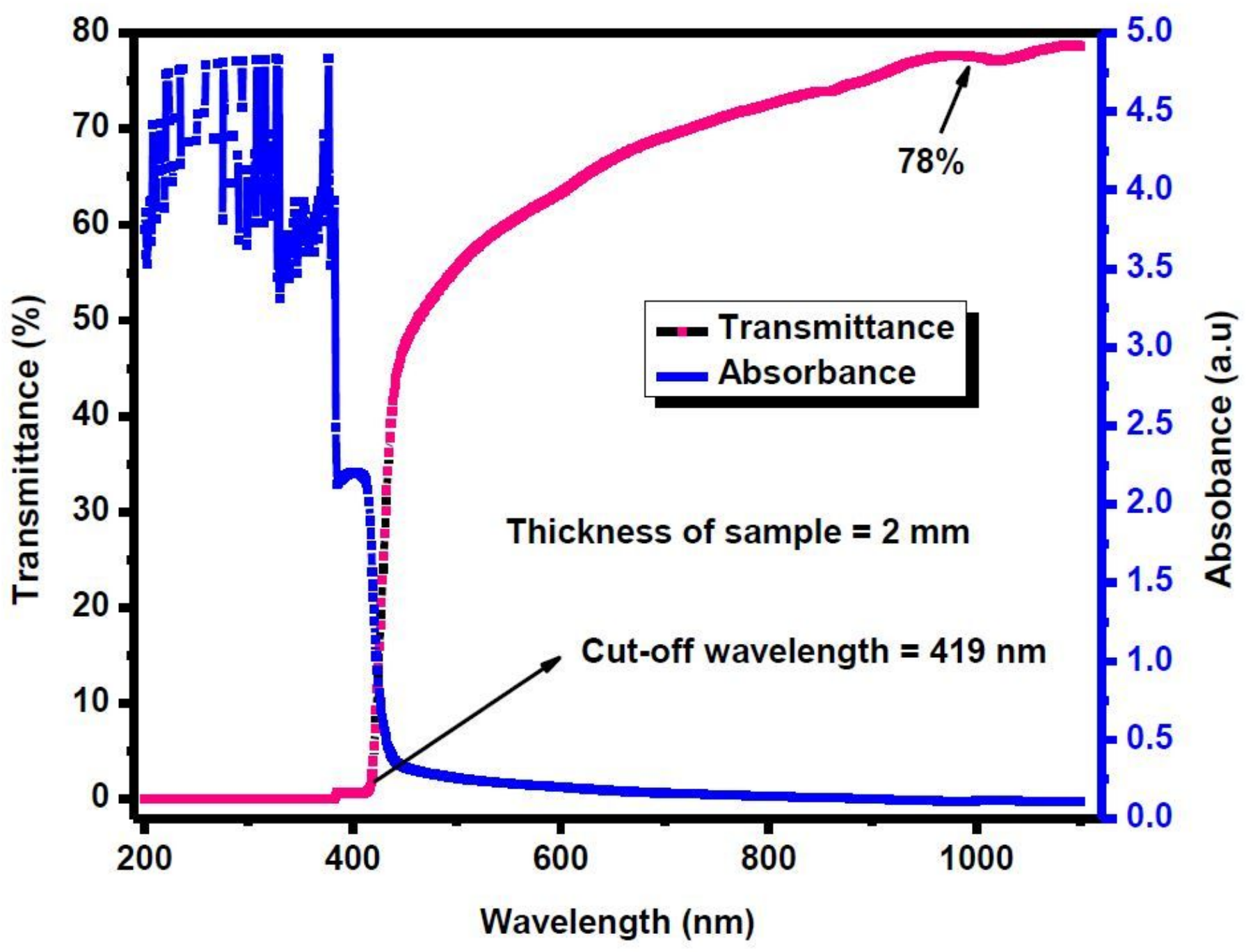

Figure 12

The UV-vis-NIR spectra of 2A5NP4CBA single crystal 

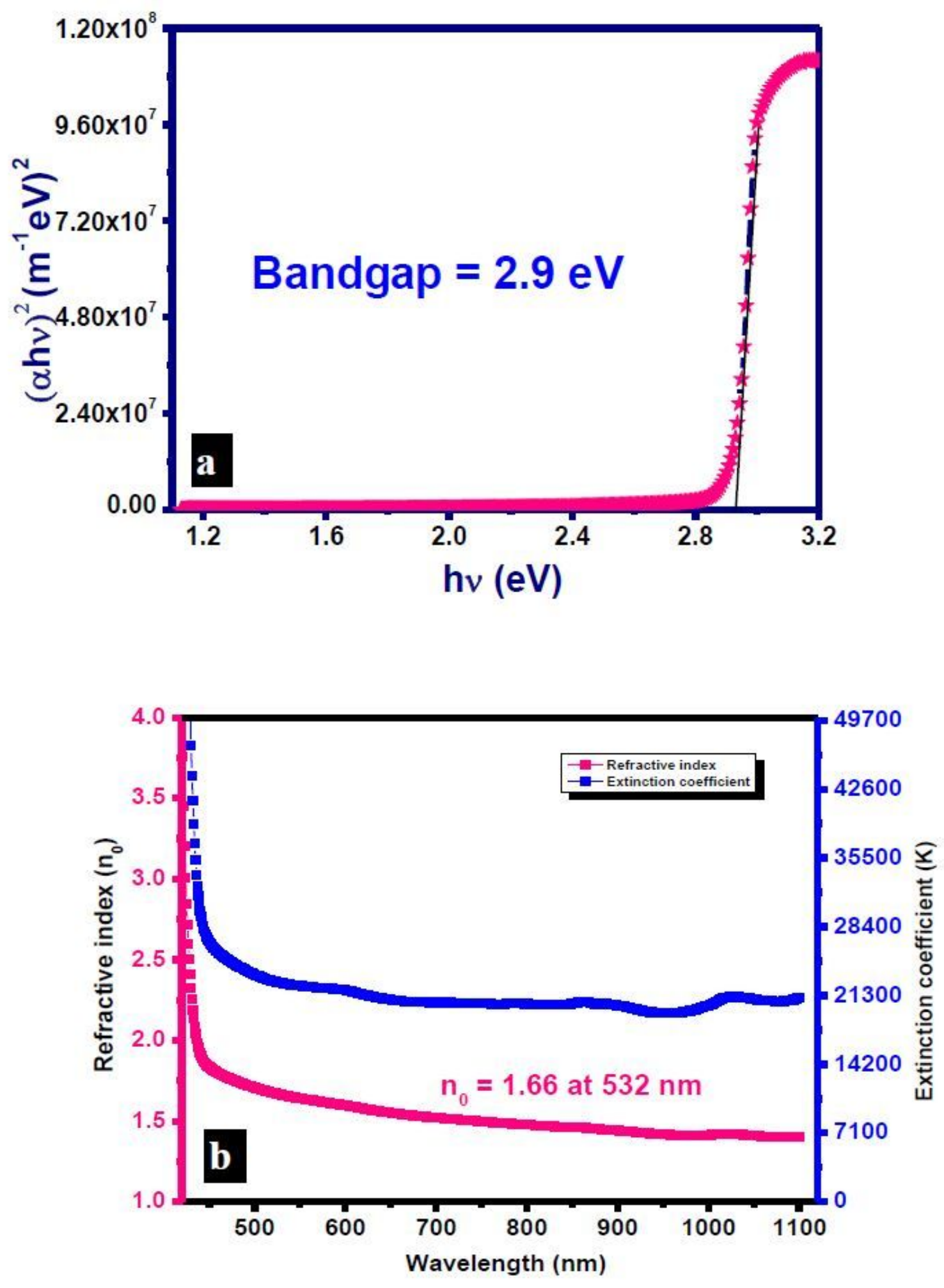

Figure 13

(a) Tauc's plot (b) refractive index and extinction coefficient spectra of 2A5NP4CBA crystal 


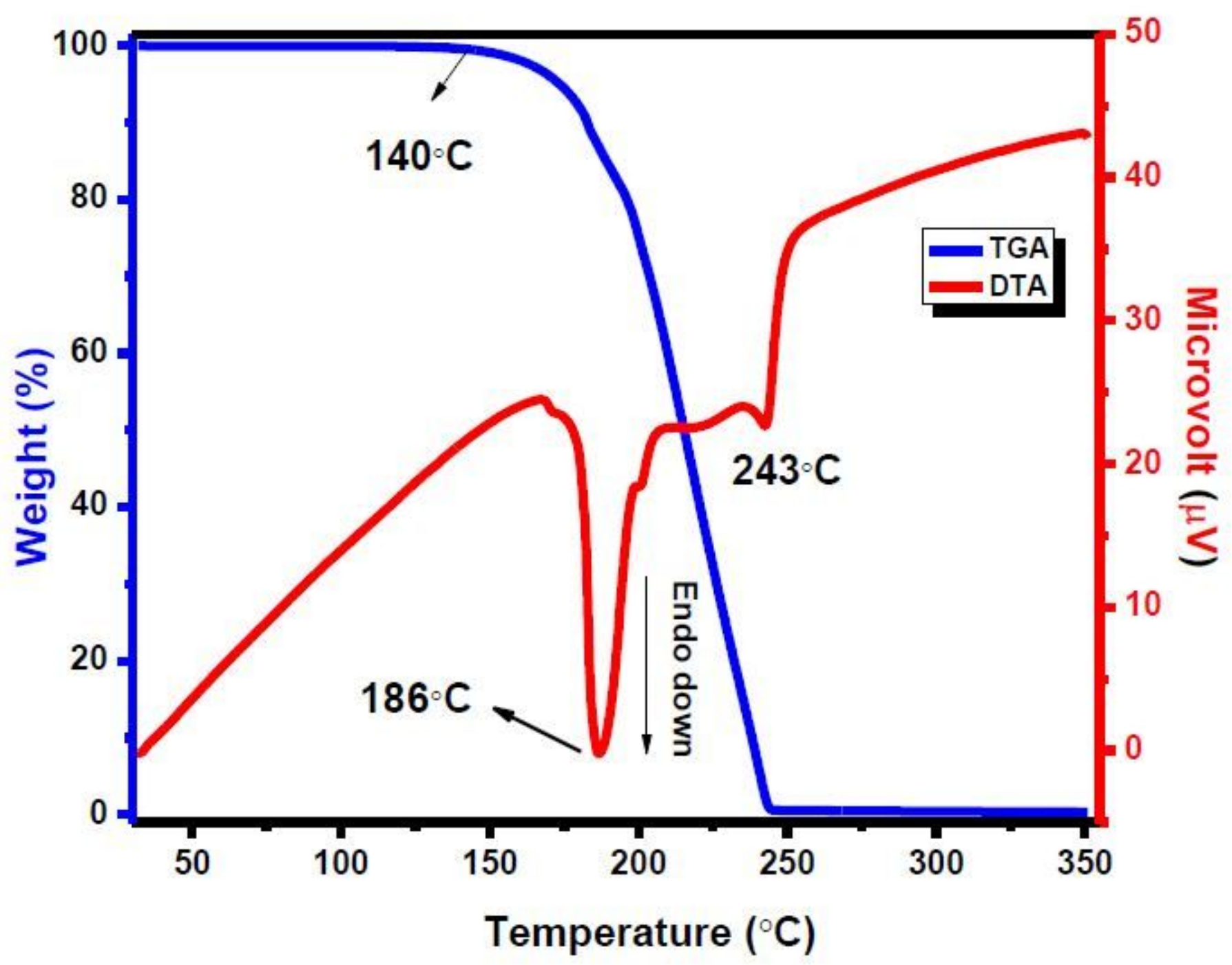

Figure 14

TG-DTA spectrum of 2A5NP4CBA single crystal 

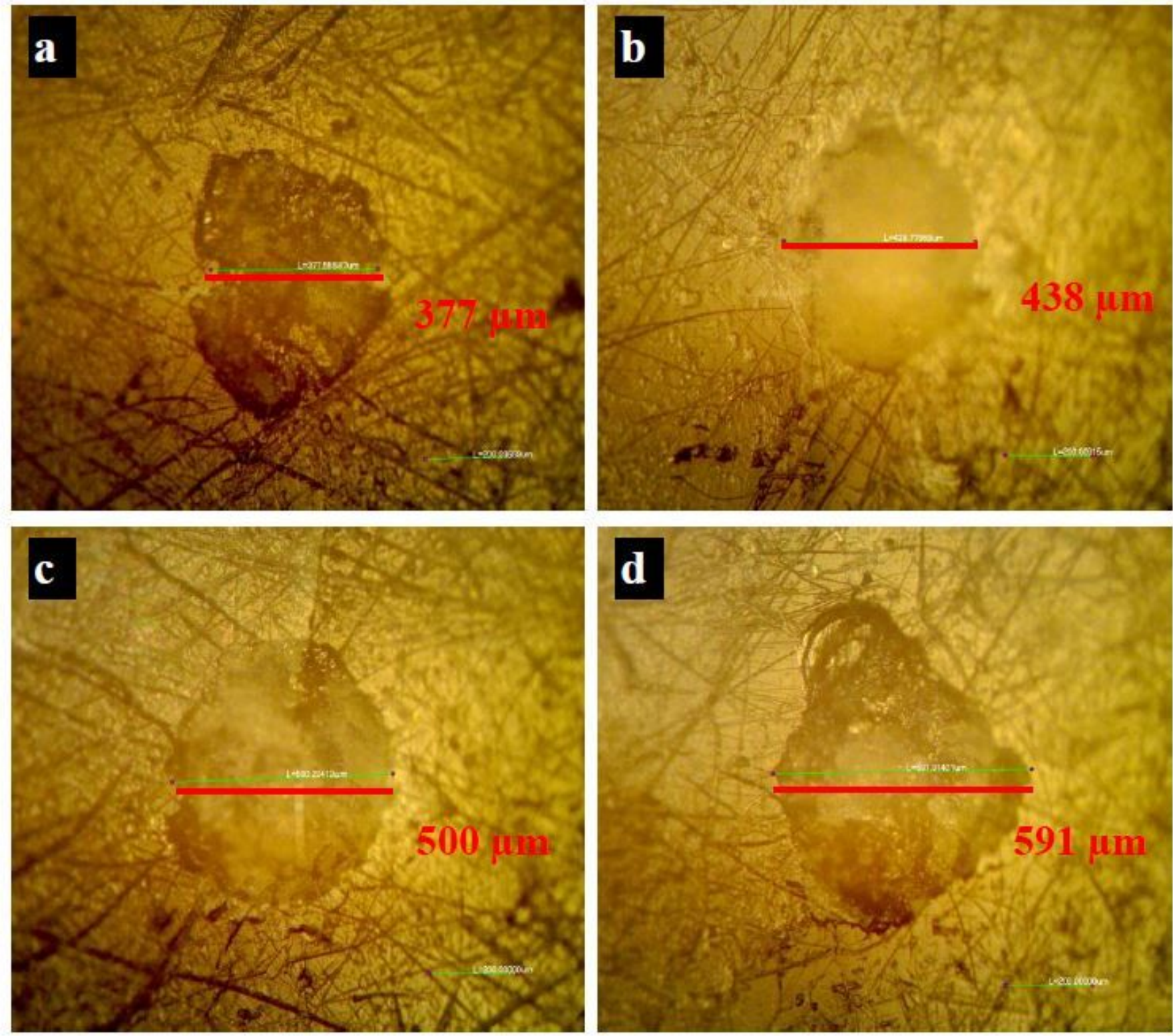

Figure 15

(a-d). Laser damage patterns of 2A5NP4CBA single crystal with the irradiation of different intensity of the laser beam 

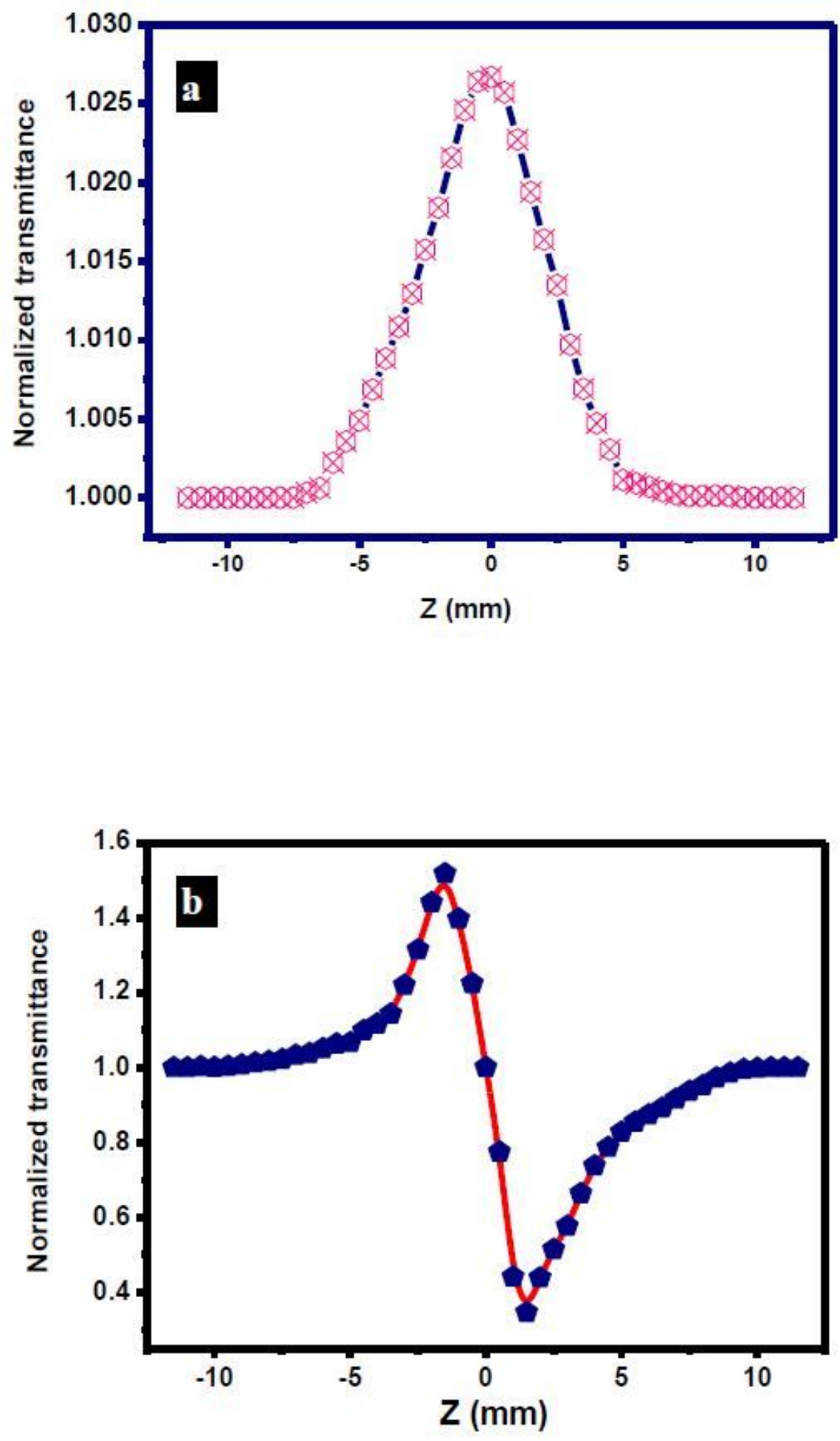

Figure 16

(a) Normalized open and (b) closed aperture spectrum of 2A5NP4CBA single crystal 


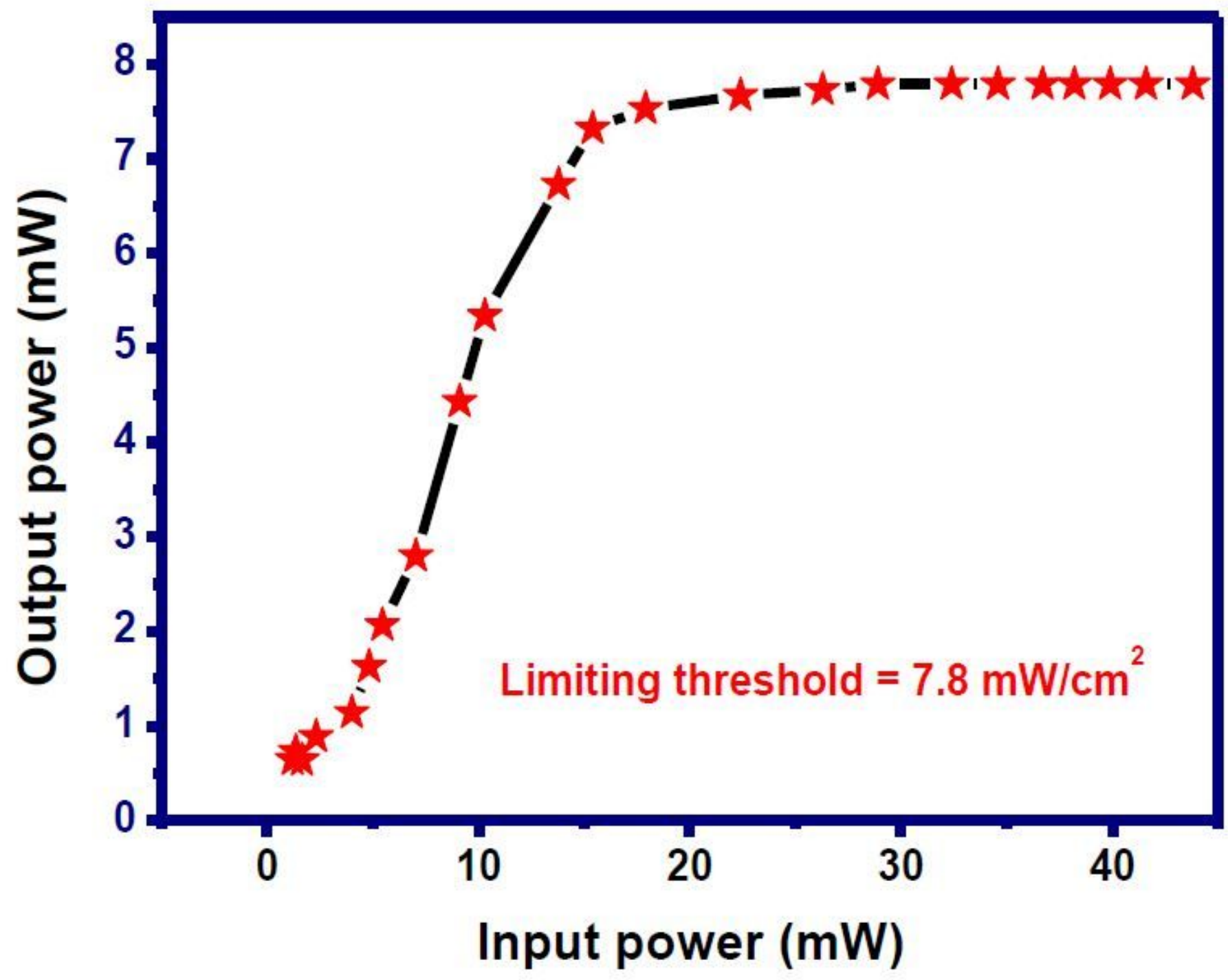

Figure 17

OL spectrum of $2 \mathrm{~A} 5 \mathrm{~N} 4 \mathrm{CBA}$ single crystal 